*ak RMIS View/Frint Document Cover Sheet tow

This document was retrieved from the Documentation and Records Manaqement (DRM) ISEARCH System. It is intended for Information only and may not be the most recent or updated version. Contact a Document Service Center (see Hanford Info for locations) if you need additional retrieval information.

Accession \#: D196013244

Document \#: SD-WM-ER-534

Title/Desc:

THERMAL HYDRAULIC EVALUATION OF CONSOLIDATING TANK C106 WASTE INTO TANK AY102

Pages: 129 


2. To: (Receiving organization)
Distribution

5. Proj./Prog./Dept./Div.:

8. Originator Remarks:

Approval/Release

11. Receiver Renarks:
3. From: (Originating Organization) Process Engineering Analysis/TwRs safety and Technical Integration

6. Cog. Engr.:

K. Sathyanarayana
18.



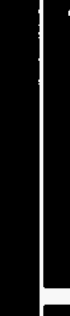

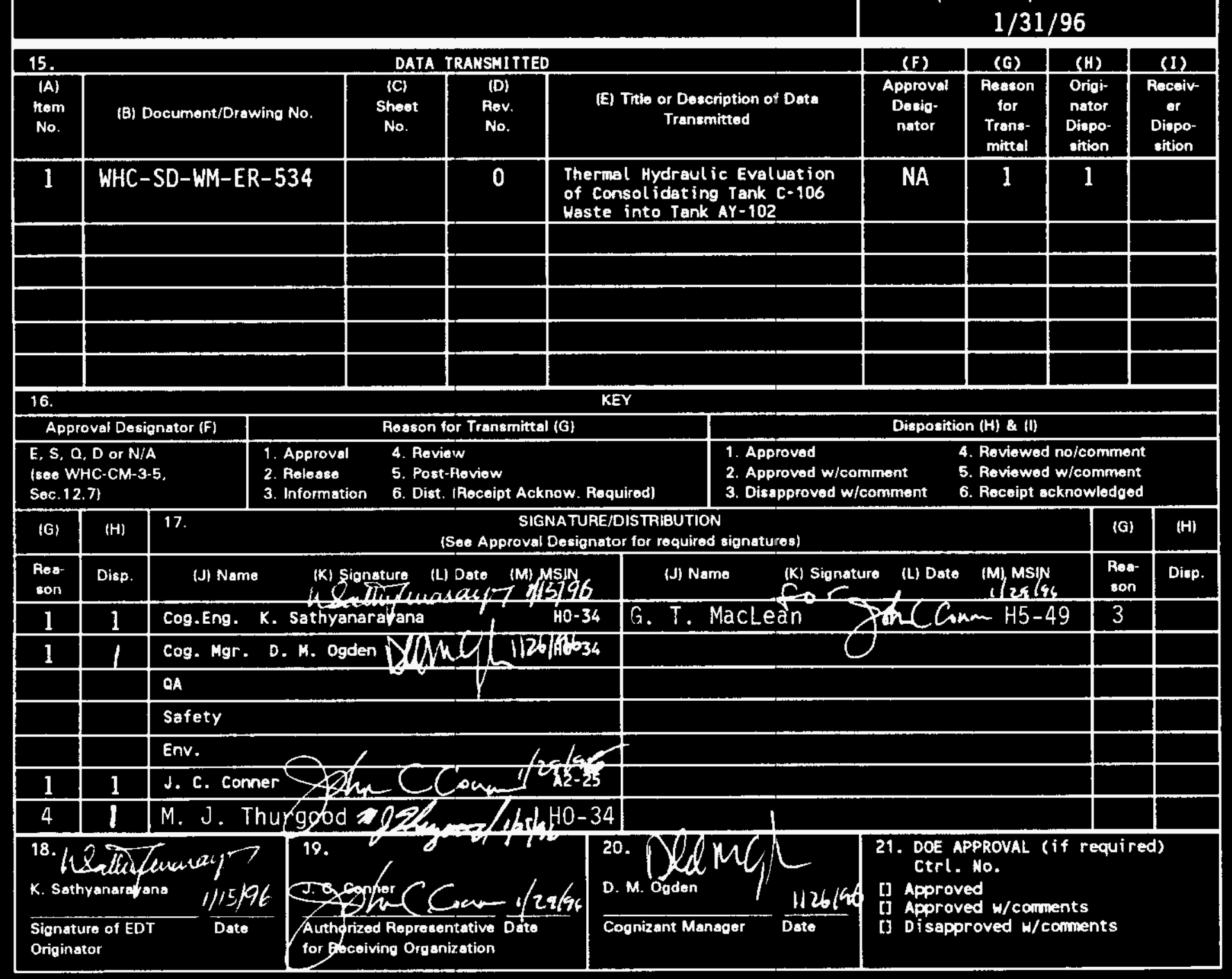

BD-7400-172-2 (04/94) GEF097 


\section{Thermal Hydraulic Evaluation of Consolidating Tank C-106 Waste into Tank AY-102}

K. Sathyanarayans

West inghouse Hanford Company, Richland, MA 99352

U.S. Department of Energy Contract DE-AC06-87RL10930

$\begin{array}{ll}\text { EDT/ECK: } 613542 & \text { UC: } 2020 \\ \text { Org Code: } 74450 & \text { Charge Code: D2MT5 } \\ \text { B\&R Code: EU3135040 } & \text { Total Pages: 126 }\end{array}$

Key Words:

Waste Consol idation, Tank C-106, Tank AY-102, Sludge Temperature, HUB, COTH Computer Code, Particle Settling

Abstract: This report describes the thermal hydraulic analysis performed to provide a technical bas is in support of consolidation of tank C-106 waste into tank AY-102. Several parametric calculations were performed Using the HUB and COTH computer codes. First, the current heat load of tank AY-102 was determined. Potential quantities of waste transfer from tank C-106 were establ ished to maintain the peak temperatures of consolidated sludge in tank AY-102 to remain wi thin Operat ing Specification limits. For this purpose, it was shown that active cooling of the tank floor was essential and a secondary ventilation flow of 2,000 cfm should be maintained.

Transient calculations were also conducted to evaluate the effects of ambient meteorological cyclic conditions on sludge peak temperature, and loss of ventilation systens. Detailed calculations were also performed to estimate the insulating concrete air channels cooling effectiveness and the resulting peak temperatures for the consol idated sludge in tank AY-102. Calculations are were also performed for a primary and secondary ventilation systems outage, both individually and combined to establish limits on outage duration. Because of its active cooling mode of operation, the secondary ventilation system limits the outage duration.

TRADEMARK DISCLAIMER. Reference herein to any specific commercial product, process, or service by trade name, trademark, manufacturer, or otheruise, does not necessarily constitute or inply its endorsentent, recommendation, or favoring by the United States Govermment or any agency thereof or its contractors or subcontractors.

Printed in the United States of America. To obtain copies of this document, contact: UHC/BCS Document Control Services, P.O. Box 1970, Mailstop H6-08, Richland HA 99352, Phone (509) 372-2420; Fax (509) 376-4989.
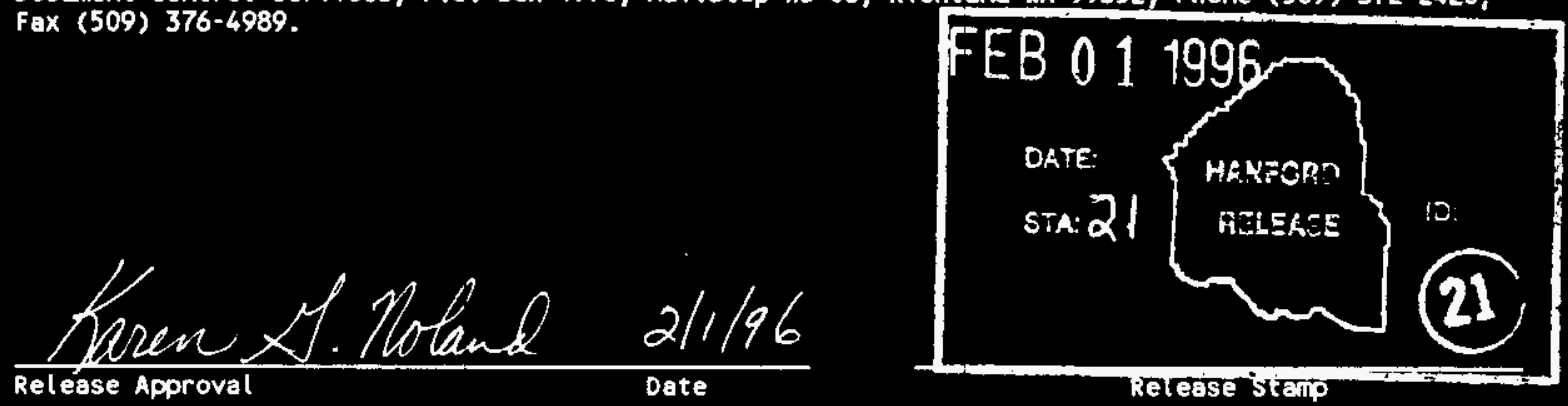

\section{Approved for Public Release}


WHC-SD-WM-ER-534

Rev. 0

THERMAL FYDRAULIC EVALUATION

OF CONSOLIDATING PANK C-106 WASHE INHO AY-102

\author{
K. Sathyanarayana \\ Westinghouse Hanford Company \\ Richland, WA \\ B. C. Fryer \\ John Marvin, Inc. \\ Richland, WA \\ January 9, 1996
}

Issued by

WESTINGHOUSE HANFORD COMPANY

for the

U.S. DEPARTMENT OF ENERGY

RICHLAND OPERATIONS OFFICE

RICHLAND, WASHINGTON 
WHC-SD-WM-ER- 534

Rev. 0

\section{MABLE OF CONPENHS}



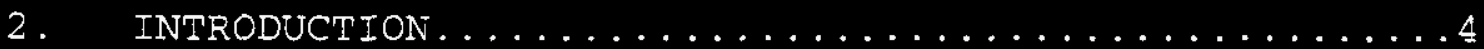

3. CURRENT AND NEW OPERATING SYSTEMS $\ldots \ldots \ldots \ldots \ldots \ldots \ldots$

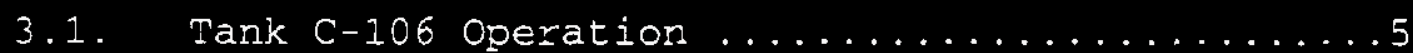

3.2. Tank AY-102 Operation ................

3.3. Current AY/AZ Tank Farm Ventilation Systems ...10

3.3.1. Comparison of $A Y$ and $A Z$ Tank Floor Cooling

Channels ........................ 20

3.3.1.1. Top of Cooling Channel Surface Area anä Heat mransfer Coefficient......20

3.3.1.2. Steel Plate Thickness and Distance

Between Channels.............21

3.3.2. AY and AZ Tank Insulating Concrete

Thermocouples ..................22

3.4. New Primary Ventilation System - Project

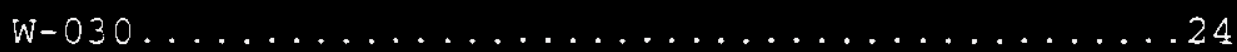

3.5. Ventilation Systems summary ...........26

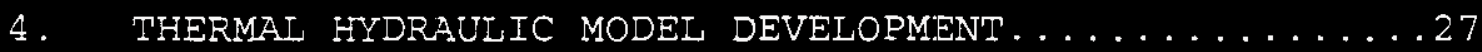

4.1. Thermal Hydraulic Model ..................

4.1.1. HUB Thermal Hydraulic Mode1..........31

4.1.2. 1-D GOTH Thermal Hydraulic Model ......33

4.1.3. 2-D GOTH Thermal Hydraulic Model ......36

4.2. Modeling Parameters...............43

4.2.1. Ventilation Flow Tank Inlet Conditions ..44

4.2.1.1. Average Flow Inlet Conditions......44

4.2.1.2. Annual Meterological Cycle .....44

4.2.2. Tank Waste Parameters.............46

4.2.2.1. Sludge and Soil Thermophysical

Properties................46

4.2.2.2. Waste Liquid Vapor Pressure ......48

4.2.2.3. Waste Particle settling

Characteristics..............52 
WHC-SD-WM-ER -534

Rev. 0

4.2.2.4. Total Heat Load and Distribution in Tank C-106 Sludge Before and After

Transfer..................... 58

5. RESULTS AND DISCUSSION..................60

5.1. Tank AY-102 Heat Load Estimation..........60

5.2. Tank AY-102 with Consolidated Sludge- Phase I..64

5.2.1. HUJB Parametric Calculations ........64

5.2.2. GOTH 1-D Simulation .............67

5.3. Tank AY-102 With Consolidated Sludge- Phase

II............................ 73

5.3.1. HUB Parametric Calculations .........73

5.3.2. 2-D GOTH Model Simulations............81

5.3.2.1. 3000 CFM Flow with Average Summer Conditions ................... 81

5.3.2.2. 2000 CFM Flow with Average Summer Conditions ................. 87

5.3.2.3. 3000 CEM Flow with Annual Meteorological Conditions .........9?

5.3.2.4. 3000 CEM Flow with 2 weeks of Abnormaliy Hot Summer Conditions....993

5.3.3. Loss of Ventilation Systems...........95

5.3.3.1. Combined Ventilation Systems Outage3000 CFM Flow Operation..........95

5.3.3.2. 2000 CFM floor Ventilation and 58 Day Combined Ventilation Systems Outage..97

5.3.3.3. 2000 CFM floor Ventilation and 58 Day Secondary Ventilation Outage.......101

5.3.3.4. 2000 CFM floor Ventilation and 58 Day Primary Ventilation Outage .......104

5.4. Summary of Results...................

6. CONCLUSIONS .......................112






\section{$W H C-S D-W M-E R-534$}

Rev. 0

\section{IIST OF TABLES}

3.1 Az Tank Floor Cooling Channel Flow areas, Velocities, and Heat Transfer coefficients. ......21

3.2 AY Tank Floor Cooling Channel Flow areas, Velocities, and Heat Transfer Coefficients:......21

4.1 Summary of Phase I and Phase II Aralytical Methods,



4.2 Sludge and So:I Thermophysical Properties .......47

4.3 Power and Power Distribution ..................... 59

5.1 Summary of GomH Model Simulation Cases ...........107 


$$
\begin{gathered}
W H C-S D-W M-E R-534 \\
\text { ReV. } 0
\end{gathered}
$$

\section{LIST OF FIGURJS}

3.1 Tank C-106 cross-section, contents and major

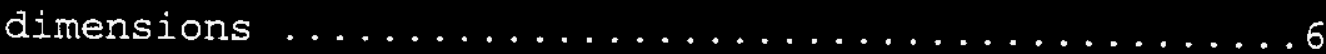

3.2 Tank AY-102 Current Contents and Primary and Secondary Annulus and Floor Ventilation .........9

3.3 Current Tank Farm AY/AZ Tanks and 702-A Primary

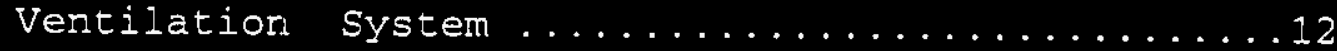

3.4 Tank AY 102 Floor Channel and Insulating Concrete Thermocouple Locations, and Expected Maximum Floor Sludge Temp. Locations when Secondary Vent. is On..13

3.5 Tank AY-102 Tank Steel and Insulating Concrete Floor and Floor Ventilation Channel Dimensions .........14

3.6 Tank AY-102 Inner \& Middle Region Coolant Channel Spaceing Near Outside of Each Channel Region, and Sludge Layers and Supernatant Thickness Post

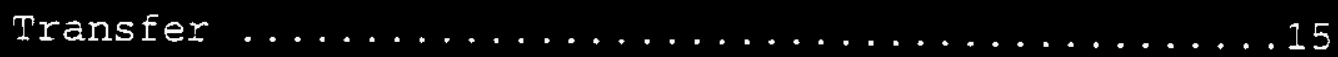

3.7 Tank Ay-102 Middle and Outer Region Coolant Channel Spaceing Near Outside of Each Channel Region, and Sludge Layers and Supernatant Thickness Post

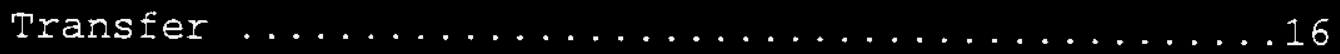

3.8 Tanks AZ-101 \& 102 Floor Channel and Insulating Concrete Thermocouple Locations, and Expected Maximum Floor Sludge Temp. Locations when Secondary

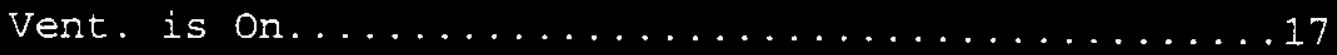

3.9 Tank AZ-101\& 102 Tank steel and Insulating Concrete Floor and Floor Ventilation Channel Dimensions....18

3.10 Tank AZ-101 \& 102 Inner, Middle and Outer Ring Coolant Channel Spaceing Near Outside of Each

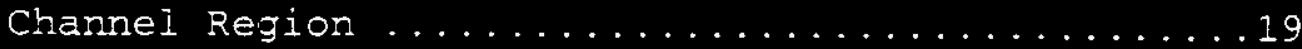

3.11 Project W-030 New AY/AZ Primary Tank Ventilation

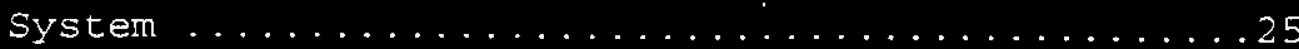

4.1 Tank AY-102 after a 4.5 ft or 6 ft Transfer of C-106

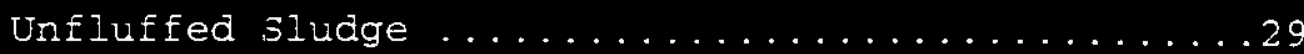


WHC-SD-WM-ER- 534

Rev. 0

4.2 Tank AY-102 After Transfer of $4.75 \mathrm{ft}$ of C-106

Sludge which is Fluffed a Factor of 2 to $9.5 \mathrm{ft}$...30

4.3 Side view of GOTH 1-D Multi-Cell Aging waste Tank



4.4 Plan View of GOTH 3 Region 2-D Tank AY-102 Model. Showing Inner, Middle and Outer sludge and Air Channel Regions based on AZ tank floor geometry...38

4.5 Side View of GOTH 3 Region 2-D Tank AY-102 Model Nodalization for Inner Sludge and Floor Region -Approximate Average Distance Between Channels 2.24

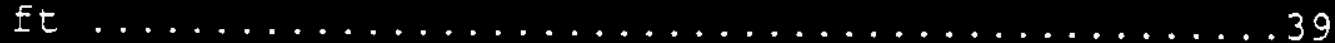

4.6 Side View of GoTH 3 Region 2-D Tank AY-102 Model Nodalization for Midale Sludge and Floor Region-Approximate Maximum Distance Between Channels 4.5 feet................................ 40

4.7 Side View of GOTH 3 Region 2-D Tank AY-102 Model

Nodalization for Outer Sludge and Floor Region-Approximate Maximum Distance Between Channels 3.66 feet........................... . . . 1

4.8 Assumed Annual Meteorological Cycle based on measured monthly average air temperature .......45

4.9 Assumed Annual Meteorological Cycle based on measured monthly average steam and saturation partial pressures...................46

4.10 Saturation Pressure versus Temperature for water...49 4.i1 Pressure and Saturation Temperature Versus Distance

Erom Tank Bottom...........................

4.12 NCAW Simulant Settling Test--Heated Vessel......55

4.13 NCAW Simulant Settling Test--Ambient Vessel .....56

4.14 Temperature Profiles During Settling ...........57

5. I Tank AY-102 Current Contents Temperature Response to Annual Meteorological Cycle, 1 ft of sludge - -Second. Vent. Off...................662

5.2 Tank AY-102 Current Contents Heat Load Partitioning Response to Annual Meteorological Cycle, 1 ft of sludge --Second. Vent. Off..............63

5.3 Comparison of Temperature Distributions for Different Transferred Sludge Thicknesses --Tank-C-105 Heat Load 110,000 btu/hr--Phase I. . . .66 
WHC-SD-WM-ER- 534

Rev. 0

5. 4 Tank AY-102 Contents Temperature Response to Annual Meteorological Cycle After $4.5 \mathrm{ft}$ Sludge Transfer From Tank C-106--Second. Vent. Off, Fluff Factor

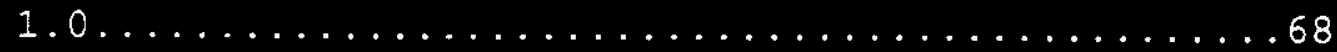

5.5 Tank AY-102 Contents Temperature Response to Annual Meteorological Cycle After 4.5 ft Sludge Transfer From Tank C-106--Second. Vent. 500 CFM, Fluff

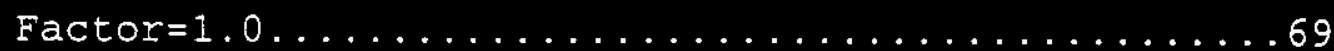

5.6 Tank AY-102 Contents Temperature Response to Annual Meteorological Cycle After $6 \mathrm{ft}$ Sludge Transfer From Tank C-106--Second. Vent. 500 CFM, Fluff



5.7 Temperature Distribution in Sludge Layer of Tank AY-102 with Annulus Vent. Flow Effectiveness as a parameter for Secondary Vent. Flow $=3000 \mathrm{cfm} . \ldots 76$

5.8 Temperature Listribution in Sludge Layer of Tank AY-102 with Annulus Ventilation Flow Effectiveness as a parameter for secondary Vent. Flow of 2000 cfm. ........................... 77

5.9 Temperatire Eistribution in Sludge Layer of Tank AY-102 with Annulus Ventilation Flow Effectiveness as a parameter for Combined sludge Heat Load of $125,400 \mathrm{Btu} / \mathrm{hr}$ and Height of $5.8 \mathrm{ft} \ldots \ldots \ldots \ldots . \ldots 78$

5.10 Temperature Distribution in Sludge Layer of Tank AY-102 with Annulus Ventilation Flow Effectiveness as a parameter for Combined sludge Heat Load of $125,400 \mathrm{Btu} / \mathrm{hr}$ and Height of $15.4 \mathrm{ft} \ldots \ldots \ldots \ldots 79$

5.11 Combined Sludge Peak Temperature in AY-102 Versus Effectiveness of Cooling Channels in the Insulating Concrete with Sludge Fluff Factor as a Parameter. ........................ 80

5.12 Three Region Sludge and Floor Temperature Contours--3000 CFM Floor Ventilation Flow, Fluff

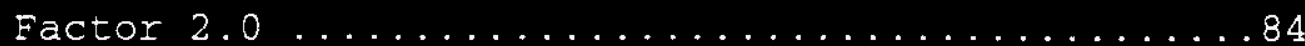

5.13 Temperatures at 3 Locations Near Hottest Sludge

Region in Outer Region - -3000 CFM Floor Ventilation Flow, Fluff Factor $2.0 \ldots \ldots . \ldots . \ldots 5$ 


$$
\begin{aligned}
& W H C-S D-W M-E R-534 \\
& \text { ReV. } 0
\end{aligned}
$$

5.15 Three Region Sludge and Floor Temperature Contours--2000 CFM Floor Ventilation Flow, Fluff Factor $2.0 \ldots \ldots \ldots \ldots \ldots \ldots \ldots \ldots \ldots$

5.16 Temperatures at 3 Locations Near Hottest Sludge Region in Outer Region - -2000 CFM Floor Ventilation Flow, Fluff Factor $2.0 \ldots \ldots \ldots . . .89$

5.17 Air Outlet Temperatures at the 3 Different Floor Ventilation Regions - -2000 CFM Floor Ventilation Flow, Fluff Factor $2.0 \ldots \ldots \ldots \ldots \ldots \ldots$

5.18 Annual Meteo:ological Cycle--Tank Contents Temperatures - -3000 CFM Floor Ventilation Flow, Fluff Factor $2.0 \ldots \ldots \ldots \ldots \ldots . \ldots \ldots 2$

5.19 Annual Meteorological Cycle Plus 2 Weeks of Continuous $105{ }^{\circ} \mathrm{F}$ weather--Tank Contents Temperatures - -3000 CFM Floor Ventilation Flow, Fluff Factor 2.0....................94

5.20 Temperatures Near Hottest Axial Jocation in Outer Region--3000 CFM Floor Ventilation Flow, Fluff Factor 2.0,--Combined Ventilation Outage.......996

5.21 Temperatures Near Hottest Axial Jocation in Outer Region--2000 CFM Floor Ventilation Flow, Fluff Factor 2.0--Combined Ventilation Outage .......98

5.22 Air Dome Gas and Supernatant Temperature - -2000 CFM Floor Ventilation Flow, Fluff Factor 2.0-Combined Ventilation Outage..................100

5.23 Temperatures Neax Hottest Axial Location in Outer Region--2000 CFM Floor Ventilation Flow, Fluff Factor 2.0--Secondary Ventilation Outage .......102

5.24 Air Dome Gas and Supernatant Temperature --2000 CFM Floor Ventilation Flow, Fluff Factor 2.0--Secondary Ventilation Outage ...........103

5.25 Temperatures Near Hottest Axial Location in Outex Region--20010 CFM F-oor Ventilation Flow, Fluff Factor 2.0--Primary Ventilation Outage ........105 5.26 Air Dome Gas and Supernatant Temperature --2000 CFM Floor Ventilation Flow, Fluff Factor 2.0--Primary Ventilation Outage .................106 
WHC-SD-WM-ER- 534

Rev. 0

\section{SUMMARY}

This report documents the thermal hydraulic analysis conducted to provide a technical basis supporting consolidation of Tank C-106 waste in Tank AY-102. Tank C-106 is a single shell high heat watchlist tank. Currently the tank contains about 197,000 gallons $(\approx 6 \mathrm{ft})$ of sludge with an estimated heat load in the range of 110,000 to $132,400 \mathrm{Btu} / \mathrm{hr}$. Tank AY-102 is a double shell tank designed to store boiling neutralized current acid wastes (NCAW). Currently the tank contains about 32,000 gallons $(\approx 1 \mathrm{ft})$ of sludge with an estimated heat load of $33,000 \mathrm{Btu} / \mathrm{hr}$. The consolidation of waste in Tank AY-102 will increase the heat load as well as the settled nonconvective sludge thickness, both of which will potentially lead to higher waste temperatures. The tank farms Interim Operational Safety Requirements (IOSR) document specifies the limits on sludge peak temperature that it must be $17^{\circ} \mathrm{C}\left(30^{\circ} \mathrm{F}\right)$ less than the local saturation temperature/boiling point to eliminate the potential for a thermal bump.

A description of thermal hydraulic models, assumptions, and results of analyses performed to estimate the temperature distribution of the consolidated waste in AY-102 for different quantities of transferred waste and settled sludge conditions, as well as various potential operating conditions, are presented in this report.

The following conclusions were drawn from the results of a limited parametric analysis conducted in this study.

1. 157,000 gallons of Tank C-106 sludge (4.75 ft, 92400 btu/hr) can be transferred to Tank AY-102 while keeping the peak sludge temperatures within the operational safety limits and qualifying Tank $\mathrm{C}-106$ as a low heat tank provided:

a. secondary floor ventilation flow of 2000 CFM 


$$
\begin{aligned}
& \text { WHC-SD-WM-ER }-534 \\
& \text { ReV. } 0
\end{aligned}
$$

and a primary once through ventilation flow of 600 CFM can be supplied to AY-102;

b. the transferred C-106 sludge becomes nonconvective only after it has settled to at least $1 / 2$ of the current particle volume fraction in Tank C-106 (i.e. transferred sludge must have an initial settled and non-convective, thickness not greater than $9.5 \mathrm{ft}$, i.e. fluff factor less than or equal to $2.0)$; and,

c. waste levels are maintained high to increase the local hydrostatic pressure and therefore the saturation temperature in the sludge.

The maximum temperature calculated for the consolidated sludge in tank AY-102 under normal operation with assumed average summer meteorological conditions, was $201^{\circ} \mathrm{F}$ for a secondary ventilation flow rate of 2000 CFM through the tank floor cooling channels. The maximum sludge temperature would decrease to $190^{\circ} \mathrm{F}$ if the flow rate could be increased to $3000 \mathrm{CFM}$. These temperatures are well below local saturation conditions.

2. Secondary floor ventilation flows as low as $2000 \mathrm{CFM}$ will provide adequate cooling to allow transfer of 157,000 gallons of C-106 waste. The margin of safety relative to saturation temperature is $42^{\circ} \mathrm{F}$ assuming a waste level of $30 \mathrm{ft}$. Lower secondary flow allows less uncertainty in terms of: C-106 and AY-102 heat loads and the distribution of heat; saturation temperature; waste physical parameters such as sludge conductivity; fluff factor; and cooling effectiveness. Lower flow also reduces the allowable outage time for ventilation systems. Therefore increasing the secondary flow to 3000 CFM should be considered.

3. Operating a double shell tank with floor ventilation flow in an active heat removal mode is a significant departure from normal operating practice and apparently was 


$$
\text { WHC-SD-WM-ER }-534
$$

Rev. 0

not part of the original design basis. Potential problem areas should therefore be thoroughly evaluated before operation in this mode is undertaken. These include: increased thermal cycling of tank structural components, plugging of one or more floor coolant channels, and plans and experience with rapid restoration of ventilation system after outages. Both the capacity to provide high ventilation air flow rates and the cooling effectiveness should be assured before waste transfer. Calculated cooling effectiveness should be verified by increasing floor ventilation flow rates in a high heat tank such as AZ-101 or 102 and comparing the resulting tank temperatures with the GOTH simulation models used in this analysis.

4. Project $W-030$ new primary ventilation system operating in the recirculation mode is less effective in providing cooling compared to the current systern since the air flow rates are lower and the tank air inlet conditions are worse than for either the current system, or the new system operating in the once through mode. Either the old or new system operating in the once through mode should be used until operating experience coupled with additional analysis confirms that the recirculation mode will provide adequate cooling.

5. A secondary ventilation outage for a period of 30 days results in the sludge reaching a maximum temperature of about $217^{\circ} \mathrm{F}$. This is within $30^{\circ} \mathrm{F}$ of the local saturation temperature and therefore acceptable. However, outages of more than 2 weeks should not be allowed to provide for unforeseen contingencies.

GOTH is a trademark of JMI, which is derived from GOTHIC - a registered trademark of the EPRI Corp. of California. 
WHC-SD-WM-ER-534

Rev. 0

\section{INTRODUCTION}

Double-shell tank waste consolidation effort includes the transfer of high heat waste from single shell Tank C-106 to Tank AY-102 and ultimate consolidation in Tank AZ-102. The consolidation effort will resolve the safety issues associated with Tank $\mathrm{C}-106$ by transferring that high heat waste to a double-shell tank. Because of the limited solids volume and radionuclide content of Tanks AY-102 and $\mathrm{C}-106$, it is reasonable to consolidate these wastes into a double shell tank, thereby also minimizing the potential consequences due to leakage.

Safe storage and consolidation of wastes requires careful investigation of the problems associated with the chemical compatibility, nuclear criticality and thermal hydraulics of these wastes. mhis report documents the analysis

performed to determine the necessary operating conditions and the amount of waste that can be safely stored in tank AY-102 from the point of thermal hydraulic conditions. The conclusions are based on the limits specified in the tank farms interim operational safety requirements document [Aguirre, 1994] in regard to the peak sludge temperature. The specifications requires that the peak temperature of the waste must be $17{ }^{\circ} \mathrm{C}\left(30^{\circ} \mathrm{F}\right)$ less than the local saturation temperature (i.e. boiling point).

Safe operation of transferring and consolidating of Tank C-106 sludge into Tank AY-102 requires an understanding of the current thermal hydraulic characteristics of both the tanks, their current ventilation systems, maximum achievable Tank AY-102 secondary floor ventilation flow rates, and the changes being made in the AY/AZ tank farm primary ventilation system with Project $W-030$. The background information on these current and new operating facilities is provided in section 3. 
WHC-SD-WM-ER- 534

Rev. 0

\section{CURRENT AND NEW OPERATING SYSTEMS}

The current operating conditions of Tank C-106, Tank AY-102, AY/AZ tank farm primary ventilation system, secondary ventilation systems and the details of the insulating concrete floor air slots for both $A Z$ and $A Y$ tanks are briefly described in this section. Also the Project W-030 new primary ventilation system and its expected potential performance in relation to cooling capability is sumnarized.

\subsection{Tank C-106 Operation}

Tank C-106 is a 530,000 gallons capacity single shell tank and currently contains about 6 feet of heat generating sludge covered with a few inches of water as illustrated in Figure 3.1. The sludge is primarily cooled by evaporation and convective heat transfer from the pool surface to the dome ventilation air. A small amount of heat is also removed by heat conduction through the top soil to the atmosphere and through the bottom soil to the groundwater. Periodic batch additions of water, equivalent to about 4 inches of tank level, are made approximately every 2 months to make up for evaporation, thereby keeping the sludge covered with liquid. Tank heat load estimates have varied from a nominal value of 110000 btu/hr [Bander, 1993] to an upper bound heat generation rate of $132400 \mathrm{btu} / \mathrm{hr}$ [Fryer, et.al., 1995] estimated by the most recent thermal hydraulic analysis. The dome ventilation air flow rate is currently about 2300 CFM. Tank waste temperatures cycle with the annual meteorological cycle. Sludge at the bottom central region of the tank is estimated to be close to saturation temperature $\left(\sim 230^{\circ} \mathrm{F}\right)$ corresponding to tank bottom hydrostatic pressure [Thurgood, et.al., 1995]. 


\section{WHC-SD-WM-ER- 534 \\ Rev. 0}



Figure 3.1 Tank C-106 cross-section, contents and major dimensions 


$$
\text { WHC-SD-WM-ER- } 534
$$

Rev. 0

It appears that "loose sludge" is present to within 1 foot of the tank bottom. It would be desirable to remove all of the "loose sludge" from Tank C-106. The remaining material immediately above the tank bottom being a "hard pan" may not be removable via sluicing during project W-320.

\subsection{Tank AY-102 Operation}

Tank AY-102, as illustrated in Figure 3.2, is a double-shell tank which has a design capacity of one miliion gallons. Currently the tank contains 812,000 gallons of waste in the form of supernatant and sludge. Based on the latest information [Hanlon, 1995], the tank contains 32,000 gallons $(\approx 1$ foot) of heat generating sludge, covered with about 780,000 gallons $(\approx 23.5$ feet $)$ of liquid waste. The heat load and primary ventilation flow are estimated to be about $33000 \mathrm{btu} / \mathrm{hr}$ and $600 \mathrm{CFM}$ respectively. Maximum measured sludge temperature at the tank bottom is about $92^{\circ} \mathrm{F}$. The tank waste is currently cooled by evaporation and convective heat transfer from the pool surface to the dome ventilation air, with minor heat removal via conduction through the soil to the atmosphere and groundwater.

The secondary floor/annulus ventilation system has not operated for several years but is being rehabilitated for future operation. Previously when it did operate the total annulus exhauster flow was apparently set at 1000 CFM. It was estimated [Tardiff, 1995a] that the Tank AY-102 annulus/floor ventilation exhauster may be capable of supplying 2000-3000 CFM to the tank floor cooling channels. More recently [Tardiff, 1995b], based on additional review of the secondary system, it appears 2000 CFM may be the maximum floor ventilation flow achievable. As discussed later in the report, the capability to increase flow to the floor cooling channels is a major factor keeping the waste temperatures within 


\section{WHC-SD-WM-ER- 534 \\ Rev. 0}

allowable limits, thereby providing the potential to transfer large quantities of Tank C-106 waste to Tank AY-102. 
WHC-SD-WM-ER- 534

Rev. 0

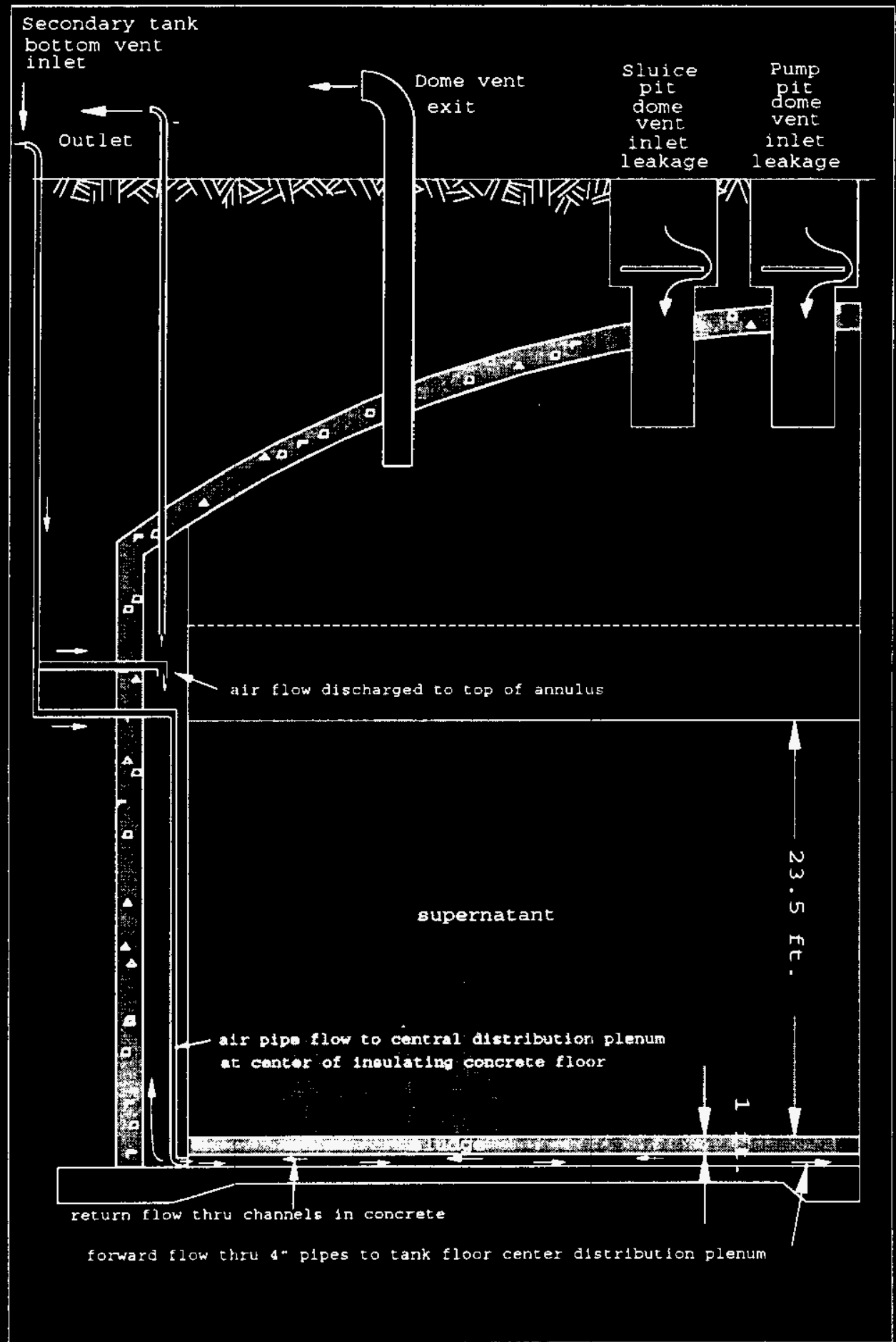

Figure 3.2 Tank AY-102 Current Contents and Primary and Secondary Annulus and Floor Ventilation 
$W H C-S D-W M-E R-534$

Rev. 0

\subsection{Current AY/Az Tank Farm Ventilation Syotems}

The ventilation systems for the AY/AZ tank farm consists of the primary ventilation system with backup, individual annulus ventilation systems for each of two AY tanks and a combined annulus ventilation system for the AZ tanks. All four tanks in the AY/AZ tank farm are currently served by the single prinary ventilation system which is illustrated in Figure 3.3. A major part of the liquid evaporated from the tanks is condensed in the condenser, retained for a period of time in catch tanks, and periodically returned to the AY/AZ waste tanks to make up for evaporation. Other liquid is removed at the de-entrainers, one located upstream and one downstream of the condenser. This liquid is also retained in a catch tank and periodically returned to the AY/AZ tanks. Approximately 850 gallons of condensate is received per day in the various catch tanks. An unquantified amount of liquid is also apparent $1 y$ condensed in the piping system upstream of the first de-entrainer, due to the combining of the different temperature air stream from the four tanks. This liquid apparently drains back to one or more of the tanks via the piping system.

The purpose of the annulus ventilation system is to provide clean air to monitor for leaks from primary tank. The flow through the air slots in the insulating concrete slab provides cooling to the tank waste and transports radioactive particulates to an air monitor. Additional cooling of the sludge and supernatant in each tank is possible with the floor/annulus secondary ventilation systems with increased secondary ventilation flow. Currently a major part of the secondary ventilation system air flow is delivered to the upper annulus (estimated at $\sim 80 \%$ ) and a smaller part (estimated at $20 \%)$ is delivered to coolant channels in the insulating concrete floor [Powell, 1989]. Coolant channels in the floor are illustrated in Figures 3.4-3.7 [Drawing Set. 1] for Tank AY-102 and in Figures 3.8-3.10 [Drawing Set. 2] 
WHC-SD-WM-ER- 534

Rev. 0

for AZ Tanks. The number, spacing, size, and length of coolant channels in the inner, middle, and outer regions are different for the AY-102 tank compared to the AZ tanks. Also the thicknesses of the primary and secondary steel tank floor plates are different for these two tanks. 


$$
\begin{gathered}
\text { WHC-SD-WM-ER-534 } \\
\text { Rev. } 0
\end{gathered}
$$

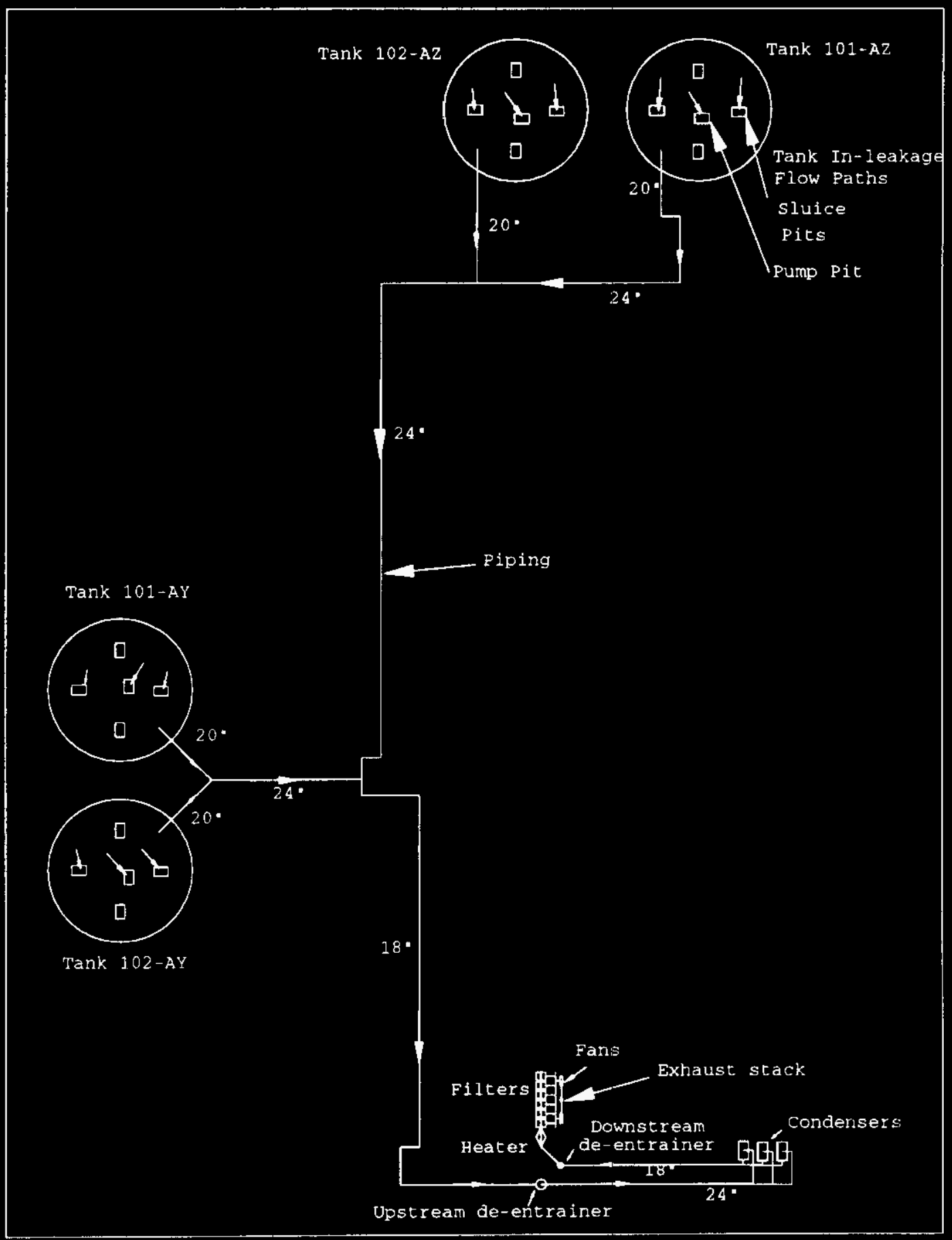

Figure 3.3 Current Tank Farm AY/AZ Tanks and 702-A Primary Ventilation System 
WHC-SD-WM-ER- 534

Rev. 0

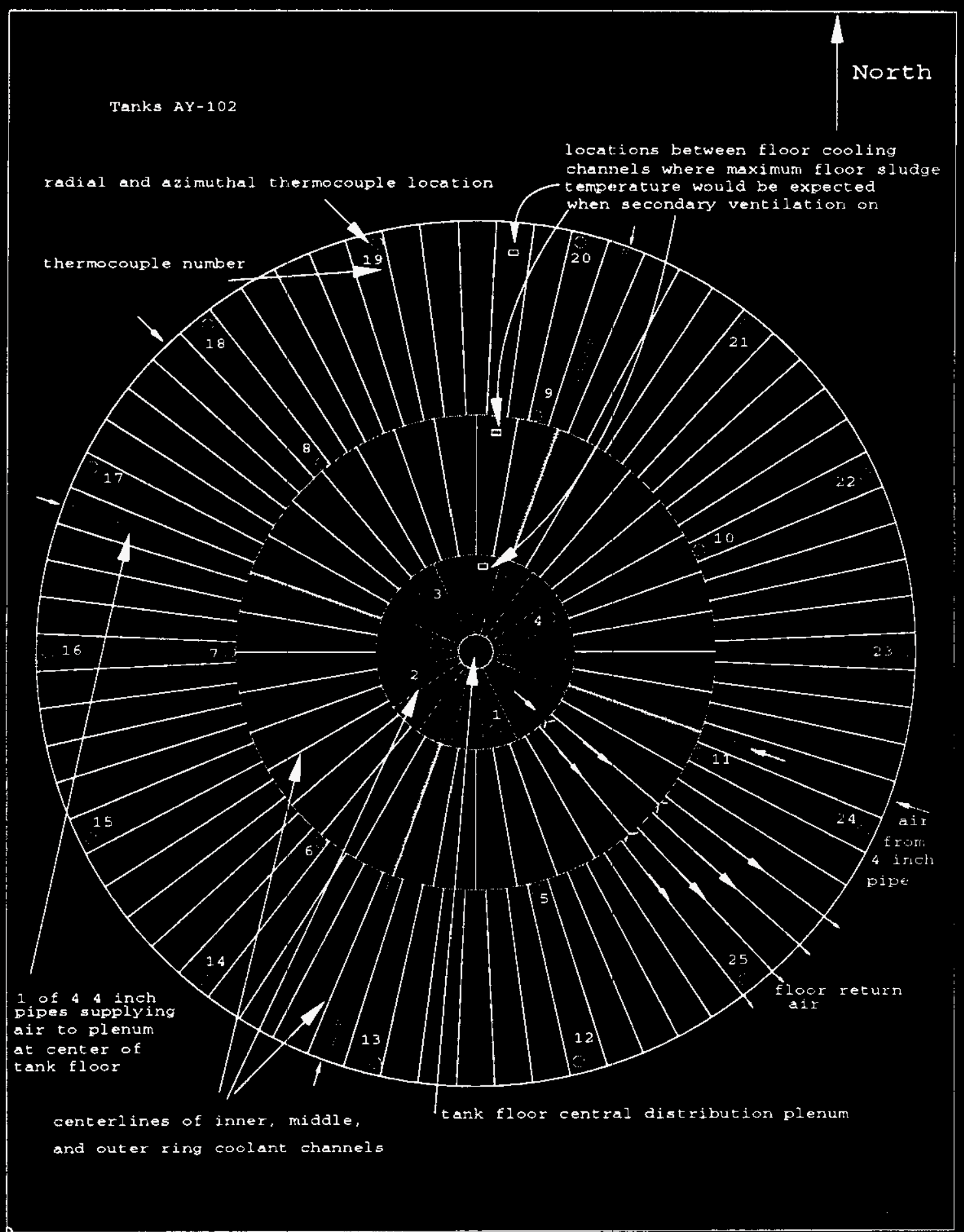

Figure 3.4 Tank AY 102 Floor Channel and Insulating Concrete Thermocouple Locations, and Expected Maximum Floor Sludge Temp. Locations when Secondary Vent. is on 


$$
\begin{aligned}
& \text { WHC-SD-WM-ER- } 534 \\
& \text { ReV } \quad 0
\end{aligned}
$$

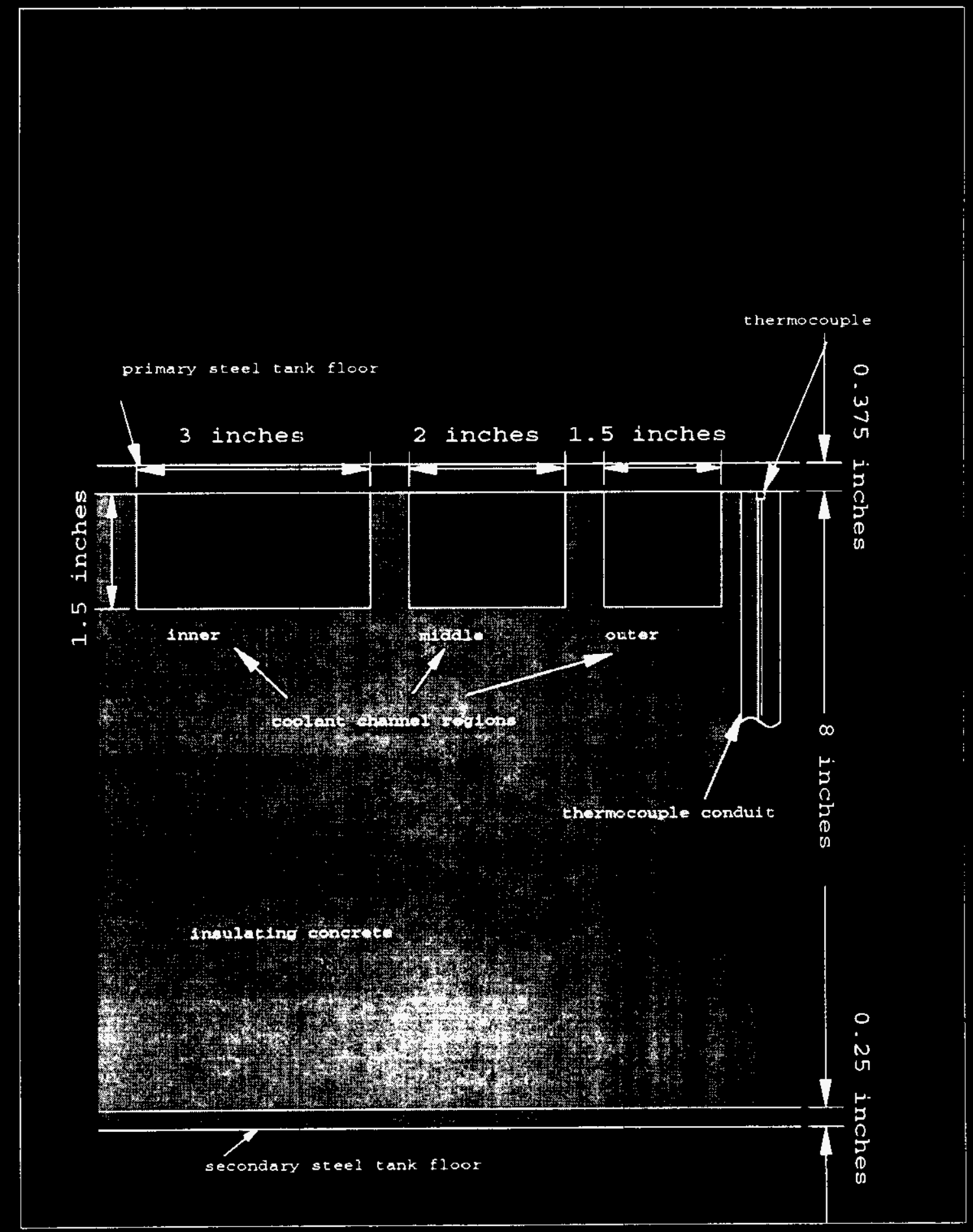

Figure 3.5 Tank AY-102 Tank Steel and Insulating Concrete Floor and Floor Ventilation Channel Dimensions 
WHC-SD-WM-ER-534

Rev. 0



Figure 3.6 Tank AY-102 Inner \& Middle Region Coolant Channel Spaceing Near Outside of Each Channel Region, and Sludge Layers and Supernatant Thickness Post Transfer 
WHC-SD-WM-ER- 534

Rev. 0

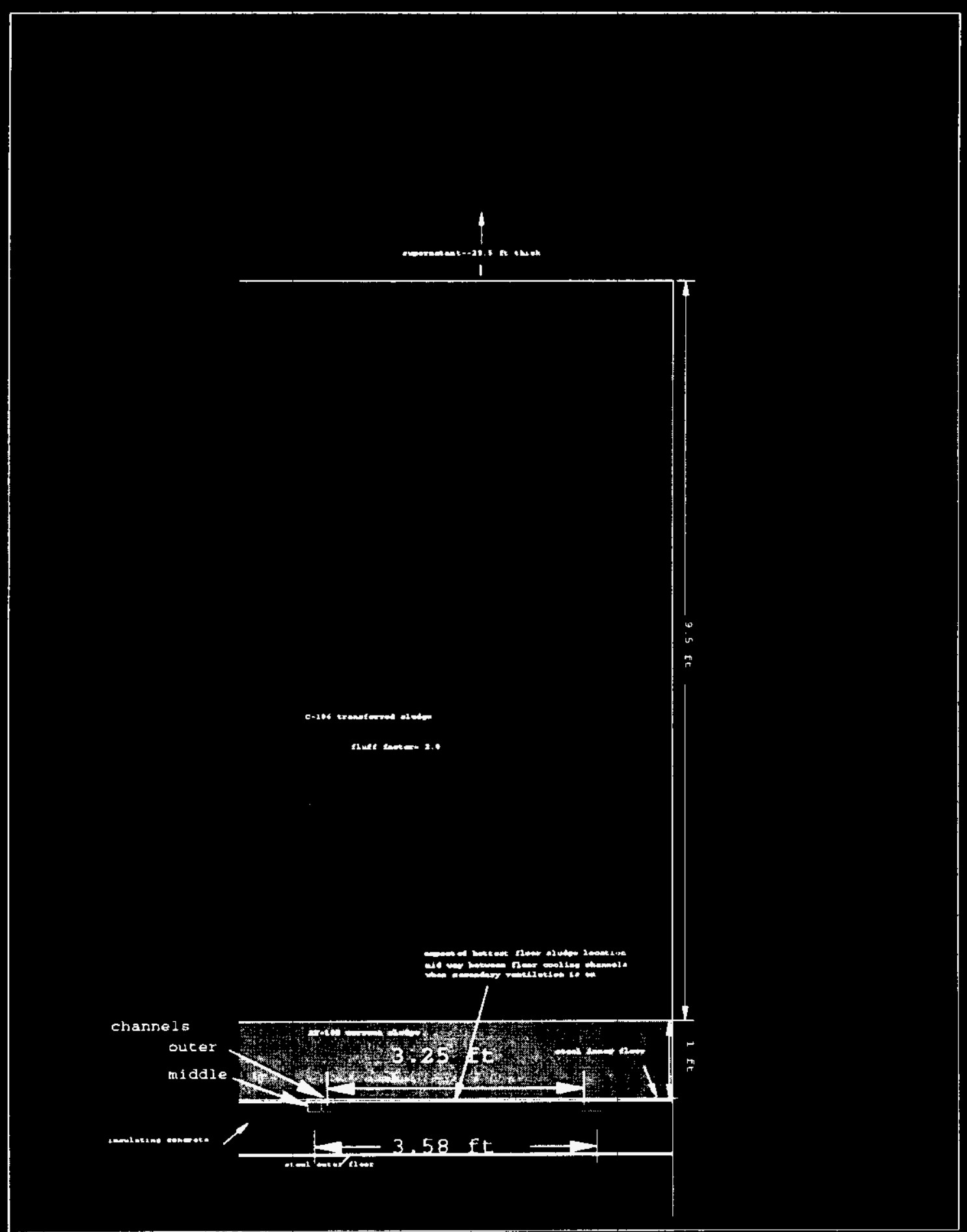

Figure 3.7 Tank Ay-102 Middle and Outer Region Coolant Channel Spaceing Near Outside of Each Channel Region, and Sludge Layers and Supernatant Thickness Post Transfer 
WHC-SD-WM-ER-534

Rev. 0

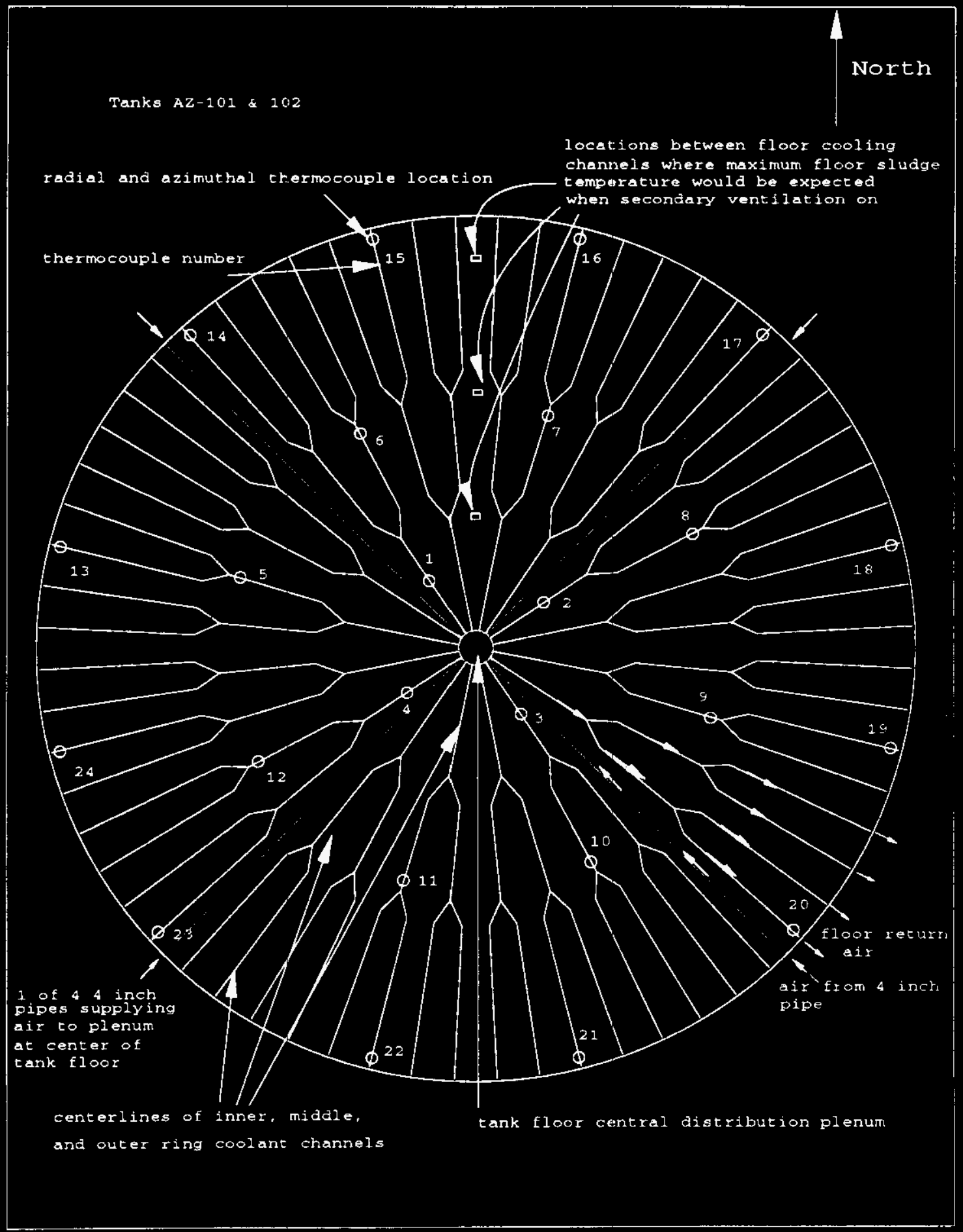

Figure 3.8 Tanks AZ-101 \& 102 Floor Channel and Insulating Concrete Thermocouple Locations, and Expected Maximum Floor Sludge Temp. Locations when Secondary Vent. is on 
WHC-SD-WM-ER- 534

Rev. 0

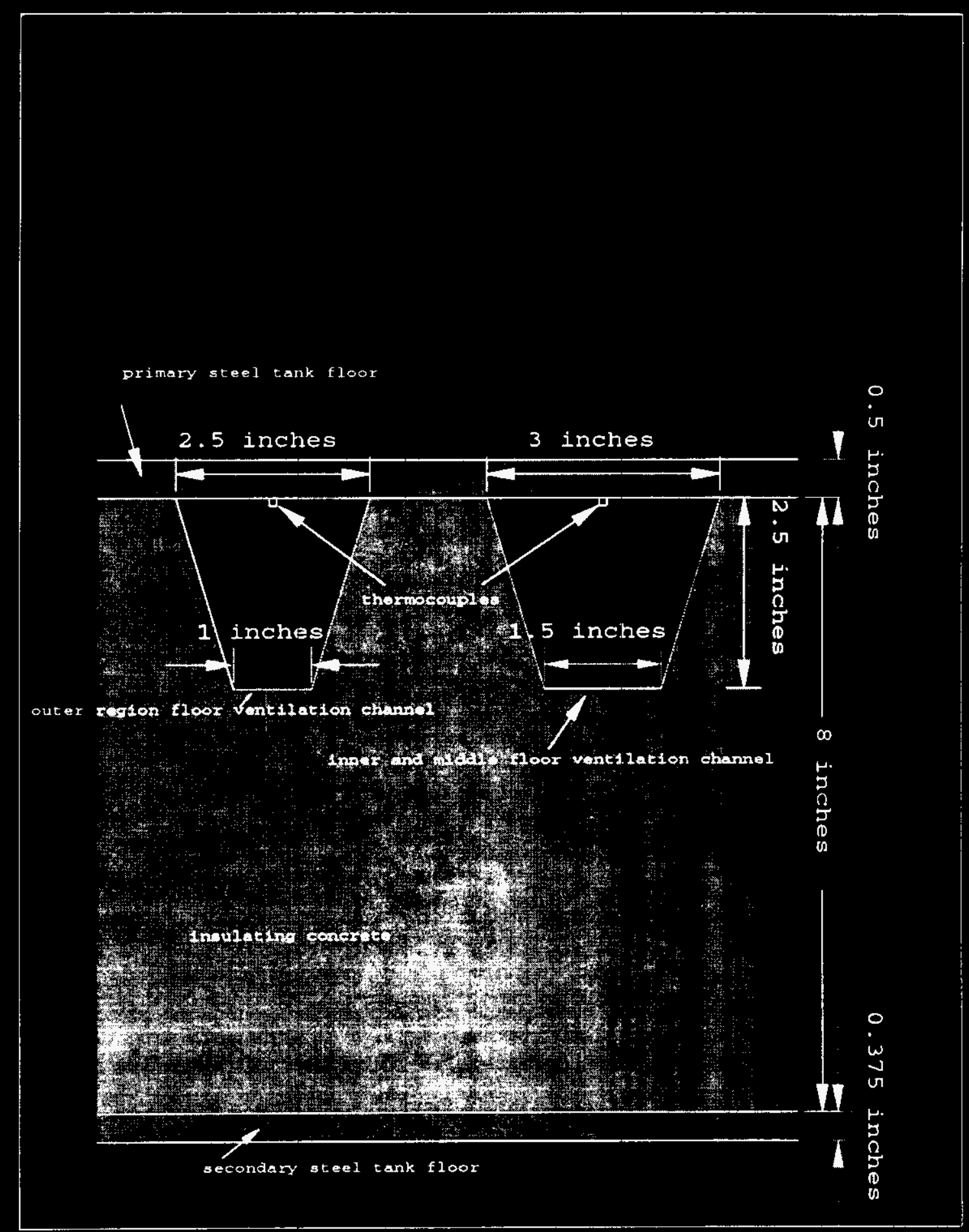

Figure 3.9 Tank AZ-101\& 102 Tank Steel and Insulating Concrete Floor and Floor Ventilation Channel Dimensions 
WHC-SD-WM-ER- 534

Rev. 0

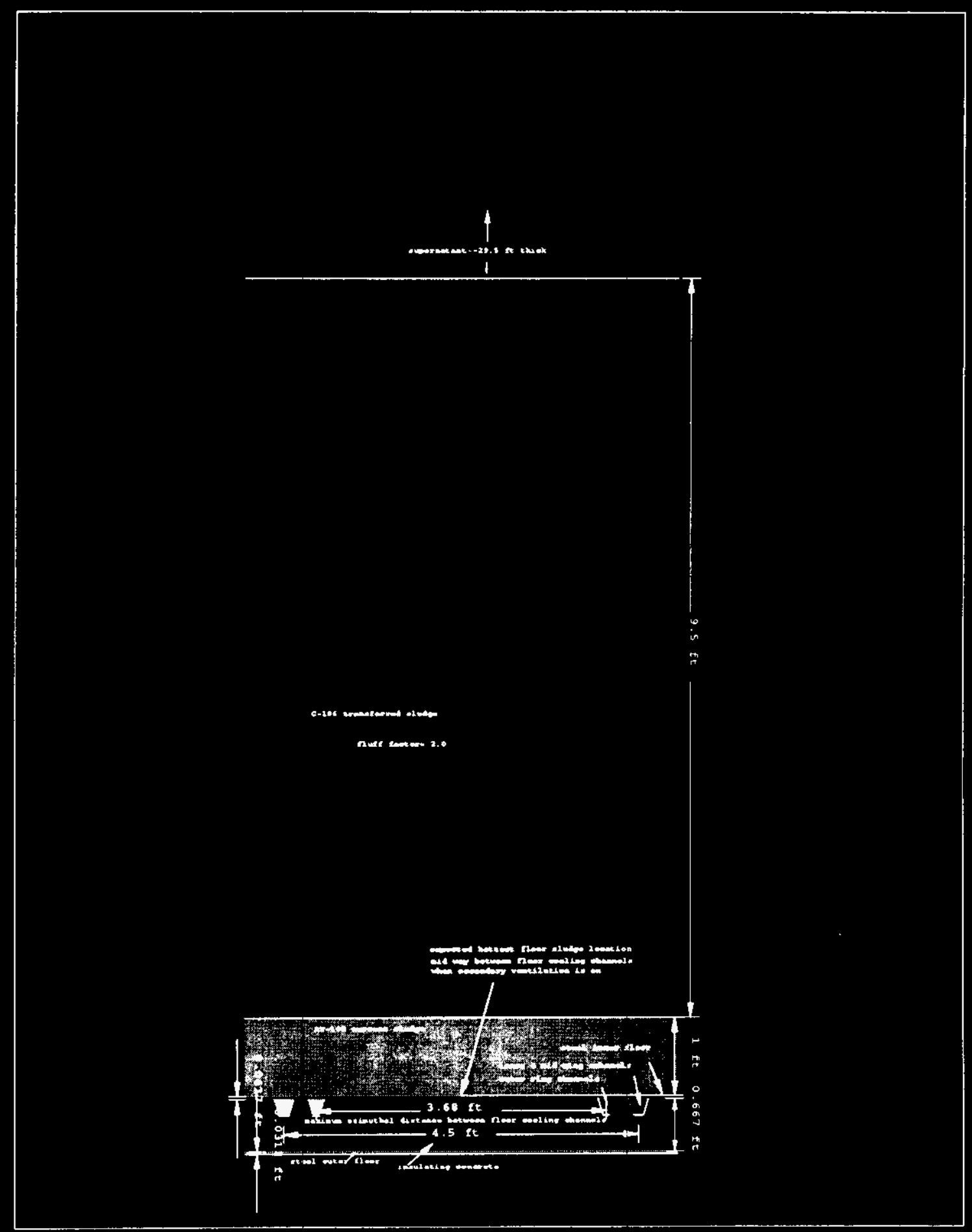

Figure 3.10 Tank AZ-101 \& 102 Inner, Middle and Outer Ring Coolant Channel Spaceing Near Outside of Each Channel Region 
WHC-SD-WM-ER- 534

ReV. 0

\subsubsection{Comparison of AY and Az Tank Floor Cooling Channels}

The 2-D GOTH model, developed to determine the cooling channel effect on sludge temperature, is based on the dimensions and arcangement of the floor cooling channels for the AZ tanks. The floor cooling channel geometry for Tank AY-102 is diEferent than the AZ Tanks. The use of the AZ tank geometry for modeling Tank AY-102 is conservative. A comparison of surface areas, air channel heat transfer coefficients, channel to mid-channel azimuthal distances, and steel floor plate thicknesses is provided and described the conservatisms involved.

3.3.1.1. Top of Cooling Channel Surface Area and Heat Transfer Coefficient.

Tables 3.1 and 3.2 provide the data for flow areas and the estimated heat transfer coefficients at different air flow rates through the floor air slots of $A Z$ and $A Y$ tanks. The AY tank has approximately $80 \%$ of the total top of channel surface area of the AZ tanks. This is more than compensated for by a 50\% increase in Tank AY channel heat transfer coefficient relative to the AZ tanks in the middle and outer regions, for a given total tank floor ventilation flow rate. In the inner region of the $A Y$ tank, the top width per channel is the same as for the AZ tanks, but there are more channels, and therefore more total surface area in the inner region. The heat transfer coefficient in the inner region is also higher than for the Az tanks in their inner region. 


$$
\begin{gathered}
\text { WHC-SD-WM-ER--534 } \\
\text { ReV. } 0
\end{gathered}
$$

Table 3.1 AZ Tank Floor Cooling Channel Flow areas,

\begin{tabular}{|c|c|c|c|c|c|c|c|c|c|}
\hline region & $\begin{array}{l}\text { flow } \\
\text { area }\end{array}$ & $\begin{array}{c}\text { velocity } \\
\text { o } 35 \mathrm{~F} \\
\text { CFM }\end{array}$ & $\begin{array}{c}\text { Hyd } \\
\text { Diameter }\end{array}$ & $\begin{array}{l}\text { Reynold } \\
\text { Number } \\
\text { O } 85 \mathrm{~F} \\
\text { - } 500 \\
\text { CFN }\end{array}$ & $\begin{array}{l}\text { turb } \\
\text { heat } \\
\text { trans } \\
\text { coef } \\
8500 \\
\text { CFM }\end{array}$ & $\begin{array}{l}\text { turb } \\
\text { heat } \\
\text { trans } \\
\text { coef } \\
01000 \\
\text { CFM }\end{array}$ & $\begin{array}{l}\text { turb } \\
\text { heat } \\
\text { trans } \\
\text { coef } \\
82000 \\
\text { CFM }\end{array}$ & $\begin{array}{l}\text { turb } \\
\text { heat } \\
\text { trans } \\
\text { coef } \\
83000 \\
\text { CFM }\end{array}$ & $\begin{array}{l}\text { lam } \\
\text { heat } \\
\text { tran } \\
\text { coef }\end{array}$ \\
\hline & \multirow{2}{*}{$\mathrm{ft} \mathrm{t}^{2}$} & fit & \multirow{2}{*}{$\mathrm{ft}$} & \multirow{2}{*}{\multicolumn{6}{|c|}{ 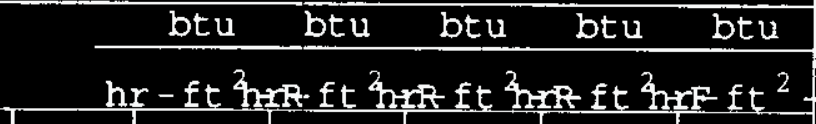 }} \\
\hline & & sec & & & & & & & \\
\hline inner ring & 0.6250 & 12.9760 & 0.192898 & 14490.9 & 3.5193 & 6.1275 & 10.6686 & 14.7564 & 0.3467 \\
\hline middle ring & 1.2500 & 6. 4880 & 0.192898 & 7245.49 & 2.0213 & 3.5193 & 6.1275 & 8.4753 & 0.3467 \\
\hline outer ring & 1.9444 & 4.1709 & 0.167237 & 4038.19 & 1.4606 & 2.5430 & 4.4277 & 6.1242 & 0.3999 \\
\hline annulus & 593.94 & 0.0137 & 4.878931 & 385.681 & 0.0076 & 0.0133 & 0.0232 & 0.0321 & 0.0137 \\
\hline
\end{tabular}
Velocities, and Heat Transfer Coefficients.

Table 3.2 AY Tank Floor Cooling Channel Flow areas,

\begin{tabular}{|c|c|c|c|c|c|c|c|c|c|}
\hline \multirow[t]{4}{*}{ region } & $\begin{array}{l}\text { flow } \\
\text { area }\end{array}$ & $\begin{array}{c}\text { velacity } \\
\text { d } 85 \mathrm{~F} \\
\text { d } 500 \\
\mathrm{COM}\end{array}$ & $\begin{array}{c}\text { Hyd } \\
\text { Diamet er }\end{array}$ & $\begin{array}{c}\text { Reynold } \\
\text { Number } \\
085 \mathrm{~F} \\
500 \\
\text { CFM }\end{array}$ & $\begin{array}{l}\text { turb } \\
\text { heat } \\
\text { trans } \\
\text { coef } \\
\text { a500 } \\
\text { CFM }\end{array}$ & $\begin{array}{l}\text { turb } \\
\text { heat } \\
\text { trans } \\
\text { coef } \\
\text { (1000 } \\
\text { CFM }\end{array}$ & $\begin{array}{l}\text { turb } \\
\text { heat } \\
\text { trans } \\
\text { coef } \\
@ 2000 \\
\text { CFM }\end{array}$ & $\begin{array}{l}\text { turb } \\
\text { heat } \\
\text { trans } \\
\text { coef } \\
83000 \\
\text { CFM }\end{array}$ & $\begin{array}{l}\text { lam } \\
\text { heat } \\
\text { trari } \\
\text { cref }\end{array}$ \\
\hline & & e & & & & & & & \\
\hline & \multirow{2}{*}{$\mathbf{f t} \mathrm{t}^{2}$} & ft & \multirow{2}{*}{$\mathrm{ft}$} & & btu & btu & btu & btu & btu \\
\hline & & $s \in C$ & & \multicolumn{6}{|c|}{  } \\
\hline inner ring & 0.5625 & 14.4178 & 0.166666 & 13911.5 & 3.8109 & 6.6351 & 11.5524 & 15.9788 & 0.4013 \\
\hline middle ring & 0.7500 & 10.8133 & 0.142857 & 8943.15 & 3.1222 & 5.4361 & 9.4648 & 13.0913 & 0.4681 \\
\hline outer ring & 1.1250 & 7.2089 & 0.125000 & 5216.84 & 2.3184 & 4.0366 & 7.0280 & 9.7209 & 0.5350 \\
\hline annulus & 593.94 & 0.0137 & 4.878931 & 385.681 & 0.0074 & 0.0129 & 0.0224 & 0.0310 & 0.0137 \\
\hline
\end{tabular}
Velocities, and Heat Transfer Coefficients.

\subsubsection{Steel Plate Thickness and Distance Between Channels}

The azimuthal distance between channels in Tank AY-102 is smaller in all regions than in the Az tanks. Although the steel plate thickness is smaller for the primary and secondary tank floors in Tank AY-102 compared to the AZ 


$$
\begin{gathered}
\text { WHC-SD-WM-ER-534 } \\
\text { ReV. } 0
\end{gathered}
$$

tanks, the smaller azimuthal conduction distances will compensate this effect. The secondary steel plate is of little importance since it is isolated by the insulating concrete. The conductance of the primary plate azimuthally is important. However for either the .5 inch thick plate in the GOTH 2-D model based on the AZ tank floor geometry, or the $3 / 8$ inch thick plate in Tank AY-102, azimuthal temperature gradients in the primary plate will be quite small. The azimuthal temperature gradients will scale with the ratio of the square of the azimuthal conduction distance divided by the plate thickness. For all but the outer region, the GOTH models based on AZ-101 plate thickness ard azimuthal separation distance are conservative relative to its application to Tank AY-102 in this regard. For the outer region the GOTH models are about $5 \%$ non conservative. This will result in an insignificant temperature increase in the outer region due to this effect since the azimuthal temperature gradients are small for either plate thicknesses.

Taken as a whole, the combination of these differences will make the use of current GOTH models for AY Tank conservative relative to modeling the thermal performance of the floor cooling channels. However, the current GOTH models should be modified to incorporate the actual Tank AY-102 floor channel geometry and arrangement to provide more accurate estimation of temperatures for use in comparing to Tank AY-102 actual thermal performance during and following the waste transfer.

\subsubsection{AY and AZ Tank Insulating Concrete Thermocouples}

Thermocouple temperature measurement logs state that measurements are made in the insulating concrete floor. For Tank AY-102, drawings and temperature logs place the thermocouples' racial and azimuthal location between air channels but within conduit imbedded in the insulating floor concrete and terminating at the tank bottom as shown in Figure 3.4. Relative to the azimuthal direction some of 


$$
\begin{aligned}
& \text { WHC-SD-WM-ER- } 534 \\
& \text { ReV. } 0
\end{aligned}
$$

the thermocouples are located about midway between air coolant channels, while others are located near the air channels. Drawings do not indicate if the thermocouples inside the conduits are adjacent the bottom of the tank, welded to it, or retracted somewhat into the conduit (see Figure 3.5).

The drawings for AZ Tanks and the temperature logs place the thermocouples radial and azimuthal location in the air channels, but welded to the bottom of the steel tank in the center of the air channel with a thermocouple weld pad as shown in Figures 3.8 and 3.9 . The vertical location is specified as -1 inch below the top of the tank primary steel floor in the logs, but attached to the tank bottom in the drawings. The temperature log tables would place the thermocouples directly in the air channels $1 / 2$ inch below the bottom of the primary steel tank floor. Comparison of calculated temperatures for air, steel, and sludge with the data from the insulating concrete thermocouples suggests that they are attached to the steel tank primary floor. It is also noted on the drawings that additional conduits for thermocouples were installed and terminate at the tank steel floor, but are somewhat displaced azimuthally from being positioned directly in the air channels. Currently these conduits apparently do not contain thermocouples, but may have future utility for monitoring the cooling effectiveness of the air channels.

There are currently no temperature measurements made directly within the sludge, supernatant, or dome gas space in Tanks AY-102, or AZ-101 and 102--with exception of a sludge temperature measurement near the bottom of the air lift circulators (ALC's), and sludge temperature measurements made 4 inches above the tank floor near the center and also near the periphery of the tank. With these exceptions sludge, supernatant, and dome gas temperature can only be inferred based on thermocouple measurements made in the tank structure such as floor, walls, and dome components. When the ventilation is off the thermocouples 
WHC-SD-WM-ER- 534

Rev. 0

attached to the steel floor provide the best available estimate of maximum sludge temperature. When the ventilation is on they are the best available estimate of minimum sludge bottom temperature. They provide the best data for calibrating or benchmarking the thermal hydraulic analysis methods and GOTH models.

The secondary ventilation system for AZ tanks has been operated intermittently during the last two years. The secondary ventilation systems for AY tanks have not operated for several years, but are being rehabilitated for future use.

\subsection{New Primary Ventilation System - Project $w-030$}

Under Project $W-030$, a new primary ventilation system will replace the current system for AY/AZ tank farm [Clifton, 1994]. The new system is illustrated in Figure 3.11. The new system will supply approximately 100 CFM of ambient air to each tank dome in addition to about 400 CFM from a recirculation loop at a tank inlet temperature of about $83^{\circ} \mathrm{F}$ and $100 \%$ relative humidity. The system operating in the recirculation mode will have less cooling capability than the current system since the total air flow will be reduced and the air inlet conditions will also be worse. However, the new system can also provide about 600 CFM to one of the four tanks when operating in a once through mode. The once through mode is the preferred mode of operation for rank AY-102. The new system is not designed to provide $600 \mathrm{CFM}$ in a once through mode to all four tanks simultaneously. 
WHC-SD-WM-ER- 534

Rev. 0

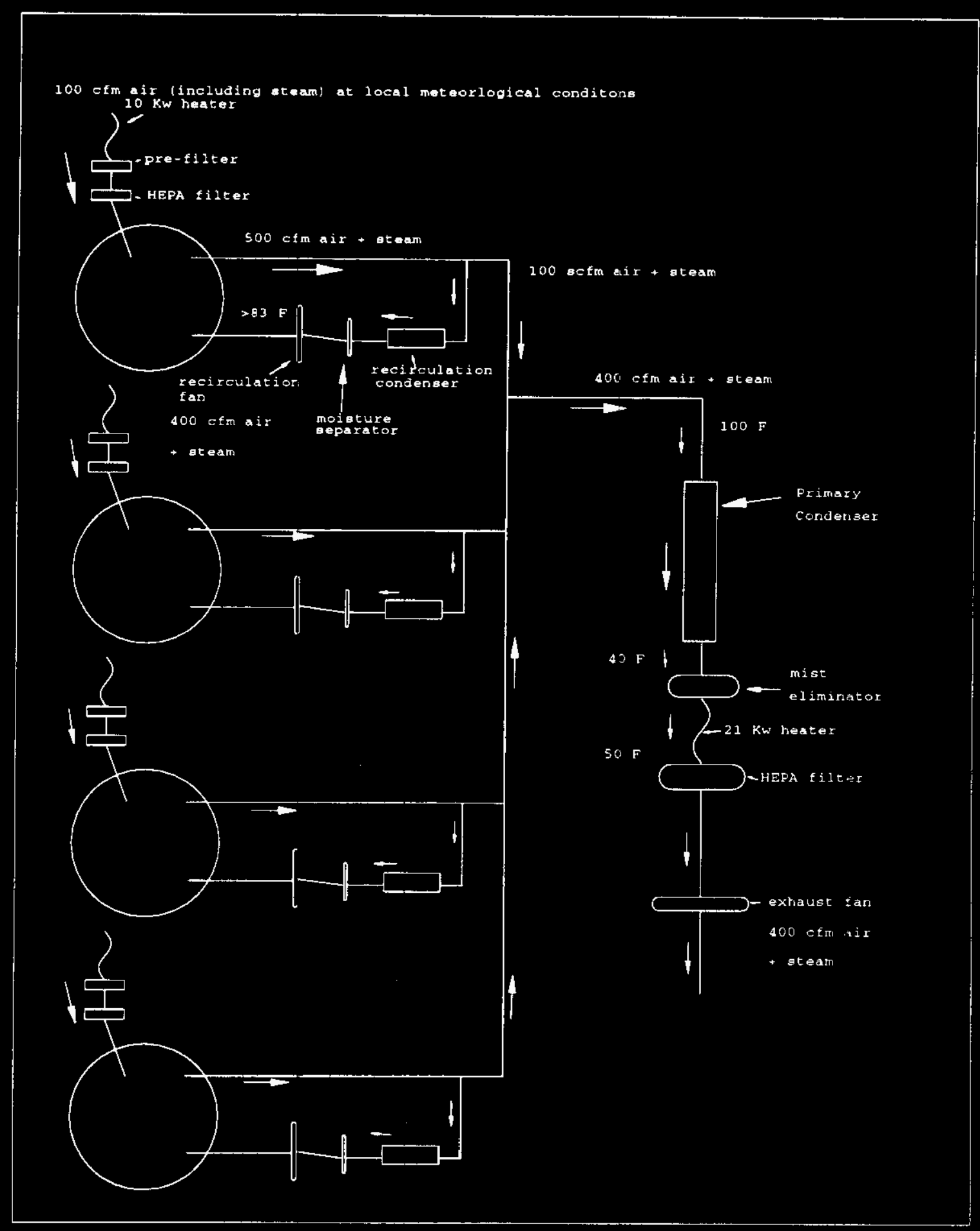

Figure 3.11 Project W-030 New AY/AZ Primary Tank Ventilation System 
WHC-SD-WM-ER- 534

Rev. 0

\subsection{Ventilation Systems Summary}

The current primary ventilation system will provide less cooling to Tank AY-102 with combined waste from C-106 than the current $C-106$ primary ventilation system, due to the 4 fold reduction in tank air flow. The Project $W-030$ new primary ventilation system for the AY/AZ tank farm will provide even less cooling than the current AY/AZ primary ventilation system when operating in the recirculation mode due to further reduced air flow and increased tank air inlet temperature and relative humidity conditions. In the once-through or non-recirculating mode the new primary ventilation system will provide about the same tank inflow rate at ambient conditions as does the current system.

On the otherhand, Tank C-106 does not have a floor/annulus ventilation system. The results from HUB calculations showed that the secondary ventilation systems could provide significant local cooling to the sludge immediately above the channels. However, it was not clear how effective the cooling would be to sludge located midway between channels, and therefore how effective the floor channels would be in reducing the maximum sludge temperature, or at what radial, azimuthal, and axial location maximum sludge temperature would occur. Also it has been estimated that the secondary ventilation system has the capacity to increase the floor cooling channel flow from 500 CFM up to 2000-3000 CFM [Tardiff, 1995a]. The increase in air flow rate and the effectiveness of the cooling channel will have a significant impact on the importance of secondary floor ventilation on maximum sludge temperature.

Detailed analysis of Tank AY-102 and its ventilation system has been conducted to determine the quantities of sludge that can be transferred from Tank C-106 and the ventilation system flow rates that must be achieved to maintain the peak temperatures in the sludge below saturation temperature limits. 
WHC-SD-WM-ER- 534

Rev. 0

\section{THERMAL HYDRAULIC MODEL DEVELOPMENT}

The development of analytical methods, models, and assumptions for thermal hydraulic evaluation of sludge transfer occurred in two phases. The two phases are summarized in Table 4.1 in terms of the analysis methods or tools, computer models, and major assumptions.

Table 4.1 Summary of phase I and Phase II Analytical Methods, Models, and Assumptions

\begin{tabular}{|c|c|c|c|c|c|c|c|c|}
\hline $\begin{array}{c}\text { Analysis } \\
\text { Phase }\end{array}$ & $\begin{array}{l}\text { Analytic } \\
\text { Tool } \\
\text { or } \\
\text { Computer } \\
\text { Model }\end{array}$ & $\begin{array}{c}\text { Assumed } \\
\text { C-106 } \\
\text { Current } \\
\text { Heat } \\
\text { Load }\end{array}$ & $\begin{array}{c}\text { Sludge } \\
\text { Removed } \\
\text { From } \\
\text { C-106 }\end{array}$ & $\begin{array}{c}\text { C-106 } \\
\text { Sludge } \\
\text { Fluff } \\
\text { Factor } \\
\text { after } \\
\text { transfer } \\
\text { to } \\
\text { AY-102 }\end{array}$ & $\begin{array}{l}\text { Transferred } \\
\text { sludge } \\
\text { Assumed } \\
\text { Thermal } \\
\text { Conductivity } \\
\text { after } \\
\text { transfer }\end{array}$ & $\begin{array}{c}\text { Primary } \\
\text { Ventilation } \\
\text { System } \\
\text { Type }\end{array}$ & $\begin{array}{l}\text { Primary } \\
\text { Recirc } \\
\text { Flow }\end{array}$ & $\begin{array}{c}\text { Secondary } \\
\text { Vent } \\
\text { Flow to } \\
\text { Tarik } \\
\text { Bottom }\end{array}$ \\
\hline & & btu & \multirow{2}{*}{ ft } & & btu & & $\mathrm{ft}^{3}$ & $\mathrm{et} \mathrm{t}^{3}$ \\
\hline & & hr & & & $h r-f t-R$ & & $\min$ & $\min$ \\
\hline \multirow[t]{2}{*}{ Phase I } & $H \cup B$ & 111000 & 4.60 & 1.0 & 0.53 & new/recirculation & 5000 & $\Sigma_{i}(x)$ \\
\hline & GOTH/1-D & 111000 & 6.00 & 1.0 & 0.53 & new/recirculation & $50(1)$ & $\underline{s}(t)$ \\
\hline \multirow[t]{2}{*}{ Phase II } & HUB & 132400 & 4.75 & 2.0 & 0.43 & new, oldfonce thru & 600 & 200018301010 \\
\hline & GOTH $/ 2-D$ & 132400 & 4.75 & 2.0 & 0.43 & new, old/once thru & $601 i$ & $200: 8 \times 3(101,1$ \\
\hline
\end{tabular}

Phase I analysis provided upper and lower bounds on sludge cooling capability, and therefore lower and upper bounds respectively on expected sludge temperature in Tank AY-102, after sludge transfer from Tank C-106 considering both active and inactive secondary ventilation. The preliminary analysis assumed the secondary floor ventilation flow rate would be no more than 500 CFM when on, consistent with prior analyses [Sathyanarayana, et. al., 1993] of current operations for Tank AZ-101. It also considered the impact of the operation of the Project $W-030$ new ventilation system operating in the recirculation mode. Transferred sludge particles were assumed to resettle to the same volume fraction, or thickness, currently in Tank 
WHC-SD-WM-ER- 534

Rev. 0

C-106 and that the resettled sludge would have the same average properties. Two Tank C-106 transferred sludge layer thicknesses were considered, 4.6 and 6.0 feet. Tank C-106 heat load before transfer was assumed to be $110,000 \mathrm{btu} / \mathrm{hr}$. After a $4.6 \mathrm{ft}$ transfer $40000 \mathrm{btu} / \mathrm{hr}$ would remain. A $6 \mathrm{ft}$ transfer was assuned to remove all waste from Tank C-106. Parameters assumed for the preliminary analysis are illustrated in Figure 4.1 for the $4.6 \mathrm{ft}$ transfer case.

Phase II analysis considered a higher assumed Tank C-106 heat load, higher floor ventilation flow rates, and an increased fluff factor. Phase II also evaluated the impact on sludge temperatures of floor cooling effectiveness and 2-Dimensional sludge and floor geometric considerations in relationship to cooling effectiveness. Allowable ventilation system outage periods were also defined in Phase II. The parameters assumed for the final analysis are illustrated in Figure 4.2. 
WHC-SD-WM-ER- 534

Rev. 0

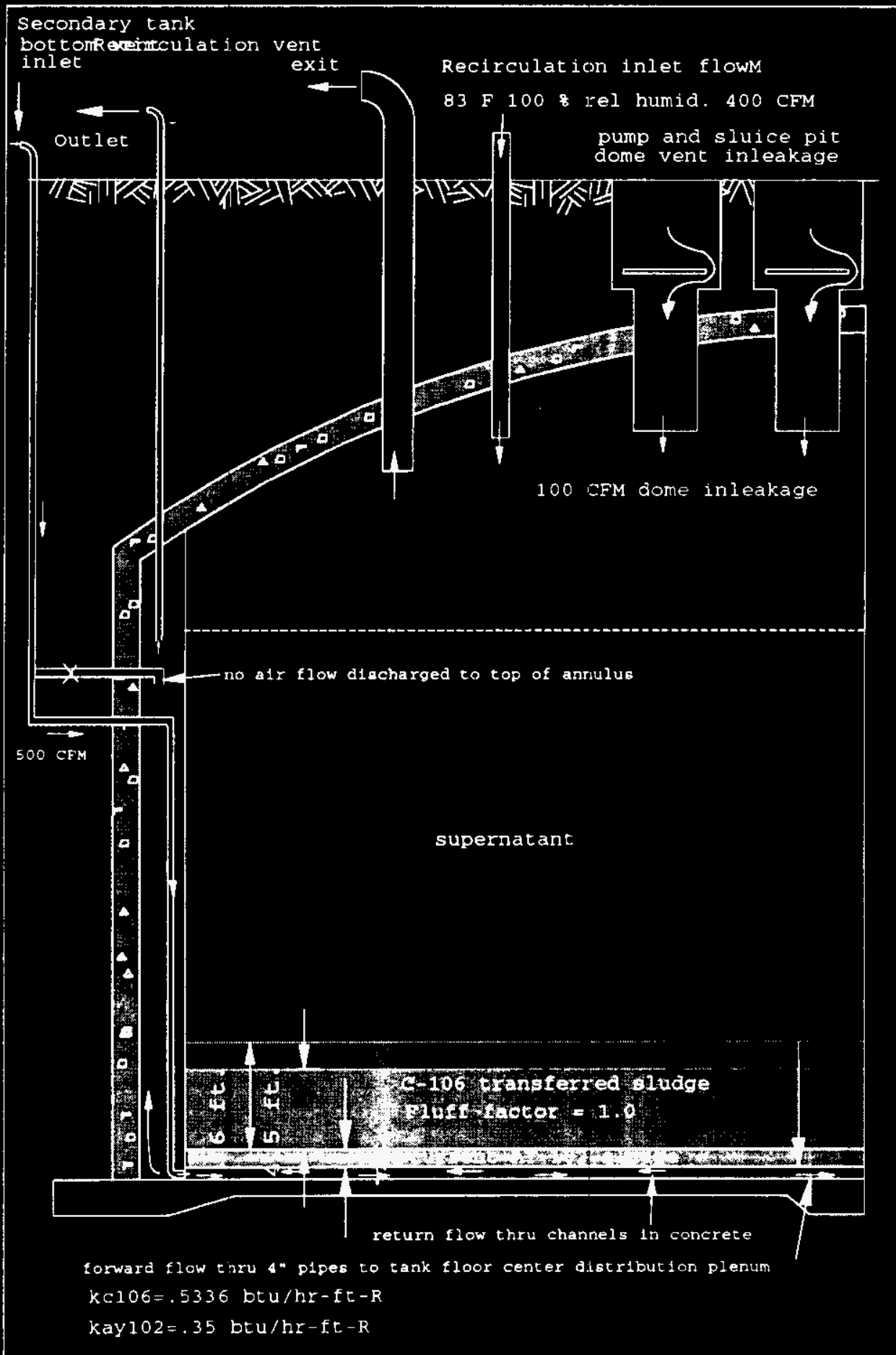

Figure 4.1 Tank AY-102 after a $4.5 \mathrm{ft}$ or $6 \mathrm{ft}$ Transfer of C-106 Unfluffed Sludge 


$$
\begin{aligned}
& \text { WHC-SD-WM-ER-534 } \\
& \text { ReV. } 0
\end{aligned}
$$

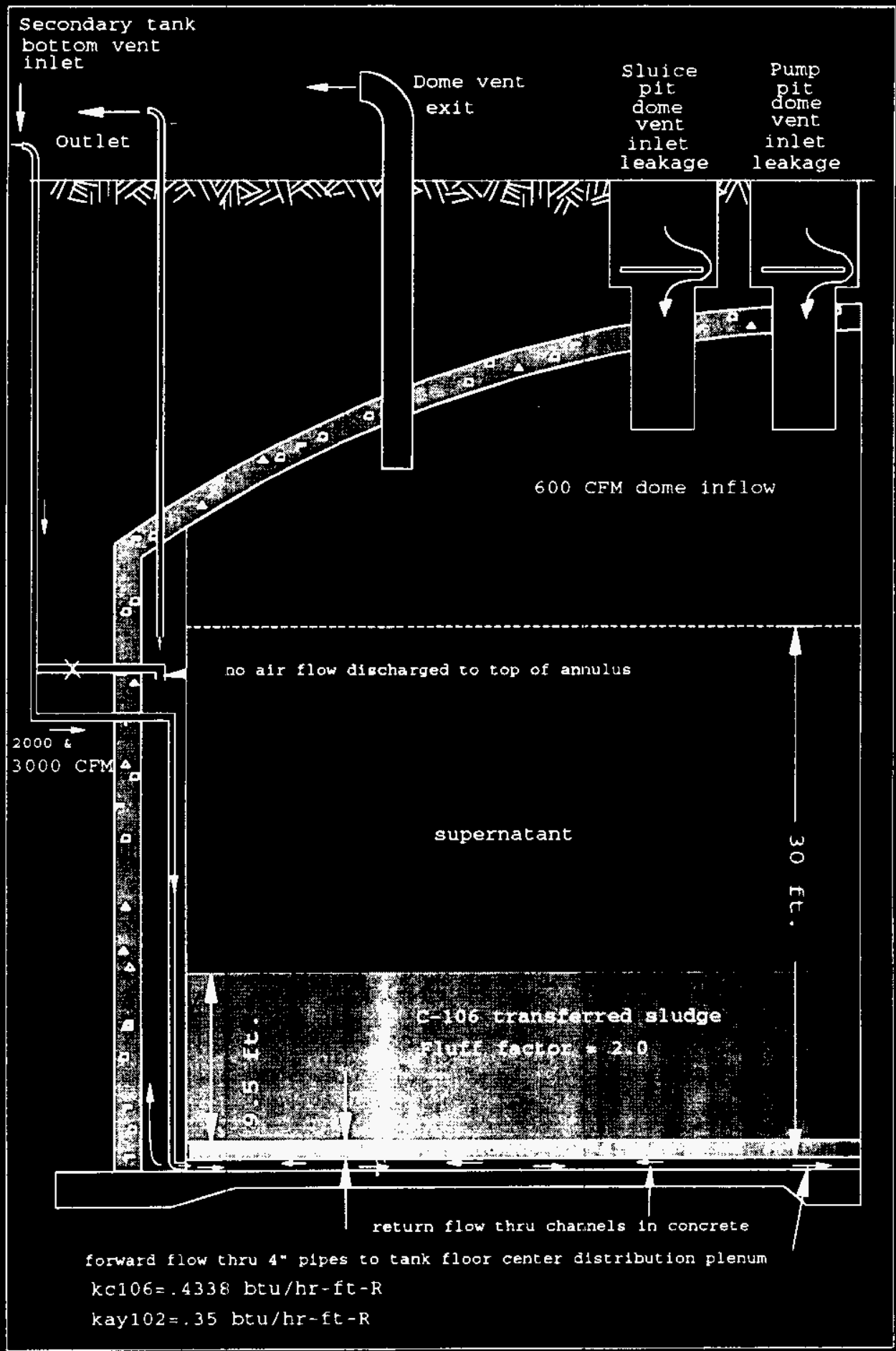

Figure 4.2 Tank AY-102 After Transfer of 4.75 ft of C-106 Sludge Which is Fluffed a Factor of 2 to $9.5 \mathrm{ft}$ 
WHC-SD-WM-ER- 534

Rev. 0

\subsection{Thermal Hydraulic Model}

Thermal hydraulic analysis was performed using a mathematical engineering notebook software, HUB, developed by Numerical Applications Inc. (NAI) and the GOTH thermal hydraulic computer code [Sathyanarayana, et. al., 1993] developed for WHC by NAI for use in tank farm analysis. First HUB methodology was developed and calculations were performed to provide quick initial estimates of allowable quantities of Tank C-106 sludge transfer maintaining the potential peak temperature of the sludge below local saturation values. These calculations were performed with and without the operation of the secondary ventilation system. The initial calculations performed, without considering the secondary ventilation flow cooling effect, showed clearly that the peak sludge temperatures would exceed local saturation temperature for the transfer of sludge generating $70,000 \mathrm{Btu} / \mathrm{hr}$. However, the calculations using the secondary ventilation air flow for tank floor cooling showed promise that larger quantities of sludge could be stored in Tank AY-102 depending on the air flow rate and its effectiveness in cooling.

Second more complex and detailed thermal hydraulic calculations were conducted using the GOTH computer code. The simulations included thermal hydraulic steady state, annual meteorological cyclic transient, and ventilation outage transient simulations. These simulations were utilized to evaluate the effect of annual cyclic meteorological conditions including extended hot periods during summer, to calculate the expected effectiveness of the insulating concrete air cooling channels, and to estimate the thermal response of the tank waste during various ventilation outage scenarios.

\subsubsection{HUB Thermal Hydraulic Model}

The HUB thermal hyaraulic model is based on one dimensional heat conduction equation having uniformly distributed heat HUB is a trademark of the Numerical Applications Inc. of Richland, WA. 


$$
\begin{gathered}
\text { WHC-SD-WM-ER-534 } \\
\text { ReV . } 0
\end{gathered}
$$

sources within the heat conducting medium. In this case the heat conducting medium is the sludge consisting of two separate layers, each with different thickness, conductivity, and volumetric heat generation rate. The boundary conditions include the effect of heat loss to the secondary ventilation flow through the insulating concrete air slots and of heat loss due to the primary ventilation flow. The methodology accounts for the liquid evaporation process at the pool/dome air interface using the correlation [Boelter, et.al., 1946] developed for water evaporation rates into quite air by natural convection.

The bottom layer is the existing sludge layer of Tank AY-102 and the top layer is the transferred sludge from Tank C-106. The HUB calculations initially assumed the secondary ventilation was either inoperable (i.e. adiabatic boundary), or that the air leaving the floor channels reaches the sludge bottom temperature (i.e. $100 \%$ effective cooling). These initial calculations either overestimated or underestimated the cooling effectiveness of the floor ventilation channels but did provide upper and lower bounds of potential temperature distribution in the combined settled sludge. In spite of these simplifications, the results provided a rapid understanding of the effects of different parameters on the sludge temperature distribution. This methodology has provided a means of estimating safe quantity sludge transfer and corresponding sludge and supernatant temperatures.

The HUB calculations were further extended to include an effectiveness factor for the floor cooling channels. The cooling channel effectiveness was defined as the ratio of the change in air temperature to the maximum possible air temperature change if the air reached sludge bottom temperature. This provided further insight on the potential and limitations for C-106 sludge transfers and pointed out the incentive to further evaluate the details of floor ventilation cooling. Parametric calculations were performed 


$$
\begin{aligned}
& \text { WHC-SD-WM-ER- } 534 \\
& \text { ReV. } 0
\end{aligned}
$$

for increased flow through air channels and various cooling effectiveness values. Further these calculations were extended to consider potential higher fluff factor of the transferred sludge. The fluff factor is defined as the ratio of particle volume fraction of the sludge in Tank C-106 before the transfer to the particle volume fraction of resettled sludge when it reaches nonconvective state.

The initial HUB simulations and GOTH 1-D sludge transfer simulations were based on a low secondary floor ventilation flow rate of 500 CFM used in prior analysis of Tank 101-Az and a fluff factor of 1.0. The GOTH model included a simplified 1-D treatment of the heat transfer between the bottom of the bottom of the sludge and the secondary ventilation air flowing within the floor cooling channels. Additional description on the GOTH 1-D model is provided below.

Additional three region 2-dimensional GOTH analysis was subsequently found necessary to further evaluate details associated with the sludge cooling effectiveness of floor channels, and to incorporate new assumptions that had evolved regarding the secondary floor ventilation flow rates and fluff factor. The 2-D simulations were conducted with secondary ventilation flow rates of 2000 and $3000 \mathrm{CFM}$ and a fluff factor of 2.0. Additional description on the three region 2-D GOTH model, is provided below. Additional HUB parametric analysis based on these revised assumptions were also conducted.

\subsubsection{1-D GOTH Thermal Hydraulic Model}

The 1-dimensional GoTH thermal hydraulic model was used to include improved heat and mass transfer modeling at the pool surface, and improved conduction and convective heat transfer modeling between the sludge bottom and the floor air cooling channels and to provide basis for the HUB calculations. The model, illustrated in Figure 4.3, is a derivative of prior analyses [Sathyanarayana, 1994] 


$$
\begin{aligned}
& \text { WHC-SD-WM-ER-534 } \\
& \text { ReV. } 0
\end{aligned}
$$

conducted for Tank AZ-101. The sludge, supernatant, and dome gas space are treated only in the vertical direction. A variable number of 6 inch axial nodes are used in the sludge depending on the thickness of the sludge being considered. Two lumped volumes are utilized to simulate the floor and annulus ventilation. Heat transfer from the sludge to the floor channel air includes $1-D$ conduction from the sludge to the steel plate and convection from steel plate to the air using a lower bound convective heat transfer coefficient for the averaged floor channel. 2-dimensional heat conduction effects are not included in the sludge, steel, or insulating concrete. All sludge is assumed to be located immediately above a coolant channel. All the heat is assumed to flow through the steel plate surface area at the top of the coolant channels. Heat transfer through the surface area associated with the side and bottom of the channel is not included. Heat transfer between the supernatant and the secondary ventilation flow which leaves the floor and traverses upwards through the annulus is also included in the model.

For the GOTH 1-dimensional model, inlet air conditions for both the primary, and secondary ventilation flow are assumed to be at ambient meteorological conditions corresponding to a typical Hanford annual cycle. For sludge transfer simulations which considered the Project $W-030$ new primary ventilation system operating in the recirculation mode, the recirculating air entering the tank is assumed to have fixed flow rate, temperature and relative humidity conditions. Soil between the tank dome and the soil surface is included in the model and the soil surface is assumed to be at ambient meteorological conditions. No radial temperature gradients in the sludge due to conduction through soil beneath, or to the side of, the tank, or due to annulus ventilation are included in the model. Neither are azimuthal temperature gradients due to non-uniform cooling from the floor air channels included. Ventilation air entering at the top of the annulus is also not considered. 


$$
\begin{aligned}
& \text { WHC-SD-WM-ER- }-534 \\
& \text { ReV. } 0
\end{aligned}
$$

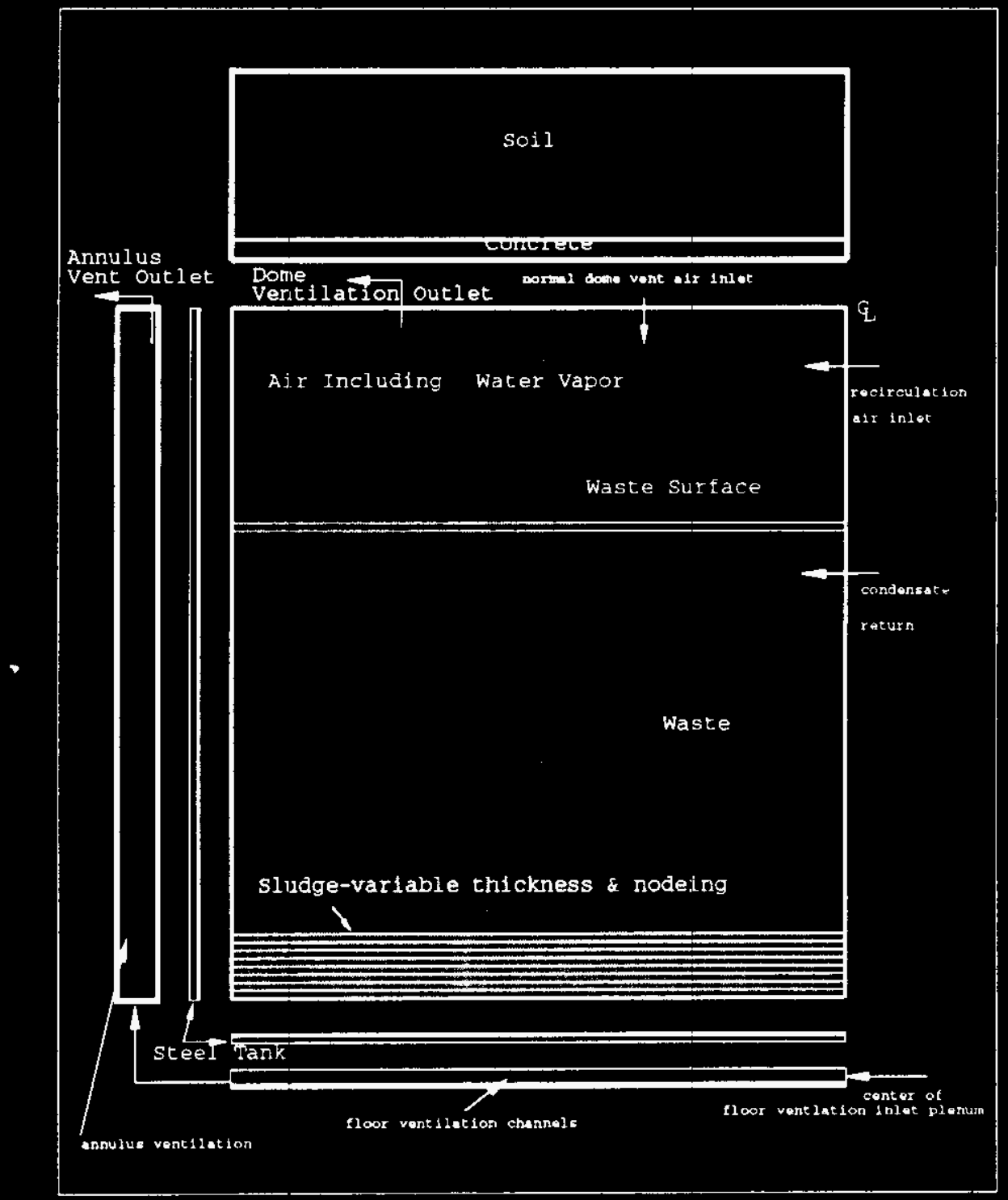

Figure 4.3 Side view of GOTH 1-D Multi-Cell Aging Waste Tank Model

When the secondary ventilation is off, the floor is assumed to be an adiabatic boundary condition, thus providing an upper bound on sludge bottom temperature. When the ventilation is on, the model provides an approximate simulation of the conduction and convection process for the 


\section{WHC-SD-WM-ER-534 \\ Rev. 0}

floor cooling channel.

The GOTH 1-D Model. was used to estimate the current heat load of Tank AY-102. The current operation of Tank C-106 simulations were also conducted earlier [Thurgood, et.al., 1995] with a similar 1-D model. GOTH 1-D model sludge consolidation simulations were conducted with and without the secondary ventilation flow and assuming that the retrieved $\mathrm{C}-106$ sludge particles re-settle to the current particle volume fraction. The GOTH 1-D simulations conducted with secondary floor ventilation considered a flow rate of $500 \mathrm{CFM}$. Also the GOTH 1-D simulations with Project W-030 new primary ventilation system have considered its operation only in recycle mode.

\subsubsection{2-D GOTH Thermal Hydraulic Model}

The 2-dimensional GOTH model was developed to evaluate the cooling effects associated with the floor cooling channels in the azimuthal and axial directions, as well as air heatup effects in the radial direction, upon maximum sludge temperature. This model consists of: (a) three 2-dimensional (azimuthal and axial) sludge regions corresponding to the inner, middle, and outer floor coolant channel regions; (b) three 2-dimensional (azimuthal and axial) floor regions located directly below the sludge regions; and, (c) 1 inner, 1 middle, and 1 outer tank floor air channel. Each sludge and floor region's radial dimension is equal to the corresponding coolant channel regions' radial length. The model also includes the supernatant and dome gas, annulus gas region, and top of tank soil.

A top view of the sludge regions and corresponding floor ventilation channels modeled is shown in Figure 4.4 and corresponding side views are shown in Figure 4.5 for the inner region, Figure 4.6 for the middle region, and Figure 4.7 for the outer region. The secondary floor ventilation model is currently based upon floor cooling channel 
WHC-SD-WM-ER- 534

Rev. 0

geometry of AZ Tanks and not Tank AY-102. As described

earlier this modeling assumption is conservative relative to predicting maximum sludge temperature. However, modifications to the model to reflect the actual geometry of Tank AY-102 should be made in the future to provide best estimate rather than conservative simulation results for tank monitoring purposes after the C-106 sludge transfer. 


$$
\begin{aligned}
& \text { WHC-SD-WM-ER- } 534 \\
& \text { ReV. } 0
\end{aligned}
$$

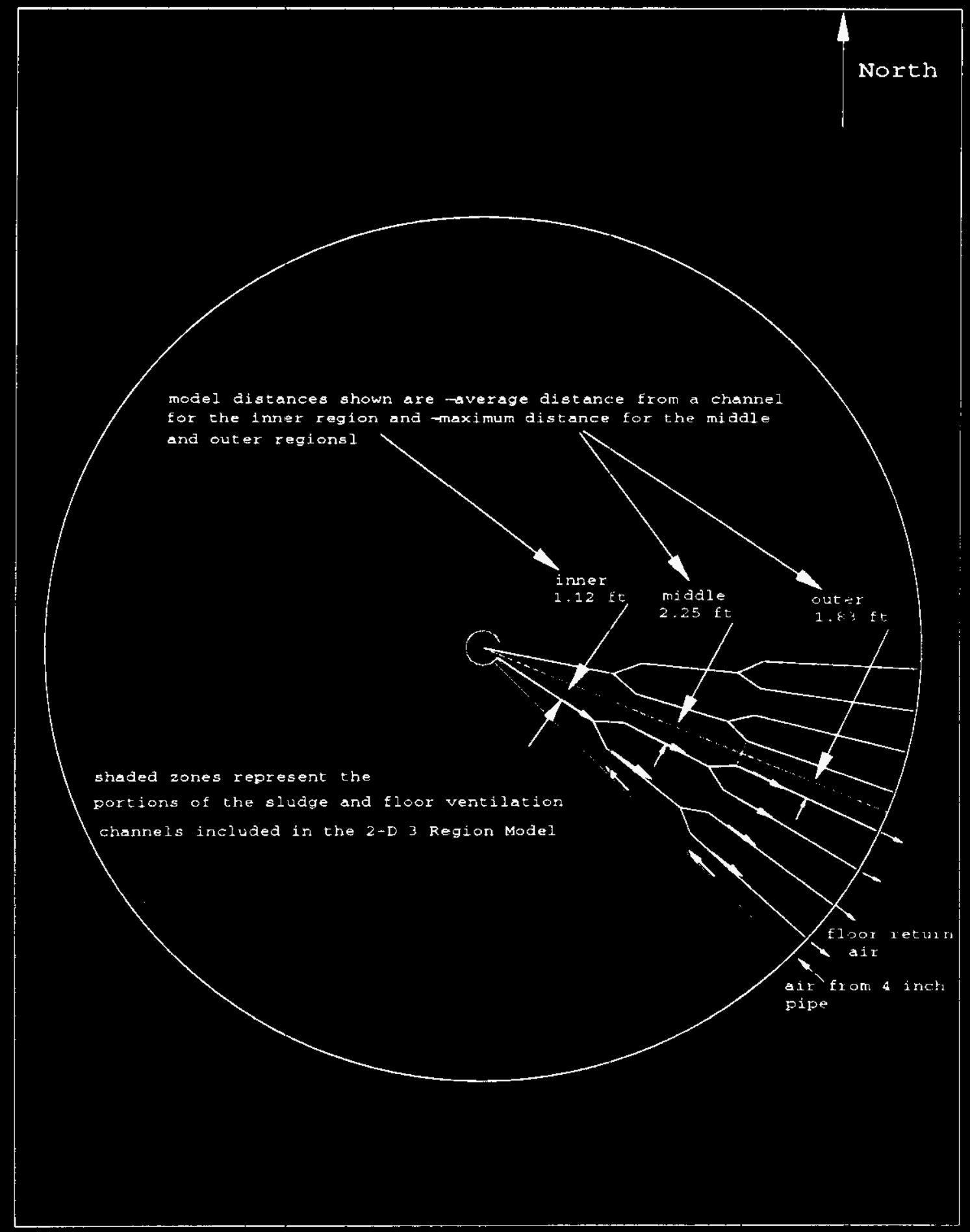

Figure 4.4 Plan View of GOTH 3 Region 2-D Tank AY-102 Model Showing Inner, Middle and Outer Sludge and Air Channel Regions based on AZ tank floor geometry. 


$$
\begin{gathered}
\text { WHC-SD-WM-ER-534 } \\
\text { Rev. } 0
\end{gathered}
$$



$92400 \mathrm{bcu} / \mathrm{hr}$

1.75 ft un-filuffed

\&ludge removed

from $c-106$

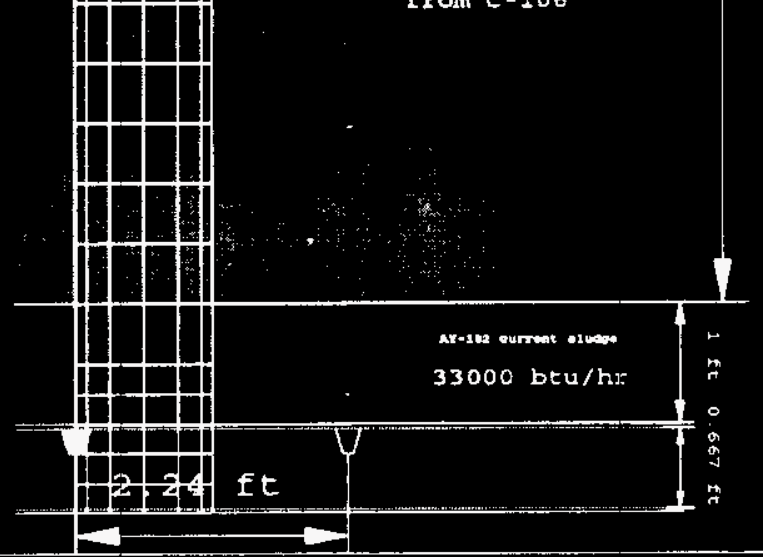

Figure 4.5 Side View of GOTH 3 Region 2-D Tank AY-102 Model Nodalization for Inner Sludge and Floor Region -Approximate Average Distance Between Channels $2.24 \mathrm{ft}$ 




$\rightarrow \rightarrow O$

강

강 
WHC-SD-WM-ER- 534

Rev. 0

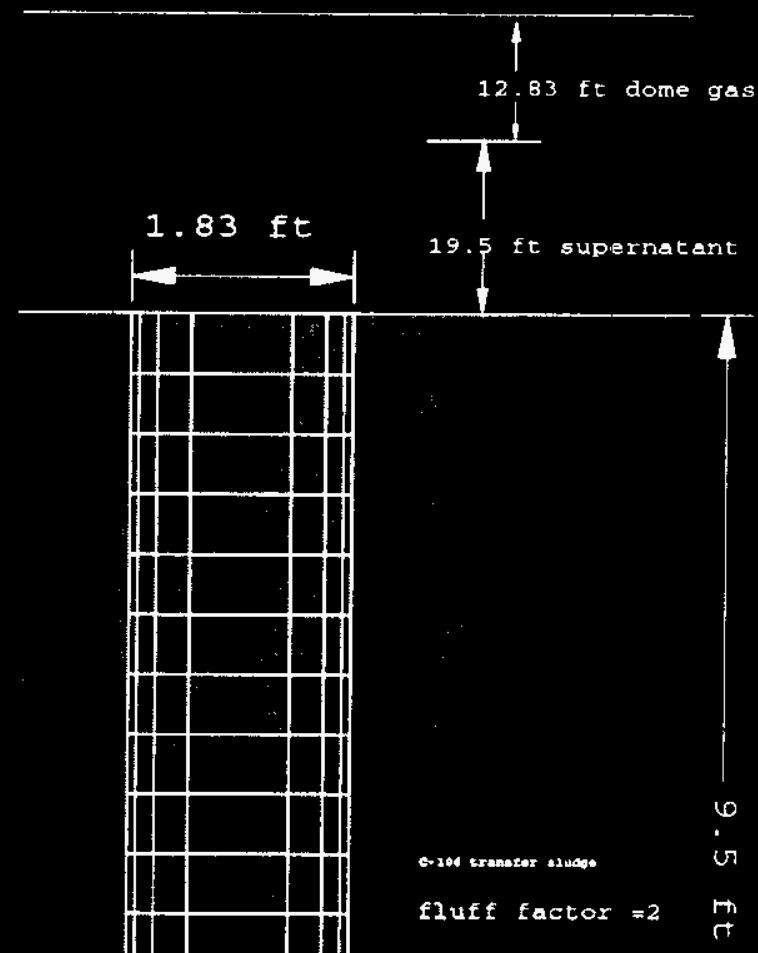

$92400 \mathrm{btu} / \mathrm{hr}$

4.75 ft un-fluffed

sludge removed

from $C-106$

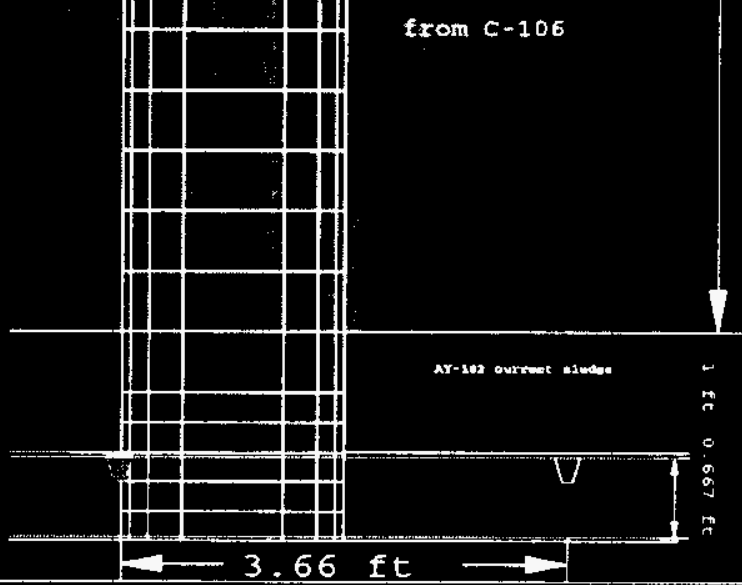

Figure 4.7 Side View of GOTH 3 Region 2-D Tank AY-102 Model Nodalization for Outer Sludge and Floor Region--

Approximate Maximum Distance Between Channels 3.66 feet 


$$
\begin{gathered}
\text { WHC-SD-WM-ER-534 } \\
\text { Rev. } 0
\end{gathered}
$$

The model inner region approximates $1 / 32$ of the inner region sludge volume and includes $1 / 2$ of one of 16 air channels. Only $1 / 2$ of the average distance between channels is used in this region. This model will approximate the inner channel outlet air temperature since the ratio of the mass of sludge in the region to the mass flow rate of ventilation air is approximately preserved. Calculated maximum sludge temperatures will be slightly low in the inner region since near the periphery of this region the maximum distance between channels is larger than the average distance used (approximately twice as large). Ignoring floor channel air heat up effects, the actual expected maximum temperature in the inner region would be similar to that in the middle region since the maximum distance between channels in both regions is similar.

For the midale region more than $1 / 64$ of the middle region sludge volume and $1 / 2$ of one of 32 air channels is included in the model. For the outer region more than $1 / 128$ of the outer region sludge volume and $1 / 2$ of one of 64 air channels is included in the model. For both the middle and outer regions $1 / 2$ the maximum distance between channels is used in the model, rather than $1 / 2$ the average distance as used for the inner region. This accounts for the maximum azimuthal conduction distance in the sludge and thereby insures that calculated maximum temperatures will be as high, or higher, than will occur anywhere in these two regions. This increases the ratio of mass of sludge to the mass flow rate of ventilation air above the actual ratio and thereby increases the air temperature rise above what the actual rise would be. This in turn also. increases the maximum sludge temperature. The model, as a result, predicts conservative temperatures.

The outer region in the GOTH 2-D model has the highest calculated sludge temperature primarily because the air channel temperature is the highest and the channel convective heat transfer coefficient is lowest. Actual 
tank data for AZ Tanks however shows that the tank floor temperatures are lower near the tank wall in the outer region than the middle region. The model outer region is 13.5 feet in radial length. The three radial regions in the model are not connected thermally (i.e. the model is 2-D, not 3-D), nor is the outer region of sludge coupled thermally to the lower annulus ventilation air. The outer region temperature measurements are taken 1 foot from the tank wall and the predicted temperature is for the averaged outer radial region of $13.5 \mathrm{ft}$ of sludge. Therefore the calculated and measured temperatures are not incompatible given the differences between the actual tank and the model near the tank wall. By including a thermal coupling for the radial sludge region near the wall to the annulus ventilation, the predicted results can be improved towards more realistic values. The current model for safety analysis purposes provides a conservative estimate of maximum sludge temperature.

The dome including the supernatant and dome space gas and dome ventilation is modeled as a single volume coupled thermally with the sludge, tank top soil, and upper annuls ventilation. Dome air flow in the model is a fraction of the total for the tank and it is based on the ratio of the total 3 region floor area to the total tank floor area. Two single volumes are used to model the annulus ventilation.

\subsection{Modeling Parameters}

The parameters used in the calculations are described in this section. The parameters include primary and secondary ventilation flow air inlet conditions for average summer and annual meteorological cycles, tank waste properties such as solids and liquid specific gravity, specific heat, thermal conductivity and volume fraction of solids and liquid. The section also addresses the waste vapor pressure and its variation with respect to temperature and waste level and transferred sludge settling characteristics. 
WHC-SD-WM-ER- 534

Rev. 0

\subsubsection{Ventilation Flow Tank Inlet Conditions}

\subsubsection{Average Flow Inlet Conditions}

HUB calculations and initial GOTH simulations were based on steady state ventilation flow conditions. The ventilation flow inlet conditions were either from the assumed ambient atmospheric conditions, or the expected tank inlet flow conditions from the recirculation loop of the new ventilation systern (Project $\mathrm{W}-030$ ). The summer average ambient atmospheric conditions were assumed to be $70^{\circ} \mathrm{F}$ and $50 \%$ relative humidity. The new ventilation system tank inlet conditions from the recirculation loop were assumed to be $83^{\circ} \mathrm{F}$ and $100 \%$ relative humidity.

\subsubsection{Annual Meterological Cycle}

The annual meteorological cycle data used in this analysis for primary and secondary ventilation systems when simulating cyclic tank operation over a period of several years is illustrated in Figures 4.8 and 4.9. This consists of monthly average dry bulb temperature and the steam partial pressure in the air (i.e. equivalent to the relative humidity times the saturation pressure at dry bulb temperature). The summer average ambient conditions, and new primary ventilation recycle inlet conditions are also shown for comparison. For the 1-D GOTH model cyclic operation is preceeded by an assumed steady state continuous winter condition of $32^{\circ} \mathrm{F}$ and $100 \%$ relative humidity operatior. (as shown in Figures 4.8 and 4.9 ) to arrive at an approximate continous winter steady state condition before continuing with 5 anrual cycles of typical ambient conditions. For the 2-D GOTH model the cyclic operation was preceeded by an assumed steady state annual average condition of $53.3^{\circ} \mathrm{F}$ and $46.5 \%$ relative humidity. Experience has shown that following this calculational procedure, result show nearly repetitive cyclic thermal hydraulic response after the first cycle. 
WHC-SD-WM-ER- 534

Rev. 0

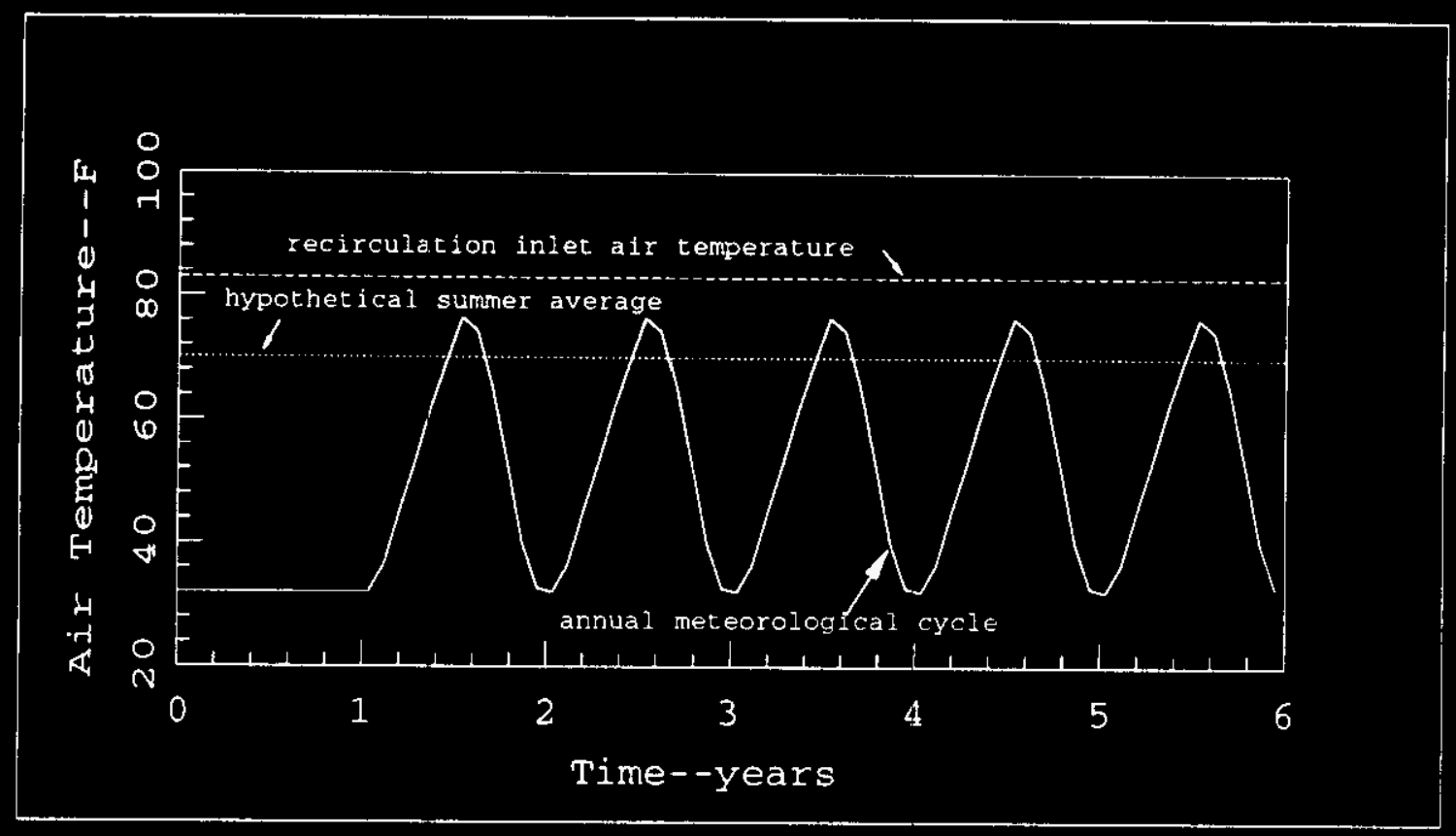

Figure 4.8 Assumed Annual Meteorological Cycle based on measured monthly average air temperature 
WHC-SD-WM-ER- 534

Rev. 0

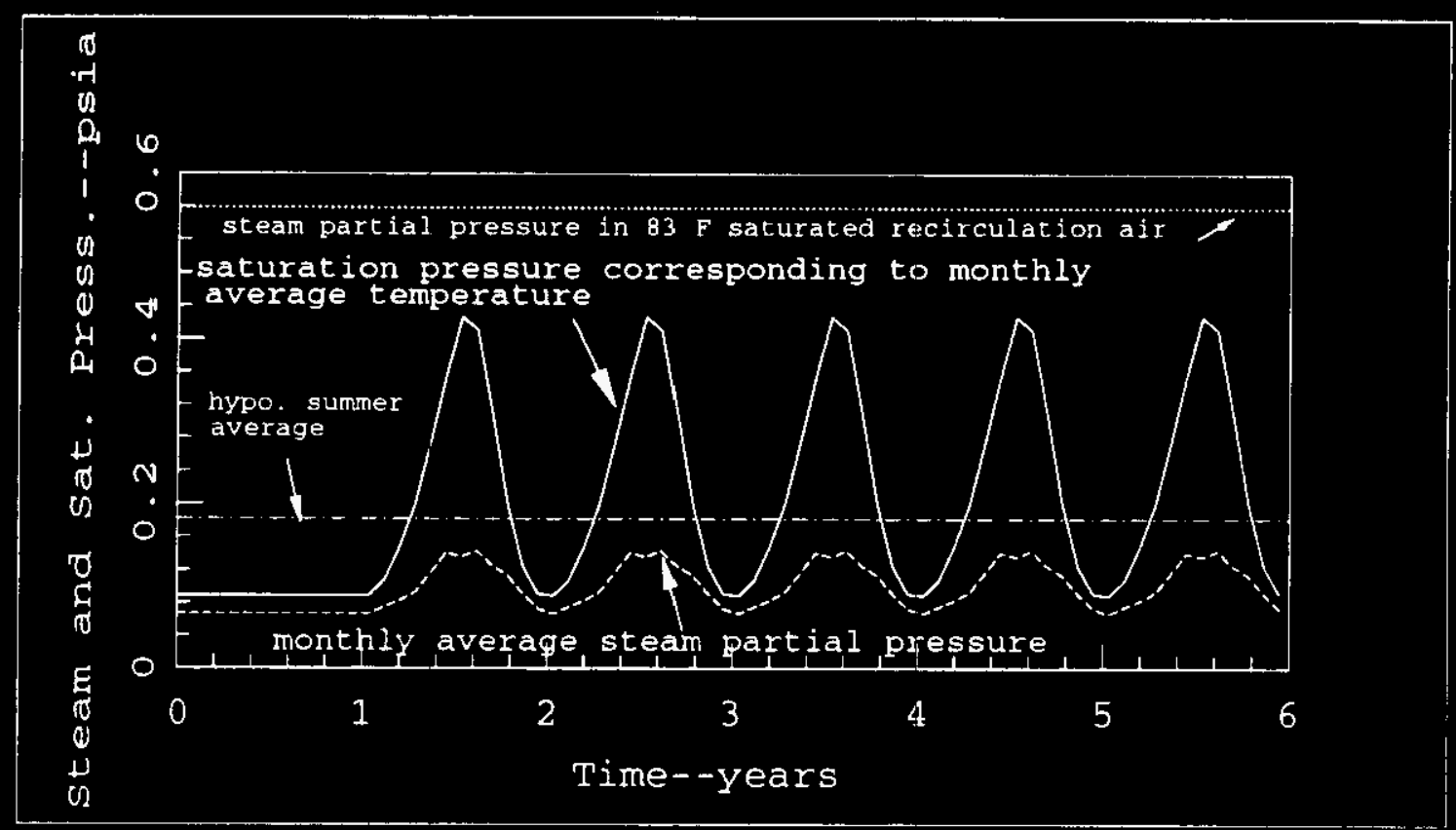

Figure 4.9 Assumed Annual Meteorological Cycle based on measured monthly average steam and saturation partial pressures

\subsubsection{Tank Wagte Parameters}

The waste parameters regarding current contents in Tank AY-102 and C-106, and combined waste in AY-102 are discussed in this section. The assumptions concern with the sludge and soil thermophysical properties, waste saturation pressure and temperature relationship and variation with respect to waste level. Also discussed below is transferred waste particle settling characteristics in relation to sludge layer thickness or particle volume fraction before and after transfer (i.e. fluff factor), tank heat loads, and heat load distribution.

\subsubsection{Sludge and Soil Thermophysical Properties}

The sludge and soil thermophysical properties are summarized in Table 4.2. The thermal conductivity of the AY-102 sludge $(.35 \mathrm{btu} / \mathrm{hr}-\mathrm{ft}-\mathrm{R})$ is the same as that of 


$$
\begin{aligned}
& \text { WHC-SD-WM-ER- } 534 \\
& \text { ReV. } 0
\end{aligned}
$$

water and is the minimum value that can rationally be assumed based on thermal conductivity models and the analysis conducted to estimate the current Tank AY-102 heat load. The conductivity assumed for Tank C-106 sludge in its current state, or transferred to Tank AY-102 and resettled to its current particle volume fraction (i.e. fluff factor $=1$.$) , is the same as used in a previous$ analysis[Thurgood, et.al., 1995] of Tank C-106 (.53 btu/hr-ft-R). This value is lower than calculated with the series conductivity model for mixture corresponding to the particle volume fraction. For Tank C-106 sludge after transfer but resettled to only half the original particle volume fraction (i.e. fluff factor $=2$. ), the value of conductivity is $.43 \mathrm{btu} / \mathrm{hr}-\mathrm{ft}-\mathrm{R}$. This is calculated using a series conductivity model for the solid/liquid mixture and therefore conservative. The other waste thermophysical properties were taken from a previous Tank C-106 analysis. In this analysis the liquid was assumed to be water, rather than aqueous solution.

Table 4.2 sludge and Soil Thermophysical

\begin{tabular}{|c|c|c|c|c|c|c|c|}
\hline Material & $\begin{array}{l}\text { Iiquid } \\
\text { specific } \\
\text { gravity }\end{array}$ & $\begin{array}{l}\text { liquid } \\
\text { specific } \\
\text { heat }\end{array}$ & $\begin{array}{l}\text { liquid } \\
\text { volume } \\
\text { fraction }\end{array}$ & $\begin{array}{l}\text { particle } \\
\text { specific } \\
\text { gravity }\end{array}$ & $\begin{array}{c}\text { particle } \\
\text { specific } \\
\text { heat }\end{array}$ & $\begin{array}{l}\text { particle } \\
\text { volume } \\
\text { fraction }\end{array}$ & $\begin{array}{c}\text { therma: } \\
\text { conductivity }\end{array}$ \\
\hline & & btu & & \multicolumn{2}{|r|}{ btu } & \multicolumn{2}{|r|}{ btu } \\
\hline & & $1 \mathrm{bm}-\mathrm{R}$ & & \multicolumn{3}{|c|}{$1 \mathrm{bm}-\mathrm{R}$} & $h r-f t-R$ \\
\hline AY-102 sludge & 1.0 & 1.0 & 0.83 & 3.90 & 0.2 & 0.17 & 0.45 \\
\hline C-106 sludge- - fluf $f=1$. & 1.0 & 1.0 & 0.52 & 1.60 & 0.2 & 0.48 & $(1,5,3$ \\
\hline C-106 sludge- - fluff $=2$. & 1.0 & 1.0 & 0.76 & 1.60 & 0.2 & 0.24 & $(1.43$ \\
\hline Tank overburden soil & & & & 1.78 & 0.2 & 1.00 & (1. 30 \\
\hline
\end{tabular}
Properties 
WHC-SD-WM-ER - 534

Rev. 0

4.2.2.2. Waste Liquid Vapor Pressure

Tank waste vapor pressure determines the saturation temperature. Operational safety requirements criteria for normal, and anticipated abnormal operating conditions such as ventilation outages, require that the maximum sludge temperature be maintained $30^{\circ} \mathrm{F}$ below local saturation temperature. Saturation temperature is a function of the liquid vapor pressure characterisitics and also the local absolute pressure in the tank. For water the vapor pressure versus temperature characteristic is illustrated in Figure 4.10. If there are dissolved salts in the liquid then the vapor pressure will be suppressed relative to water for a given waste liquid temperature. The vapor pressure of solution containing 30 weight percent of sodium nitrate is about $85 \%$ of that for water [Sathyanarayana, et. al., 1993]. 
WHC-SD-WM-ER--534

Rev. 0

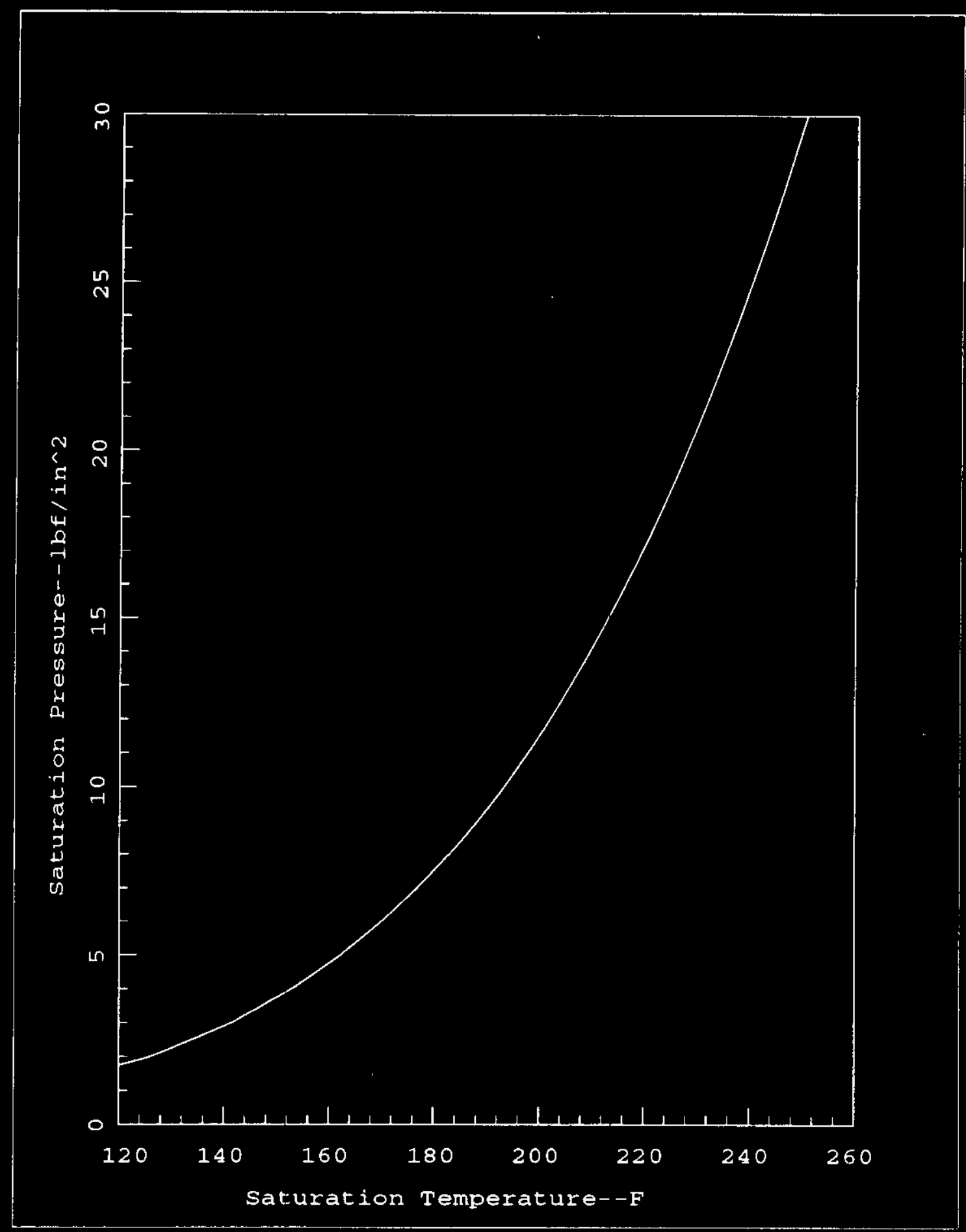

Figure 4.10 Saturation Pressure versus Temperature for Water 
WHC-SD-WM-ER- 534

Rev. 0

The local hydrostatic pressure within the waste equals atmospheric pressure plus the integrated product of the waste density times the local elevation of interest.

Assuming all supernatant and interstitial sludge liquid in

Tank AY-102 is water, with original sludge depth of $1 \mathrm{ft}$, a transferred C-106 sludge depth of $9.5 \mathrm{ft}$, and a total waste depth of $30 \mathrm{ft}$, the local hydrostatic pressure and the local saturation temperature versus waste height from the tank bottom is provided in Figure 4.11. These parameters correspond to Tank C-106 sludge transfer 157,000 gallons with a heat load of 92,400 btu/hr and a fluff factor of 2.0. If the current tank heat load is only $110,000 \mathrm{btu} / \mathrm{hr}$ and the transferred C-1.06 sludge depth is only $4.6 \mathrm{ft}$ (corresponds to a fluff factor of 1.0 ) then a slight deviation in these curves results as illustrated in Figure 4.11. If the supernatant is decanted off, and the total waste level decreases, then the saturation temperature will be lower than that shown in Figure 4.11 . The acceptable margin between operating peak sludge temperature and saturation temperature, for both normal operation and allowable ventilation outage periods discussed in this report assume that the waste level is maintained at a high level of $30 \mathrm{ft}$. 
WHC-SD-WM-ER- 534

Rev. 0



Figure 4.11 Pressure and Saturation Temperature Versus Distance from Tank Bottom 


$$
\begin{gathered}
\text { WHC-SD-WM-ER-534 } \\
\text { ReV. } 0
\end{gathered}
$$

\subsubsection{Waste Farticle Settling Characteristics}

The particle volume fraction of the sludge currently in Tank C-106 is estimated to be .48 with the balance, .52 being liquid. As described previously initial analysis assumed the particles would resettle to the same volume fraction before becoming a non-convective sludge after sluicing and transfer of the waste to Tank AY-102 (i.e. a fluff factor of 1.0). Based on experiments conducted at PNNL [Norton, et.al., 1994a], the assumption of resettling of particles to the original volume fraction is possibly not conservative. Therefore, later analysis assumed that the particles would not resettle to the same volume fraction before becoming a non convective sludge layer, but would only reach a volume fraction of .24 (i.e. a fluff factor of 2.0). The results of the FNNL experiments are replotted and briefly described to provide a basis for this assumption.

Small scale settling Tests were conducted at PNNL using NCAW simulant to investigate settling rates of unwashed and washed solids in the aging NCAW tank wastes such as Tank AZ-101 and 102. The tests were also performed using a heated vessel for both the unwashed and the washed NCAW simulant to evaluate the effects of radiological heating and in-tank washing of the waste on the behavior of particle settling. Two 7-galion pyrex vessels with each containing 5 gallons of simulant were used for the tests. One vessel was equipped with a heating element to simulate radiological heating. The heating element was designed to provide a uniform heat flux across the bottom of the vessel. The second vessel was not heated. Relative comparisons of settling rates and suspended solids concentrations in supernatant (turbidity), for heated and ambient NCAW simulant were made. Settling velocity and turbidity parameters were measured to evaluate the settling behavior of the NCAW waste. 


$$
\begin{aligned}
& \text { WHC-SD-WM-ER-534 } \\
& \text { ReV. } 0
\end{aligned}
$$

The tests were conducted with homogeneously mixed simulant initialized at $140^{\circ} \mathrm{F}\left(60^{\circ} \mathrm{C}\right)$ and allowed to settle due to gravity. In the tests with the heater, the axial temperature distribution of the waste simulant was also monitored using five thermocouples placed at different vertical elevations in the waste. The settling behavior of the solid particles was monitored by tracking the position of the solid-liquid interface overtime. The downward movement of the interface as a function of time was used to determine the settling velocity. At initiation of the tests the uniformly mixed simulant had 3 to 4 wto solids concentration and a mixture density of $1.23 \mathrm{gm} / \mathrm{cm}^{3}$. The solids density was $3.44 \mathrm{gm} / \mathrm{cm}^{3}$.

The height of the interface as a function of both heated and ambient vessel tests are shown in Figures 4.12 and 4.13 respectively. The figures also show the results for unwashed particles and also particles washed up to 3 times using a sodium hydroxide/sodium nitrite wash solution. The test particle size was around 2.5 microns and fairly uniform in size giving a distinct solid-liquid settling interface. The interface moved with the velocity of the settling particles. The axial temperature distribution development for the heated vessel test within the developing non-convective sludge is shown in Figure 4.14 [Norton, 1994b]. This coupled with the movement of the interface suggests that the simulant sludge, after settling to a 9 to $10 \mathrm{~cm}$ irterface level corresponding to about 15 wt $z$ of solids seems to behave as a non-convective sludge where only conduction is the means of heat transfer. However, further slow compression or compaction of particles will occur until the sludge finally reaches its maximum density throughout. Based on these results and discussions with wHC Retrieval Engineering [MacLean, 1995], the NCAW waste in an actual tank (large scale versus laboratory vessel) will likely settle to about 20 wt 8 before becoming non-convective. It is currently estimated that NCAW sludge in Tank AZ-101 has a particle 
WHC-SD-WM-ER-534

Rev. 0

fraction of $40 \%$ by weight and $17 \%$ by volume. Sluicing and resettling of the waste will therefore result in an initial non-convective sludge of about 20 wt 8 , or a fluff factor of about 2 .

The estimated particle density for Tank C-106 waste, s.g. 1.6 , is significantly lower than that estimated for NCAW waste, s.g. of 3.9 , suggesting slower settling characteristics for $\mathrm{C}-106$ particles. However the estimated current settled particle volume fraction in Tank C-106, 48\%, is much higher than the estimated current settled particle volume fraction in Tank AZ-101, 178, an NCAW waste tank. This suggests better settling characteristics for C-106 particles, possibly due to larger particle size or less tendency to form gelatenous or colloidal sludges. From this available data on the settleability of transferred sludge, the use of a factor of 2 seems reasonable for safety considerations to estimate potential sludge temperatures in Tank AY-102 after the transfer of Tank C-106 sludge. 
WHC-SD-WM-ER- 534

Rev. 0

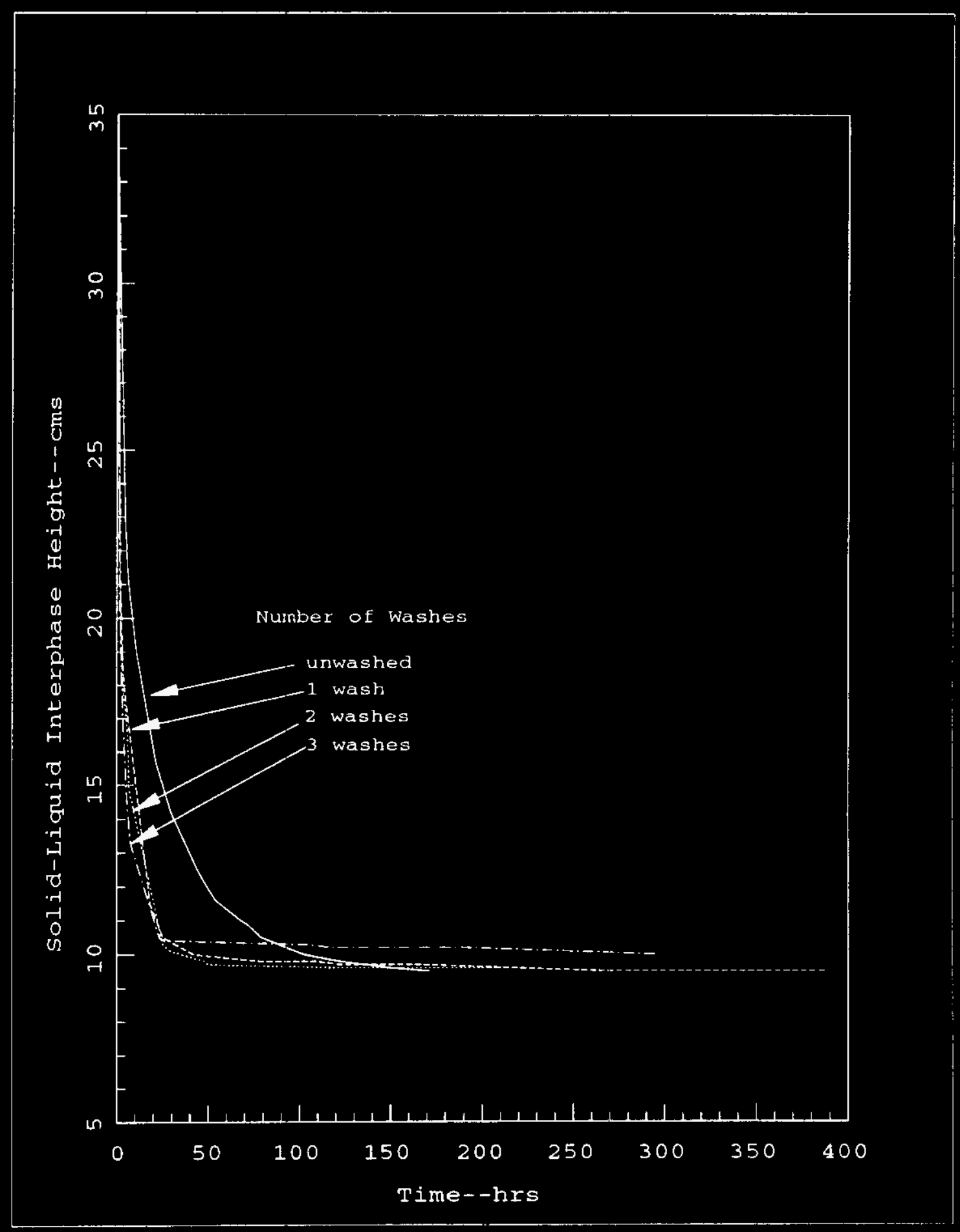

Figure 4.12 NCAW Simulant Settling Test--Heated Vessel 
WHC-SD-WM-ER- 534

Rev. 0

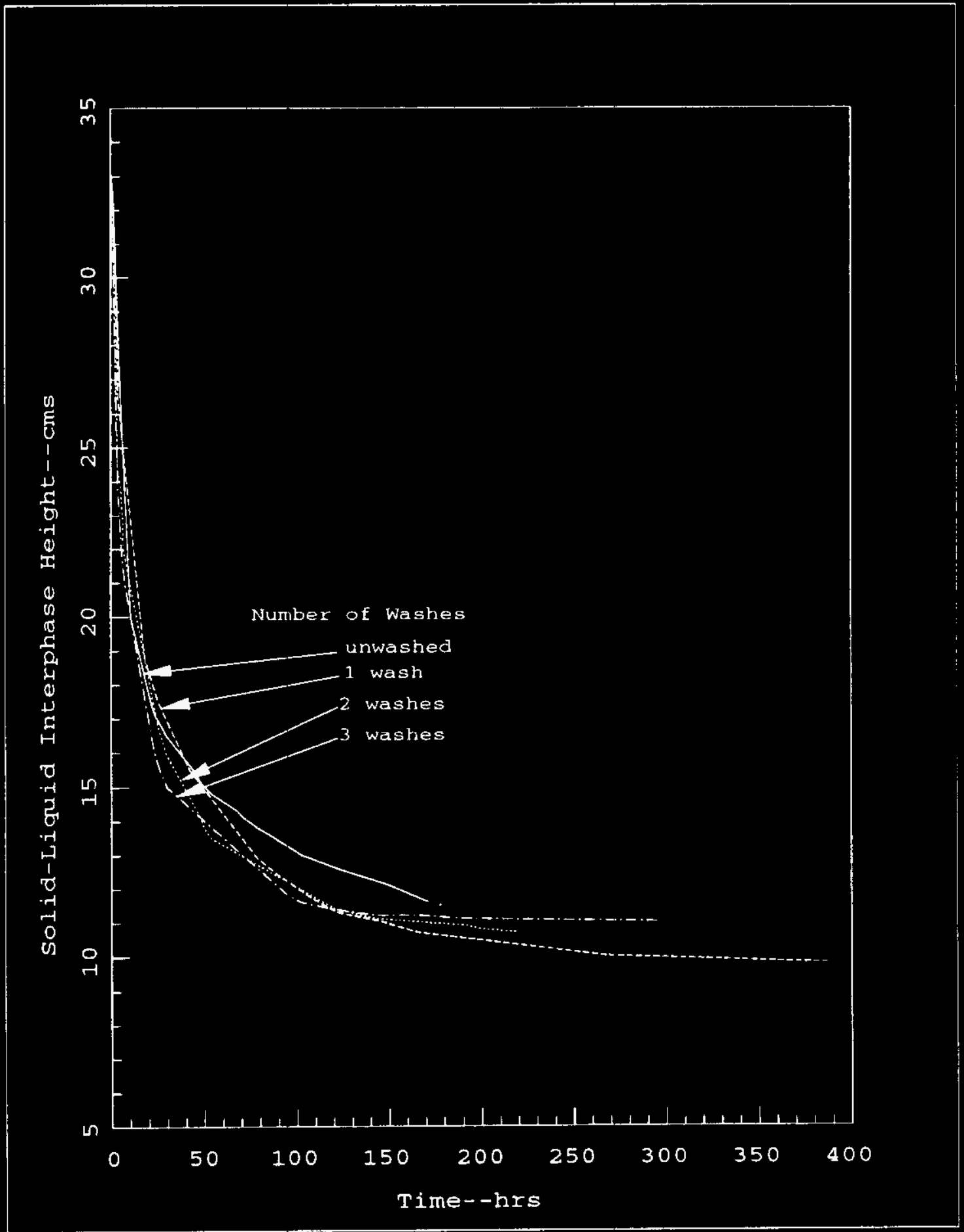

Figure 4.13 NCAW Simulant Settling Test--Ambient Vessel 
WHC-SD-WM-ER-534

Rev. 0

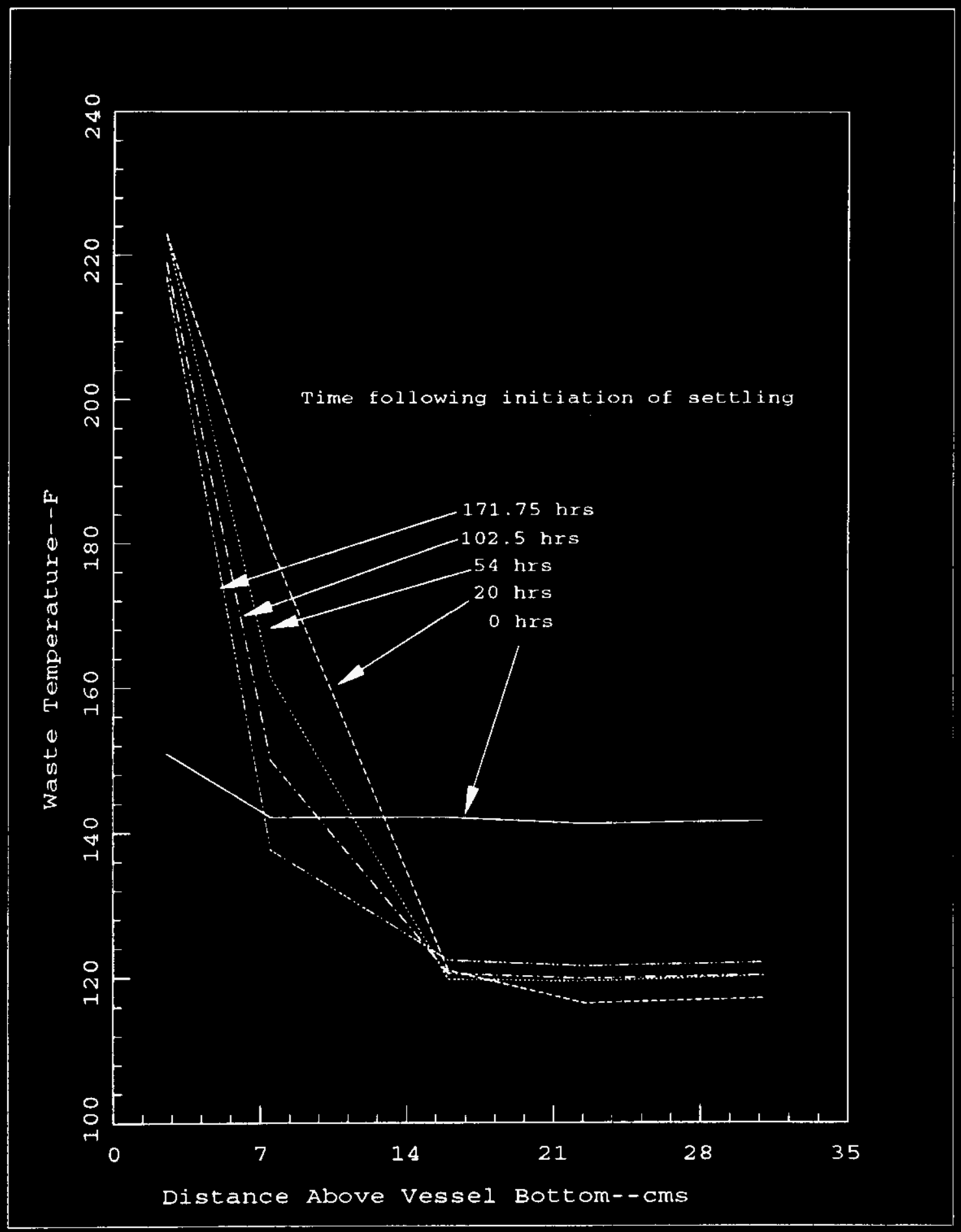

Figure 4.14 Temperature Profiles During Settling 


$$
\begin{gathered}
\text { WHC-SD-WM-ER-534 } \\
\text { ReV. } 0
\end{gathered}
$$

4.2.2.4. Total Heat Load and Distribution in Tank C-106 Sludge Before and After Transfer

Various estimates of the heat load and heat distribution have been made for Tank C-106. Following the 1994 Process Test a series of analyses were conducted assuming a total heat load of $110,000 \mathrm{btu} / \mathrm{hr}$ [Bander, 1993]. As noted earlier, a recent simulation [Fryer, et.al., 1995] of the Process Test estimated a higher tank heat load of 132,400 btu/hr. This is believed to be conservative, and so this value has become the basis for safety related analysis of this tank. Both the earlier and the new estimated heat load values have been used in this analysis and the results are reported herein. Only results based on the higher value should be used for safety purposes. Results based on the lower value are also provided to both document the results and assumptions, and to also provide some insight on what the thermal hydraulic behavior might be if the actual tank operating conditions turn out to be close to this heat load.

In this analysis the Tank C-106 sludge is assumed to have a non-uniform distribution of power. The non-uniform distribution was originally developed for a total heat load of 110,000 btu/hr[Bander, 1993]. This heat distribution was used to define the relationship between the amount of sludge removed, and its heat load. After transfer, however, the sludge was assumed to have a uniform heat load distribution as a result of sluicing and mixing during the retrieval and transfer process. In this analysis when the total tank heat load was assumed to be $132,400 \mathrm{btu} / \mathrm{hr}$, the normalized distribution was maintained the same, but the power in each axial layer was scaled up as shown in Table 4.3. Also shown below are the quantities of sludge transferred from each layer such that $40,000 \mathrm{btu} / \mathrm{hr}$ would remain in Tank C-106 after the transfer for the two different assumed tank heat load values. However, in the GOTH simulations for the combined sludge in tank AY-102 
WHC-SD-WM-ER- 534

Rev. 0

small adjustments were made to match up with computational grid thicknesses.

Table 4.3 Power and Power Distribution

\begin{tabular}{|c|c|c|c|c|c|c|c|}
\hline Layer & $\begin{array}{l}\text { Layer } \\
\text { volume }\end{array}$ & $\begin{array}{c}\text { Layer } \\
\text { Thickness }\end{array}$ & $\begin{array}{l}\text { Layer } \\
\text { Power }\end{array}$ & $\begin{array}{l}\text { Normalized } \\
\text { Power } \\
\text { Fraction }\end{array}$ & $\begin{array}{c}\text { Power } \\
\text { Distribution } \\
\text { Based On } \\
132400 \text { btu } / \mathrm{hr}\end{array}$ & $\begin{array}{l}\text { Thickness } \\
\text { Removed } \\
\text { To Leave } \\
40000 \text { btu/hr } \\
\text { in Tank C- } 106 \\
\text { Assuming } \\
\text { Current } \\
\text { Heat Load } \\
110000 \mathrm{btu} / \mathrm{h}\end{array}$ & $\begin{array}{l}\text { Thickness: } \\
\text { Removed } \\
\text { To Leave } \\
40000 \text { btu/hr } \\
\text { in Tarik. C-106 } \\
\text { Assuming } \\
\text { Current } \\
\text { Heat Loar } \\
132400 \text { bru/hr }\end{array}$ \\
\hline & $f t^{3}$ & $f t$ & $\frac{\mathrm{btu}}{\mathrm{hr}}$ & & $\frac{\text { btu }}{h r}$ & ft & ft \\
\hline $\begin{array}{l}\text { Botton } \\
\text { Middle } \\
\text { Top } \\
\text { Total }\end{array}$ & $\begin{array}{r}8264 \\
5826 \\
12281 \\
26370\end{array}$ & $\begin{array}{l}1.87 \\
1.32 \\
2.78 \\
5.97\end{array}$ & $\begin{array}{r}53600 \\
38000 \\
18400 \\
110000\end{array}$ & $\begin{array}{l}0.49 \\
0.35 \\
0.16 \\
1.00\end{array}$ & $\begin{array}{r}64515 \\
45738 \\
22147 \\
132400\end{array}$ & $\begin{array}{l}0.47 \\
1.32 \\
2.78 \\
4.5 .7\end{array}$ & $\begin{array}{l}0.71 \\
1.32 \\
\therefore .78 \\
4.41\end{array}$ \\
\hline
\end{tabular}




$$
\text { WHC-SD-WM-ER- } 534
$$

Rev. 0

\section{RESULTS AND DISCUSSION}

Both HUB calculations, and GOTH thermal hydraulic computer code simulations were performed and the results are described in this section. HUB methodology was developed to obtain steady state results faster and hence perform a number of parametric calculations. Because of some simplifications made in this methodology, the methodology was verified using the GOTH computer code. All transient simulations such as annual meteorological cycle simulations, ventilation system outages, the floor channel cooling effectiveness calculations, and HUB methodology verification simulations were performed using the GOTH computer code.

The GOTH simulation conducted to provide an estimate of the heat load currently in Tank AY-102 is first discussed. This is followed by the Phase I analysis conducted with both HUB and the GOTH 1-D model based on an estimated Tank C-1.06 heat load of $110,000 \mathrm{btu} / \mathrm{hr}$. Finally results of the Phase II analysis are discussed for both the HUB and GOTH 2-D model based on the recently revised heat load estimate for Tank C-106 of $132,400 \mathrm{btu} / \mathrm{hr}$. Included in the Phase II results is a discussion of results associated with ventilation outage simulations.

\subsection{Tank AY-102 Heat Load Estimation}

Earlier estimates of the heat load for Tank AY-102 have ranged as high as $88000 \mathrm{btu} / \mathrm{hr}$. But the measured tank temperatures are low relative to this heat source value. To establish a more consistent heat load for this tank, the GOTH model was used to determine tank heat load based on tank waste level and temperature data during a period when no waste transfers occurred. The level change data was used to compute evaporation rates, and this was then compared to evaporation rates predicted. Reasonable comparisons to tank temperatures and the evaporation rate data were obtained with a tank heat load of $33000 \mathrm{btu} / \mathrm{hr}$. 


$$
\text { WHC-SD-WM-ER }-534
$$

Rev. 0

All this heat source is assumed to be within the sludge and the sludge conductivity is assumed to be that of water.

The calculated sludge bottom temperature is somewhat lower than some of the tank floor temperature data under these assumptions. The tank floor temperature data should approach the maximum sludge temperature when the secondary floor ventilation is off, as it was when this data was taken. However, the tank data varies azimuthally around the tank with some tank floor values being within the calculated values and some being high or low. Given the overprediction of the supernatant temperatures and close comparison to evaporation data at an assumed heat load of $33000 \mathrm{btu} / \mathrm{hr}$, it is concluded that the total tank heat load should not be higher than $33000 \mathrm{btu} / \mathrm{hr}$. The higher and lower temperatures observed in the sludge relative to the calculated values suggest that the sludge thickness may be somewhat uneven, or the heat distribution may not be quite uniform in this tank.

The sludge bottom, supernatant, and dome space temperatures calculated for five annual meteorological cycles is shown in Figure 5.1 together with a comparison to typical operating data. The heat removed as sensible energy by primary ventilation air temperature change and by evaporation is illustrated in Figure 5.2. A small amount of heat is removed via conduction through the soil above the tank making up the difference between the total tank heat load and the sum of evaporation plus sensible heat carried by air temperature change. As noted previously during the February time period the calculated evaporation rate compares well to the evaporation rate computed based on level change during this period of time in 1995, for an assumed heat load of $33000 \mathrm{btu} / \mathrm{hr}$. Note that both the heat removed by evaporation and sensible air temperature vary widely over the annual cycle. 
WHC-SD-WM-ER- 534

Rev. 0

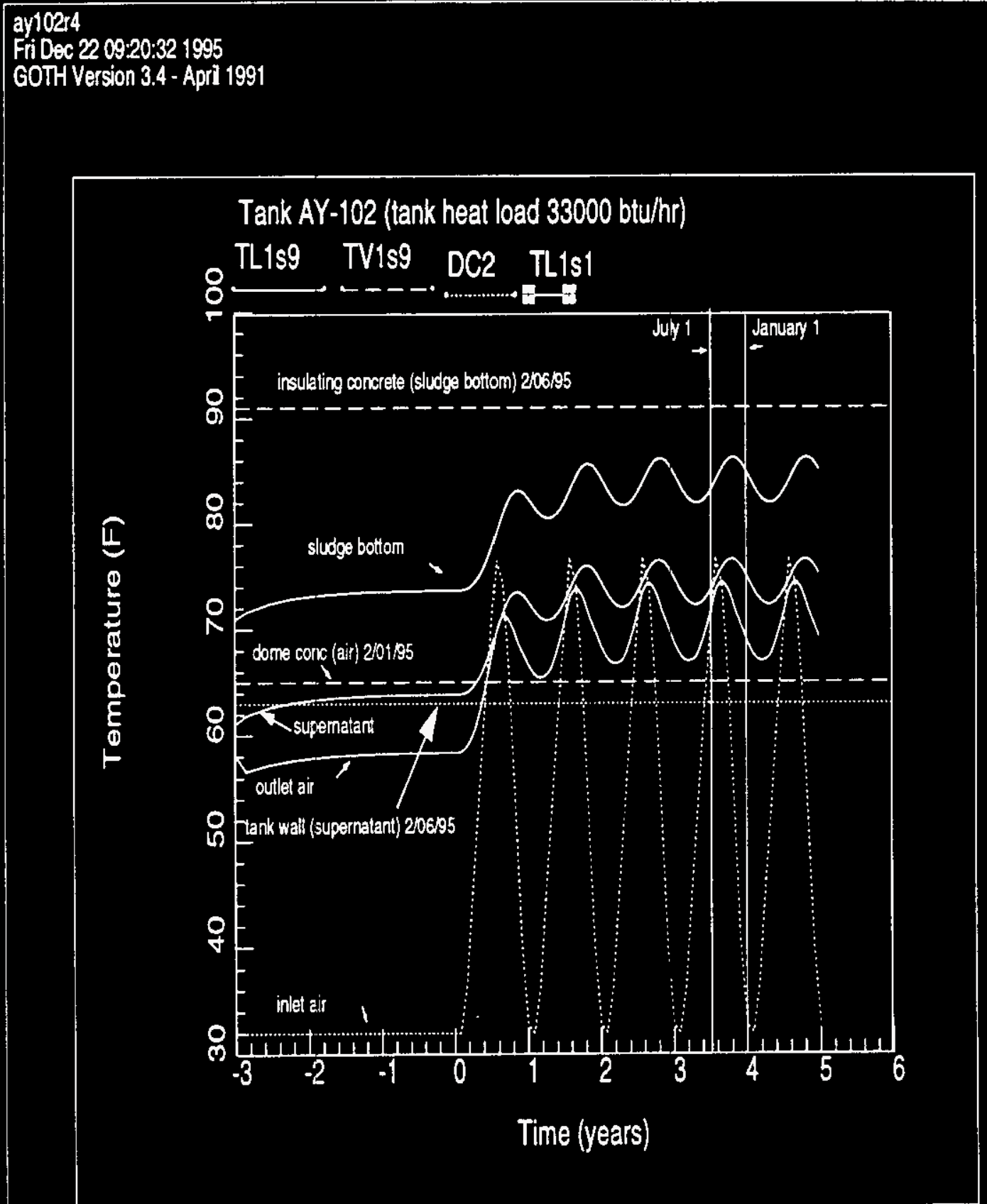

Figure 5.1 Tank AY-102 Current Contents Temperature Response to Annual Meteorological Cycle, 1 ft of sludge --second. Vent. Off 


$$
\begin{aligned}
& \text { WHC-SD-WM-ER-534 } \\
& \text { Rev. } 0
\end{aligned}
$$

\section{ay102/4}

GOTH Version 3.4 - Apri 1991

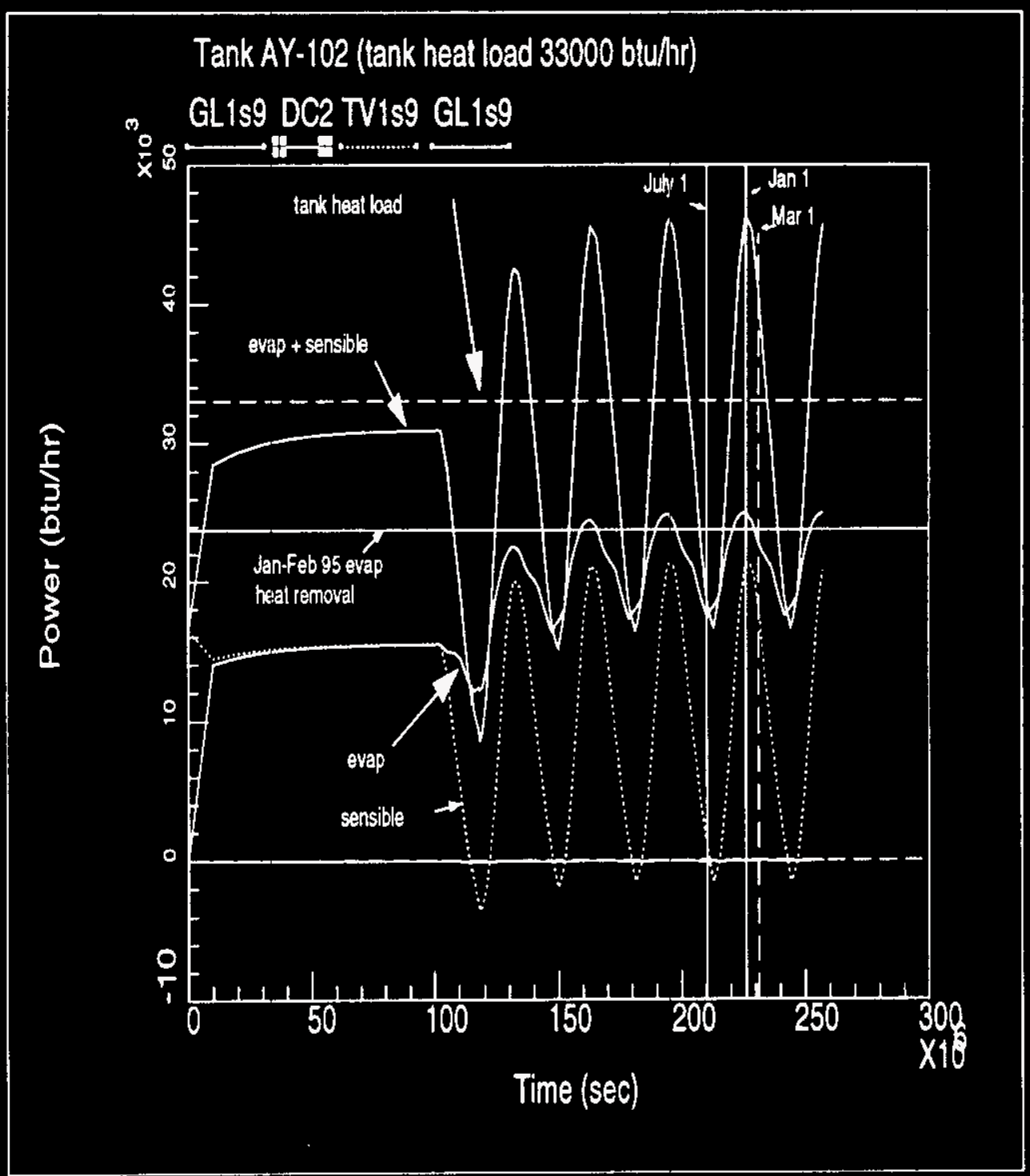

Figure 5.2 Tank AY-102 Current Contents Heat Load

Partitioning Response to Annual Meteorological Cycle, 1 ft of sludge --Second. Vent. Off 


$$
\begin{gathered}
\text { WHC-SD-WM-ER-534 } \\
\text { ReV. } 0
\end{gathered}
$$

\subsection{Tank AY-102 with Consolidated sludge- Phase I}

The phase 1 thermal hydraulic calculations of the tank AY-102 with the consolidated sludge are performed assuming the Tank C-106 heat load of $110,000 \mathrm{Btu} / \mathrm{hr}$.

\subsubsection{HUB Parametric Calculations}

Parametric calculations were conducted using HUB to rapidly evaluate the interrelationships between sludge layer heat loads, sludge layer thicknesses, sludge conductivity, and the resultant sludge temperature and temperature distribution. These calculations assumed a current estimated secondary ventilation flow rate of 500 CFM through the floor cooling channels, Project W-030 primary ventilation recirculation air flow rate of 400 CFM combined with a normal dome inlet flow of $100 \mathrm{CFM}$. The secondary inlet temperature was assumed be a nominal average summer temperature of $70^{\circ} \mathrm{F}$ and $50 \%$ relative humidity. For the primary ventilation both the recirculation flow and normal dome inlet flow were assumed to be $83^{\circ} \mathrm{F}$ and $100 \%$ relative humidity.

The sludge temperature results for two different quantities of C-106 sludge transfer are shown in Figure 5.3. A fluff factor of 1.0 and the transferred sludge conductivity of $0.5336 \mathrm{btu} / \mathrm{hr}-\mathrm{ft}-\mathrm{R}$ are assumed. The sludge transfer of 152,000 gallons $(4.6 \mathrm{ft})$ corresponds to leaving a heat load of $40000 \mathrm{btu} / \mathrm{hr}$ in Tank $\mathrm{C}-106$, and transferring the remaining sludge with a heat load of $70000 \mathrm{btu} / \mathrm{hr}$ to $\mathrm{AY}-102$. The sludge transfer of 157000 gallons $(5.8 \mathrm{ft})$ corresponds to complete transfer of Tank C-106 sludge. The heat load used in these calculations is lower than the upper bound value of $132,400 \mathrm{btu} / \mathrm{hr}$ considered later for other cases in this report.

The secondary ventilation is assumed to be either on or off. When the system is operating, it is assumed that the cooling is 1008 effective and therefore the ventilation 


$$
\begin{gathered}
\text { WHC-SD-WM-ER-534 } \\
\text { Rev. } 0
\end{gathered}
$$

flow exits the floor with sludge bottom temperature. If the sludge resettles to its current particle volume fraction, has the current sludge conductivity, and if the ventilation system is $100 \%$ effective, then adequate sludge could be transferred to reduce Tank C-106 to a low heat load tank, and still have considerable margin to local saturation temperature from the peak value of the combined sludge in Tank AY-102. The peak sludge temperature calculated was $170^{\circ} \mathrm{F}$ with a secondary ventilation flow of $500 \mathrm{CFM}$, and with no secondary ventilation, it will be above local saturation temperature. Based on these assumptions it may even be possible to transfer all the sludge and still be within operating safety limits. The calculated peak sludge temperature for complete transfer with secondary floor cooling operating is $208^{\circ} \mathrm{F}$. However if the secondary ventilation system is off, then even the transfer of $4.6 \mathrm{ft}(70,000 \mathrm{btu} / \mathrm{hr})$ of Tank C-106 sludge to AY-102 will develop temperatures higher than local saturation values. This should be obvious since Tank C-106 is currently at or approaching saturation temperature, even with a much higher primary ventilation system flow rate (currently at -2300 CFM) than currently estimated for Tank AY-102 ( -600 CFM). 
WHC-SD-WM-ER- 534

Rev. 0



Figure 5.3 Comparison of Temperature Distributions for Different Transferred Sludge Thicknesses --Tank-C-1.06 Heat Load 110,000 btu/hr--Phase I 


$$
\begin{aligned}
& \text { WHC-SD-WM-ER- } 534 \\
& \text { ReV. } 0
\end{aligned}
$$

\subsubsection{GOTH 1-D Simulation}

The results of the thermal hydraulic simulation using the GOTH 1-D model of Tank AY-102 with the transfer of $4.5 \mathrm{ft}$ of sludge from Tank C-106 are shown in Figures 5.4 and Figures 5.5 for secondary ventilation off and on respectively. The case with the secondary ventilation off provides an upper bound on expected maximum temperature in the sludge, $248^{\circ} \mathrm{F}$. The case with secondary ventilation on provides an approximate estimate of the expected maximum temperature, $198^{\circ} \mathrm{F}$, in the sludge with a floor ventilation flow rate of $500 \mathrm{CFM}$. In both cases Project W-030 primary ventilation system with recirculation tank air inflow is assumed operational and the sludge fluff factor after transfer is 1.0 . 
WHC-SD-WM-ER- 534

Rev. 0

ay1216r3
Fri Dec 22 11:48:12 1995
GOTH Version 3.4 - April 1991

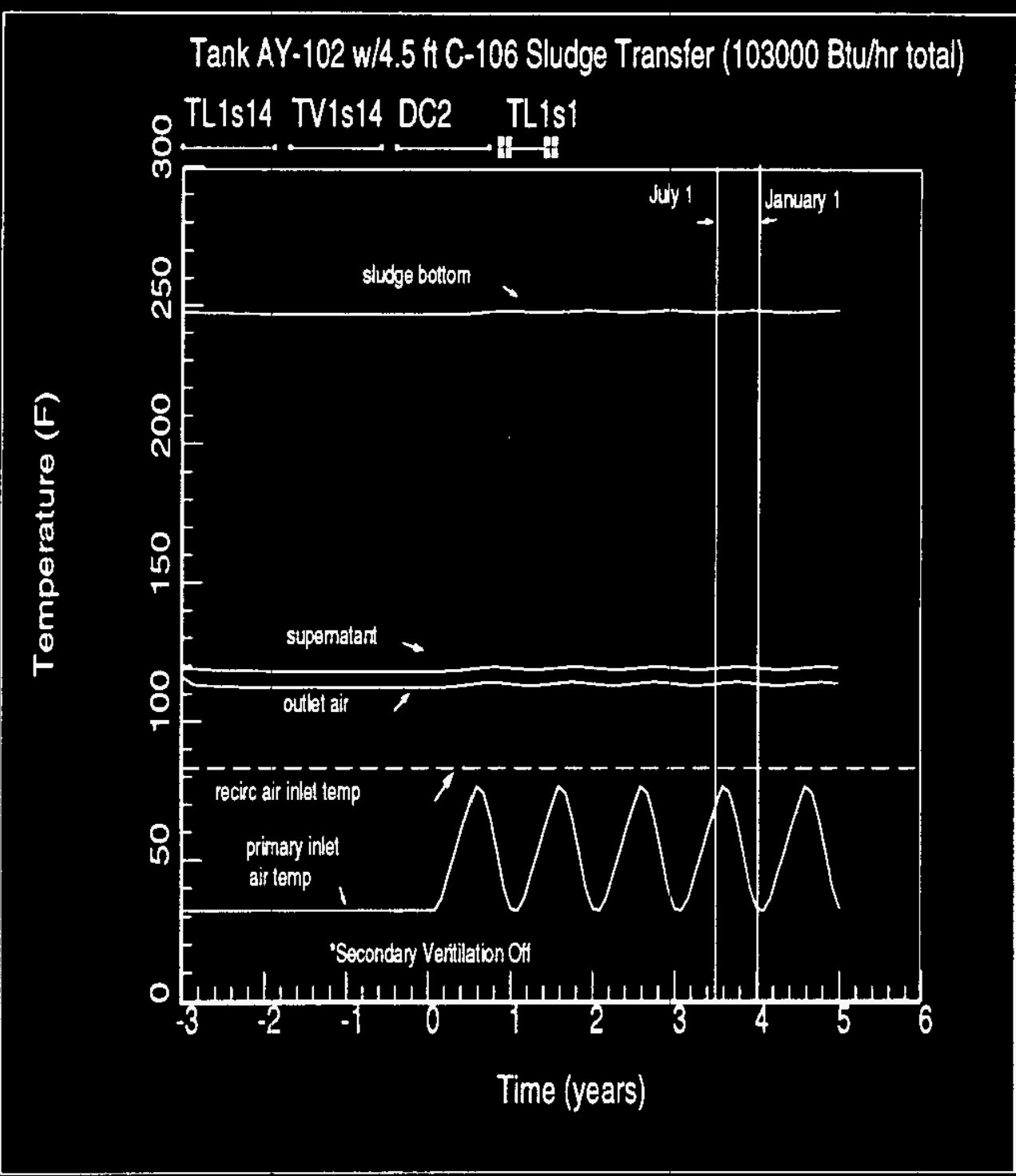

Figure 5.4 Tank AY-102 Contents Temperature Response to Annual Meteorological Cycle After 4.5 ft Sludge Transfer From Tank C-106--Second. Vent. Off, Fluff Factor 1.0 
WHC-SD-WM-ER -534

Rev. 0

ay1216r2x
Fri Dec 22 11:54:51 1995
GOTHVersion 3.4 - April 1991

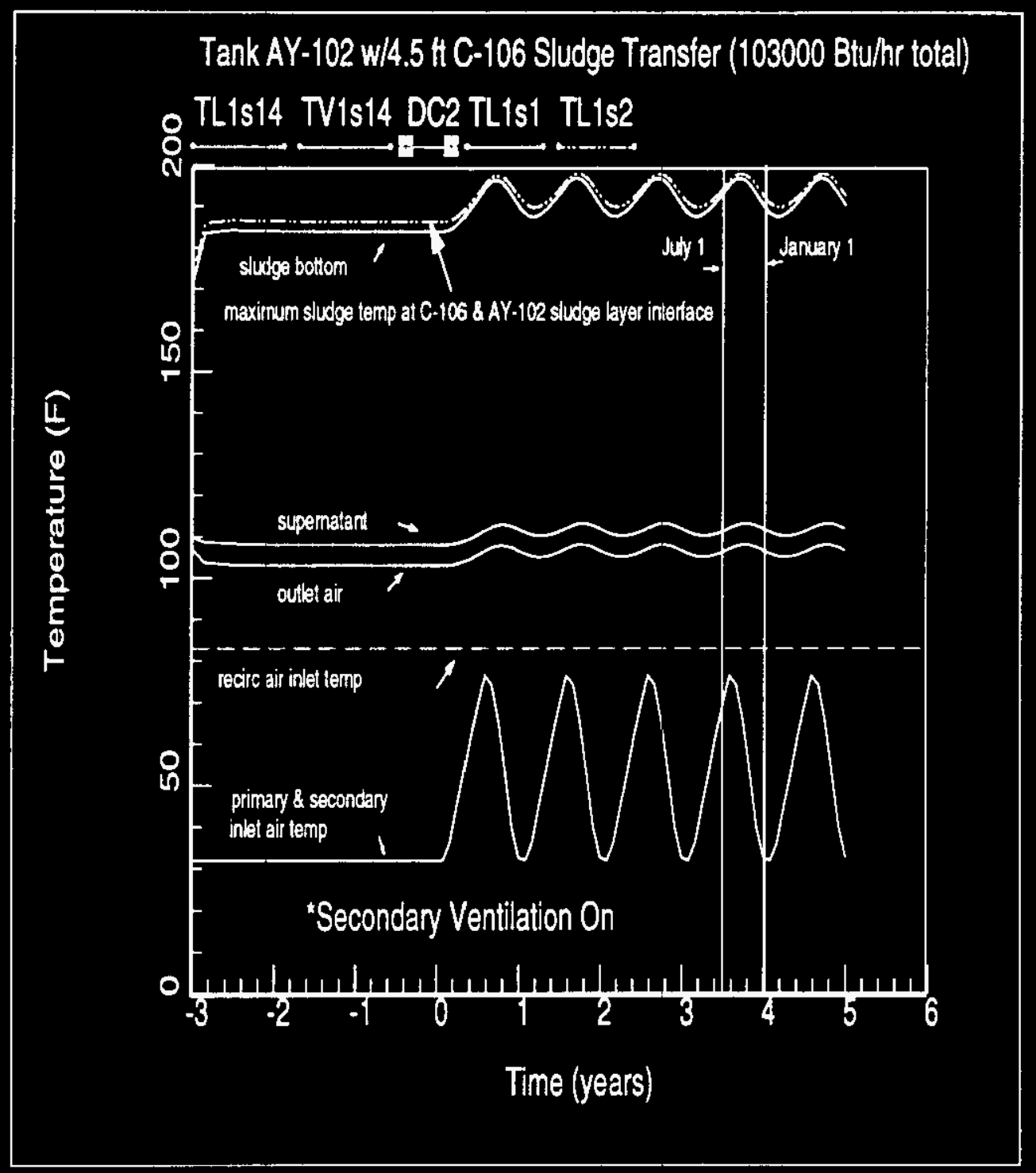

Figure 5.5 Tank AY-102 Contents Temperature Response to Annual Meteorological Cycle After 4.5 ft Sludge Transfer From Tank C-106--Second. Vent. 500 CFM, Fluff Factor $=1.0$ 
WHC-SD-WM-ER- 534

Rev. 0

When the secondary ventilation is off, the maximum sludge temperature of $248^{\circ} \mathrm{F}$ occurs at the tank bottom. The bottom sludge would then be at saturation temperature assuming the sludge interstitial liquid is water and the tank waste level is 30 feet from the tank bottom. Although the meteorological conditions cycle, the sludge temperature in this case does not vary significantly.

With the secondary ventilation on, the maximum calculated sludge temperature is $198^{\circ} \mathrm{F}$ and occurs near the interface of the two sludge layers during the september/October time period. There is significant temperature cycling of the bottom sludge due to the secondary ventilation. As noted previously these results are based on simplified 1-D modeling of the conduction of heat from the sludge to the floor cooling chaniels. The GOTH $1-\mathrm{D}$ model does not account for the distance the heat must be conducted through the sludge and possibly concrete, for sludge far removed azimuthally from a floor coolant channel. Nor does the model include the heat transfer surface area of the sides and bottom of the concrete air flow channel. The estimated sludge temperature with this model does, however, provide a measure of cooling capability based on an "average" sludge region and simplified air channel.

The maximum sludge temperature with the secondary ventilation operational will occur midway (azimuthally) between the floor coolant channels and possibly at some height above the floor, rather than at the sludge floor interface as previously illustrated in Figure 3.4.

Additional multi-D analysis was conducted to examine the details of the air cooling channel effectiveness.

Similar results are provided in Figure 5.6 for total transfer of sludge (i.e. $6.0 \mathrm{ft}$ ) from C-106 to AY-102 with the secondary ventilation on and the aforementioned simplified conductance model from the sludge to the floor ventilation channels. This results in a peak sludge temperature of $240{ }^{\circ} \mathrm{F}$ at $.25-.75$ feet above the sludge 


\section{WHC-SD-WM-ER-534}

Rev. 0

layers interface. This is about $6{ }^{\circ} \mathrm{F}$ below local saturation. No GOTH 1-D model simulations with the secondary ventilation off were conducted for the $6.0 \mathrm{ft}$ sludge transfer case since the sludge bottom will clearly reach saturation and produce steam based on the above 4.5 ft sludge transfer results. 
WHC-SD-WM-ER - 534

Rev. 0

ay $121613 x$

Tue Sep 26 16:10:22 1995

GOTH Version 3.4 - Apri 1991



Figure 5.6 Tank AY-102 Contents Temperature Response to Annual Meteorological Cycle After 6 ft Sludge Transfer From Tank C-106--Second. Vent. 500 CFM, Fluff Factor $=1.0$ 


$$
\begin{gathered}
\text { WHC-SD-WM-ER--534 } \\
\text { ReV. } 0
\end{gathered}
$$

Due to sludge cooling effects from the presence of soil and floor cooling ducts a radial gradient can be expected at the tank floor even when the secondary ventilation is off, with the sludge being hottest at the tank center and cooler immediately adjacent the tank wall. This is supported by Tank AZ-101 temperature data taken when its secondary ventilation system was off. Even with the secondary ventilation off there will be some natural convection effects which aid cooling of the sludge. When the secondary ventilation is on, the sludge temperature at the floor in Tank AZ-101 increases in the radial direction from the tank center, reaches a peak, then cools immediately adjacent the tank wall. These effects are not simulated in 1-D GOTH model.

\subsection{Tank AY-102 With Consolidated sludge- Phase II}

The phase II thermal hydraulic calculations were performed using HUB and GOTH models assuming an upper bound heat load of $132400 \mathrm{btu} / \mathrm{hr}$ for C-106 waste.

\subsubsection{HUB Parametric Calculations}

Parametric calculations were conducted using HUB to evaluate the sludge temperature distribution for different sludge heat loads, thickness or fluff factor, thermal conductivity, secondary ventilation flow rates, floor cooling channel effectiveness, primary ventilation flow rates, and ventilation flow inlet conditions. Similar calculations were performed using a secondary ventilation flow rate of $2000 \mathrm{CFM}$ and potential maximum value of 3000 CFM. The resulting temperature distributions for the transfer of $4.8 \mathrm{ft}$ of C-106 sludge to AY-102 with 3000 and 2000 CFM secondary floor ventilation flow at various floor cooling effectivenesses are presented in Figures 5.7 and 5.8 respectively. A fluff factor of 2.0 is assumed for the transferred sludge in Tank AY-102. The C-106 sludge 
WHC-SD-WM-ER-534

Rev. 0

conductivity is estimated using a series conductivity model $(0.4338 \mathrm{btu} / \mathrm{hr}-\mathrm{ft}-\mathrm{R})$. The conductivity value is less than the current estimated sludge conductivity due to the reduction of particle volume fraction after transfer (i.e. increase in fluff factor from 1.0 to 2.0 ).

The results show that the insulating concrete floor channel cooling effectiveness must be at least of the order of 25-40\% for flow rates of 2000-3000 CFM to maintain a reasonable safety margin between saturation temperature and maximum sludge temperature. With these air flow rates, and high effectiveness, half or more of tine total tank heat load would be removed by the floor ventilation air. The balance of the tank heat load is removed via evaporation and heat transfer at the waste surface to the primary ventilation air, plus smaller amounts by conduction through the soil.

Calculations to estimate the sludge temperature distribution were also performed with fluff factor as a parameter. The operating conditions of Tank AY-102 with the combined sludge are assumed to be same as for the results of the Figure 5.8 which is based on fluff factor of two. The transferred sludge heat load of $92,400 \mathrm{Btu} / \mathrm{hr}$, and average summer inlet flow conditions are assumed for the ventilation flow. The primary and secondary ventilation flow rates of 630 and 2000 CFM respectively are assumed.

Figures 5.9 and 5.10 show the results of temperature distribution for the transferred sludge with fluff factors of one and three respectively. The estimated peak temperatures of the combined sludge are shown in Figure 5.11 as a function of cooling channel effectiveness and transferred sludge fluff factor. The results show that for a cooling effectiveness of $35 \%$ and a fluff factor of 1 , for example, the peak sludge temperature will be much below OSR limit. If the fluff factor is two, then the peak expected temperature is close to the OSR limit. 


$$
\begin{aligned}
& \text { WHC-SD-WM-ER- }-534 \\
& \text { ReV. } 0
\end{aligned}
$$

However, if the fluff factor happens to be three, the peak temperature will be above even the local saturation value. The results show that the fluff factor of the transferred sludge should be less than two and the cooling effectiveness of the cooling/drain channels in the insulating concrete of the tank should be above $35 \%$ for these operating conditions to maintain the peak sludge temperatures within the OSR limits.

It is also noted that without floor ventilation 159,000 gallons $(4.8 \mathrm{ft})$ of sludge transfer would result in reaching local saturation conditions in the waste leading to the formation of steam, and the periodic or continuous promotion of some fluid convective action to transport the tank heat load from the lower sludge to the supernatant and/or tank dome. One possible mode of fluid convective action is steam bumping.

For a given cooling channel effectiveness, this analysis method computes the temperatures of the sludge and floor exit air. However, the effectiveness is an unknown parameter. In order to make a realistic estimate of this parameter, 2D GOTH model was developed. A 3 Region 2-D GOTH model was utilized to simultaneously calculate the sludge and air temperatures from which the cooling channel effectiveness is derived. 
WHC-SD-WM-ER- 534

Rev. 0

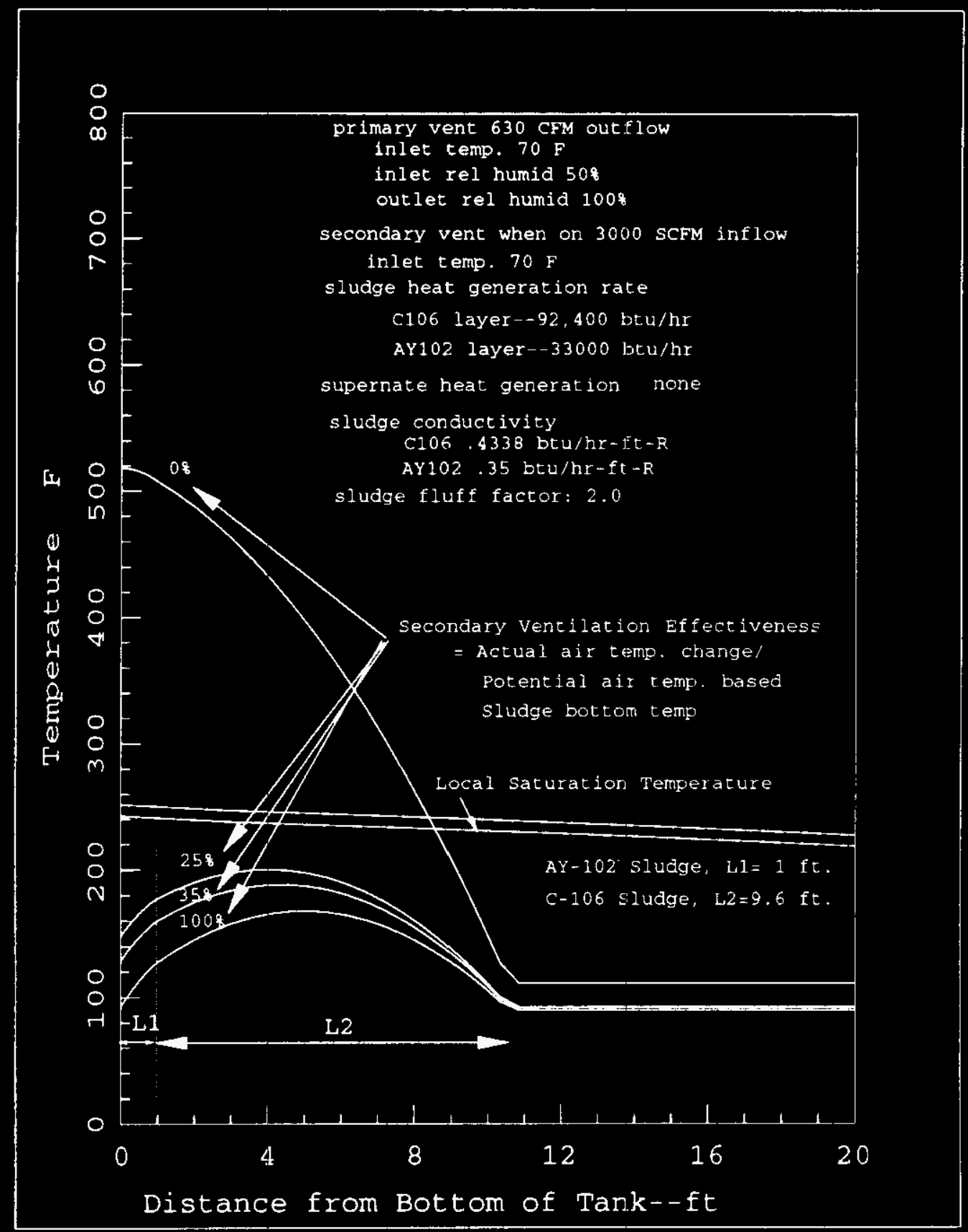

Figure 5.7 Temperature Distribution in Sludge Layer of Tank AY-102 with Annulus Vent. Flow Effectiveness as a parameter for Secondary Vent. Flow $=3000 \mathrm{cfm}$. 
WHC-SD-WM-ER-534

Rev. 0

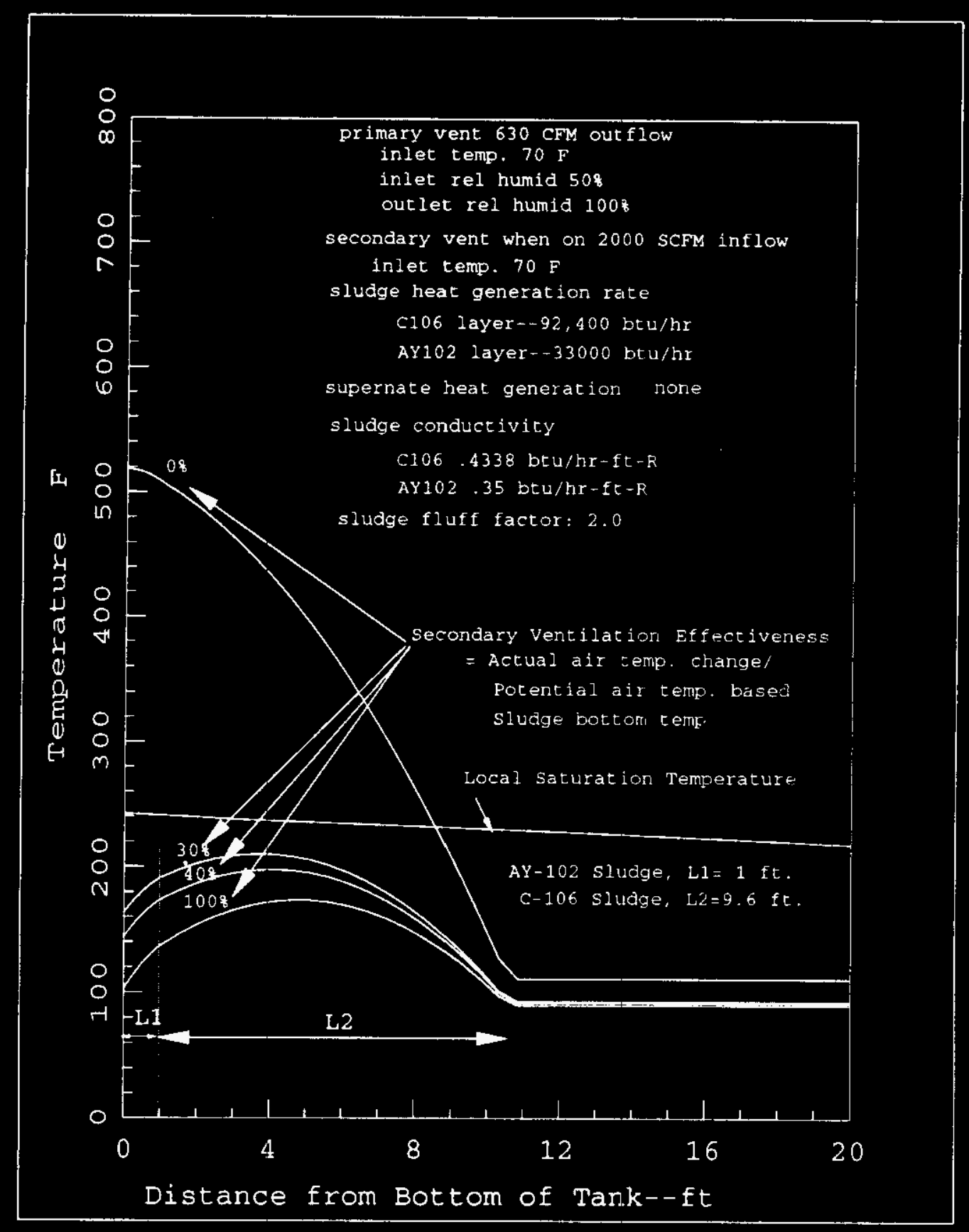

Figure 5.8 Temperature Distribution in Sludge Layer of Tank AY-102 with Annulus Ventilation Flow Effectiveness as a parameter for Secondary Vent. Flow of $2000 \mathrm{cfm}$. 
WHC-SD-WM-ER - 534

Rev. 0

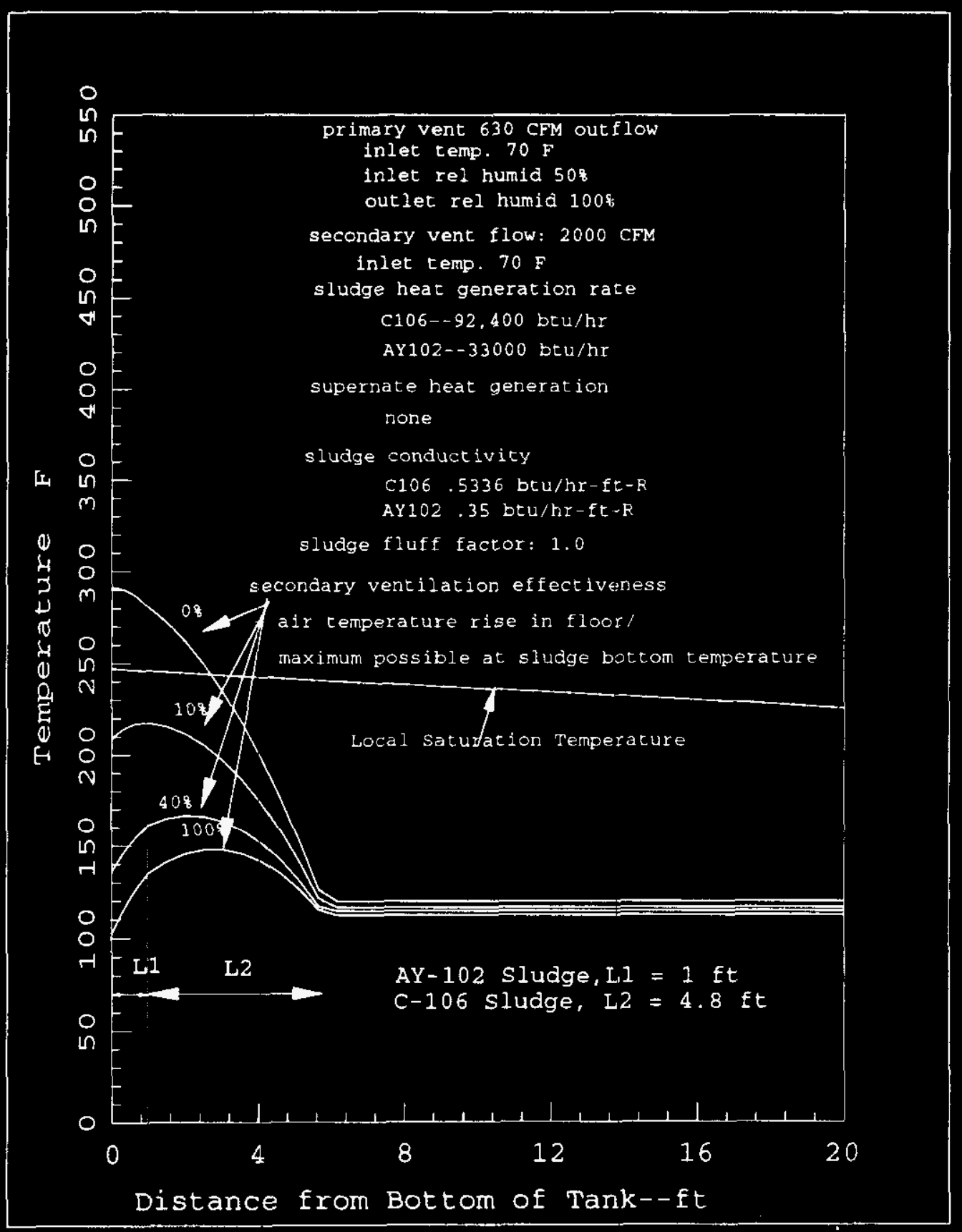

Figure 5.9 Temperature Distribution in Sludge Layer of Tank AY-102 with Annulus Ventilation Flow Effectiveness as a parameter for Combined sludge Heat Load of 125,400 Btu/hr and Height of $5.8 \mathrm{ft}$. 
WHC-SD-WM-ER- 534

Rev. 0

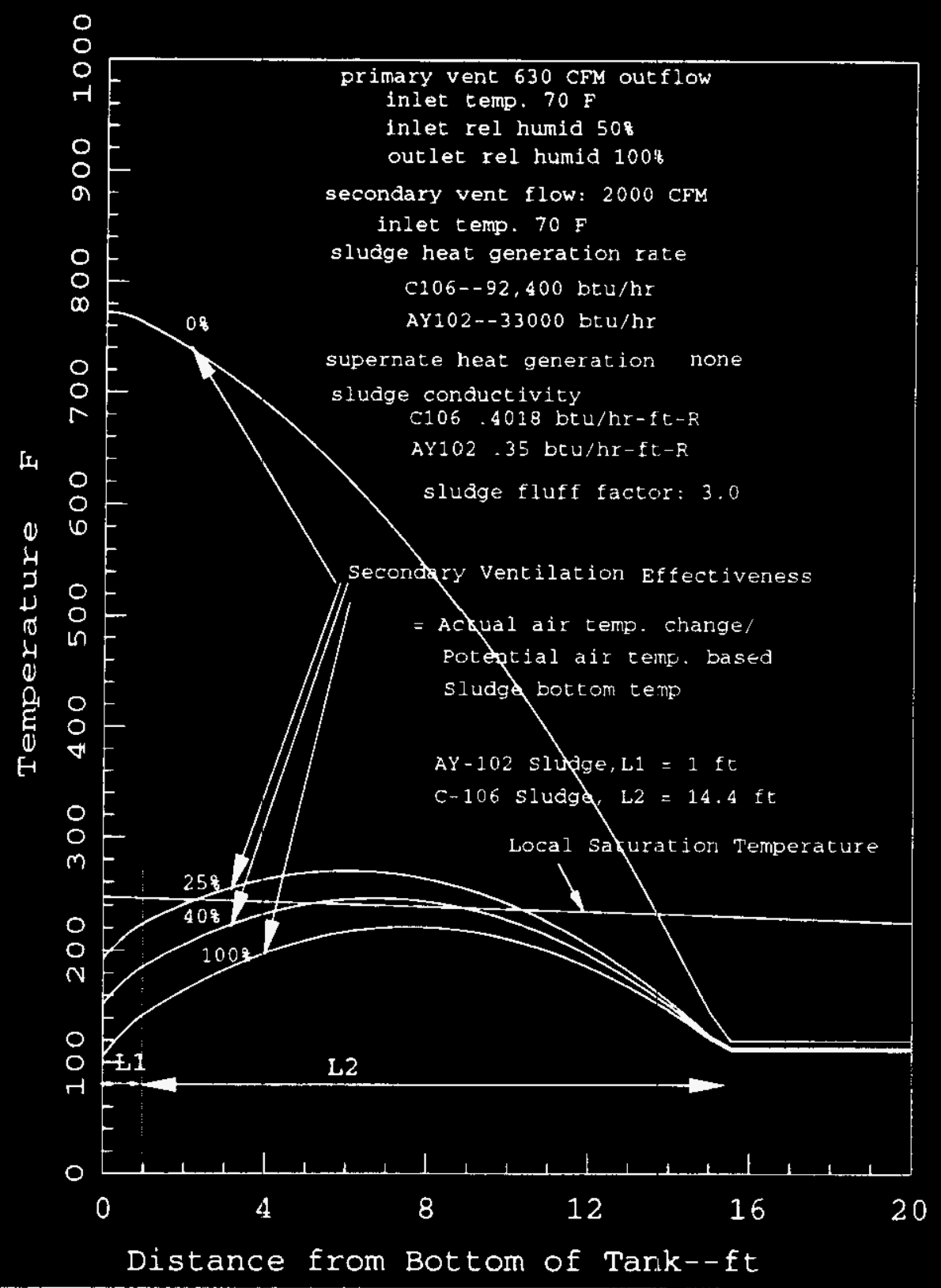

Figure 5.10 Temperature Distribution in Sludge Layer of Tank AY-102 with Annulus Ventilation Flow Effectiveness as a parameter for Combined Sludge Heat Load of 125,400 Btu/hr and Height of $15.4 \mathrm{ft}$. 
WHC-SD-WM-ER- 534

Rev. 0

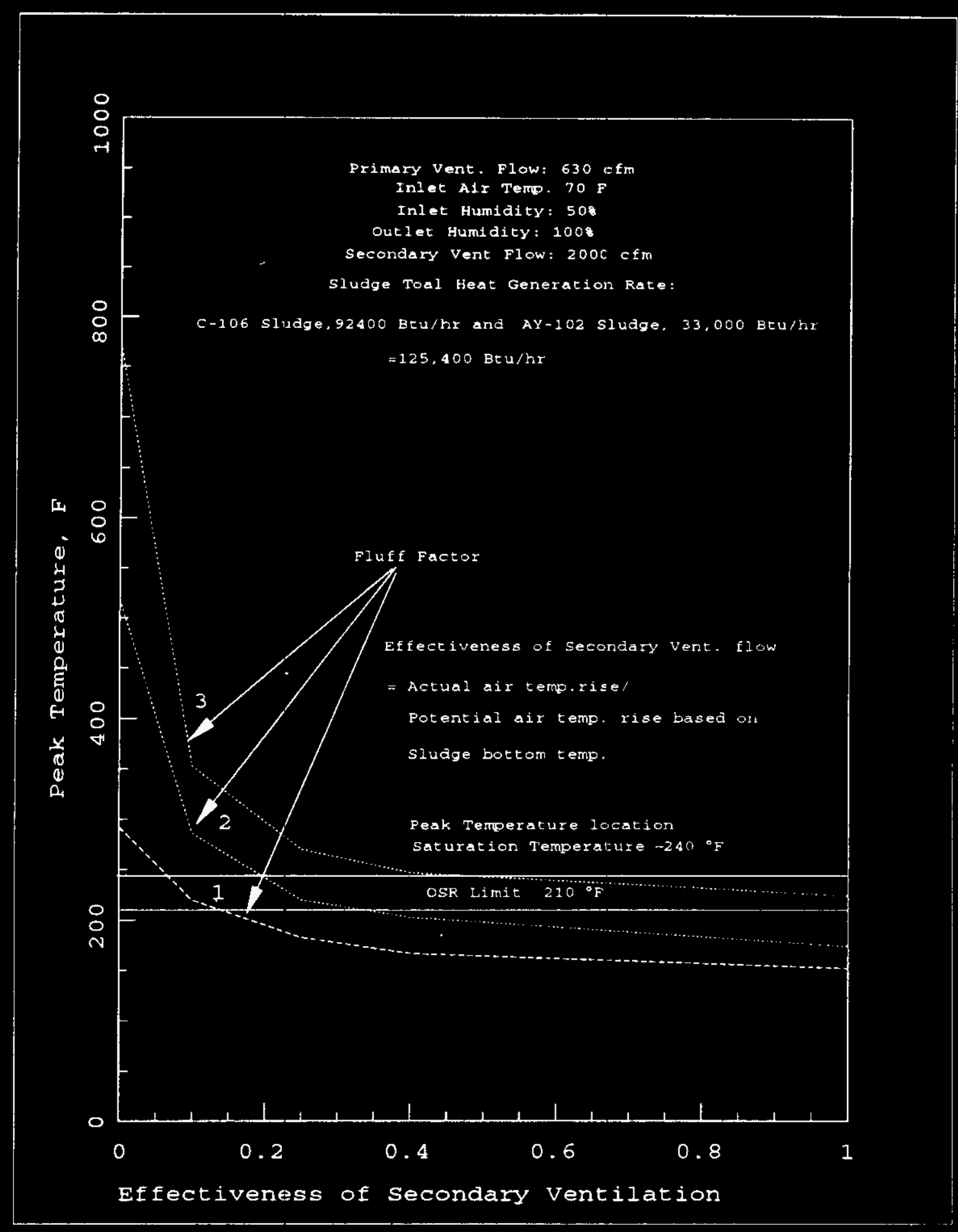

Figure 5.11 Combined Sludge Peak Temperature in AY-102

Versus Effectiveness of Cooling Channels in the Insulating Concrete with Sludge Fluff Factor as a Parameter. 
WHC-SD-WM-ER -534

Rev. 0

\subsubsection{2-D GOTH Model Simulations}

The 2-D GOTH model consists of three regions each representing the three radial sections of the floor cooling channels. Using this model, the simulations are based on upper bound Tank C-106 heat load of $132400 \mathrm{btu} / \mathrm{hr}$, and transfer of 4.75 ft of sludge to $A Y-102$. After transfer it is assumed that the sludge thickness will increase to 9.5 feet (fluff factor of 2 ) as a result of particles settling to only half the current particle volume before the sludge becomes non-convective. This sludge transfer will keep 40000 btu/hr heat load in Tank C-106.

Four simulations with normal operation of ventilation systems were performed. The first two simulations calculate steady state solutions using nominal summer average ventilation air inlet conditions and for 3000 and 2000 CFM floor ventilation flow rates respectively. The third simulation imposes repeated annual meteorological cyclic conditions at the inlet to the ventilation systems with $3000 \mathrm{CFM}$ flow rate. The fourth simulation uses a superimposed 2 week $105^{\circ} \mathrm{F}$ hot summer period upon the annual cycle simulation to evaluate the effect of an unusually hot summer on maximum sludge temperature, using again the 3000 CFM flow rate.

Although safe operating conditions for the Tank AY-102 after sludge transfer have been identified with ventilation systems operating normally in this analysis, none of these operations are acceptable under continuous outage of either the primary, or secondary, or combined primary and secondary systems. The ventilation system outage simulations were conducted to define allowable outage time periods.

5.3.2.1. 3000 CFM Flow with Average Summer Conditions Steady state simulation results for the GOTH 3 Region 2-D 
Model with primary and secondary ventilation flow rates of $552 \mathrm{CFM}$ and $3000 \mathrm{CFM}$ respectively, and having inlet air conditions of $70^{\circ} \mathrm{F}$ and $50 \%$ relative humidity are provided in Figures 5.12-5.14. Temperature contours in the sludge and tank floor are illustrated in Figure 5.12. As indicated each sludge region at the tank bottom becomes progressively hotter due to heat up of the air as it moves from the center of the tank towards the annulus. However at the top of the sludge the temperatures are nearly uniform in the radial direction. This is due to uniform cooling from the dome convective heat transfer and mass transport (i.e. evaporation) at the supernatant surface and the presence of well mixed supernatant with convection currents.

In the azimuthal direction the sludge temperature at the tank floor increases no more than $10^{\circ} \mathrm{F}$ from the top of the cooling channel to the mid channel location. The primary tank bottom steel plate acts as a very good conductor or fin to transport heat azimuthally from the sludge to the air cooling channel.

The sludge temperature variation with respect to time for three axial locations close to the peak temperature location ( 4.25 feet) in the outer radial region is illustrated in Figure 5.13. Starting from an initial guessed temperature distribution, the sludge interior reaches steady state with a peak temperature of $190^{\circ} \mathrm{F}$ at $4.25 \mathrm{ft}$ from the tank bottom. The temperature of the secondary ventilation air at inlet floor cooling channel and at outlets of the 3 radial cooling channel regions are illustrated in Figure 5.14. The outer region has the highest temperature and also the largest temperature change since the air progressively heats to higher and higher temperatures as it traverses the cooling channels, and because the outer region cools a much large volume of sludge than the middle or inner regions. The sludge temperature near the wall does not decrease as observed in 


\section{WHC-SD-WM-ER-534}

Rev. 0

the actual tank since the model does not include thermal coupling necessary between the outer sludge region and the lower annulus ventilation flow. 
WHC-SD-WM-ER- 534

Rev. 0

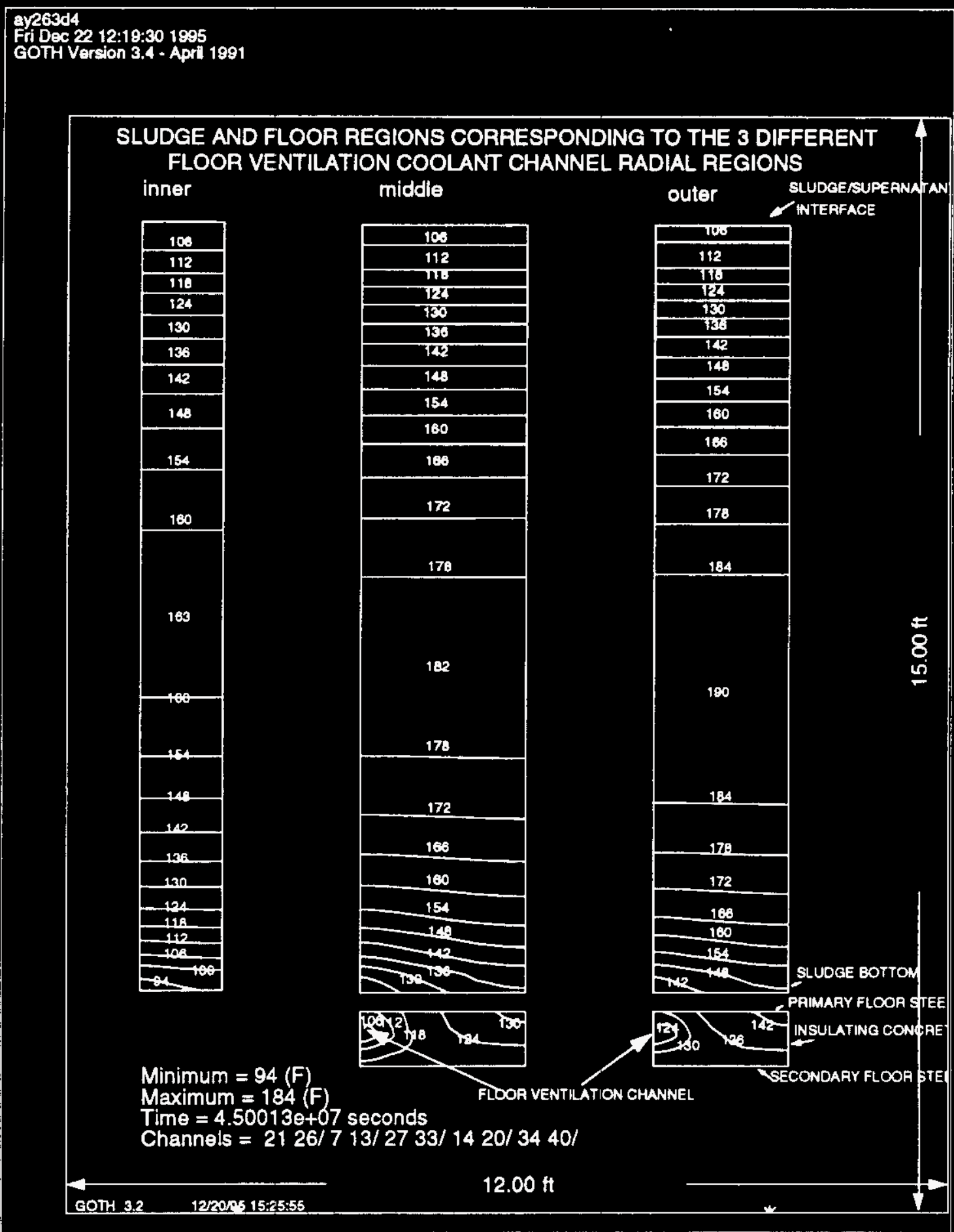

Figure 5.12 Three Region Sludge and Floor Temperature Contours--3000 CFM Floor Ventilation Flow, Fluff Factor 2.0 
WHC-SD-WM-ER- 534

Rev. 0

a)26304

Fiidec 22 12:24:42 1995

GOTH Version 3.4 - April 1991



Figure 5.13 Temperatures at 3 Locations Near Hottest Sludge Region in Outer Region - 3000 CFM Floor Ventilation Flow, Fluff Factor 2.0 
WHC-SD-WM-ER- 534

Rev. 0

ay26sd4

Fri Dec 222 12:27:00 1995

GOTH Version.3.4 - Apri 1991

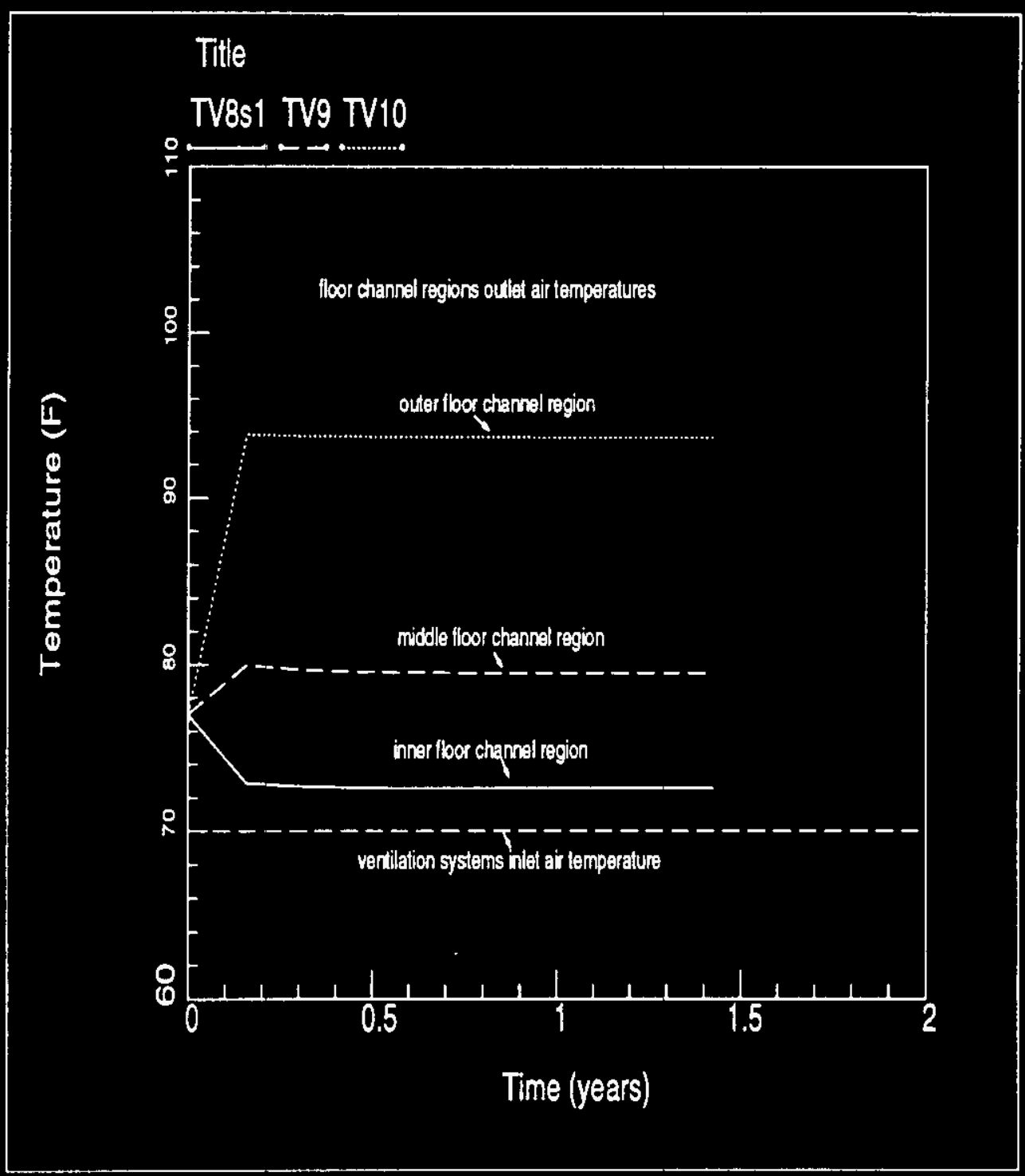

Figure 5.14 Air Outlet Temperatures at the 3 Different Floor Ventilation Regions - -3000 CFM Floor Ventilation Flow, Fluff Factor 2.0 


$$
\text { WHC-SD-WM-ER-534 }
$$

Rev. 0

\subsubsection{2000 CFM Flow with Average Summer Conditions}

Since the secondary ventilation system may not be capable of supplying a flow rate of $3000 \mathrm{CFM}$, a simulation was also conducted at a more recently estimated flow rate of 2000 CFM. The calculated sludge temperature distribution as temperature contours for all three regions, the sludge temperature variation near the peak temperature location and the cooling air temperature at inlet to the cooling channel and outlet from all the three region channels, as in the case of the $3000 \mathrm{CFM}$ flow case are shown in Figures 5.15-5.17. The maximum sludge temperature estimated with 2000 CFM flow through the floor cooling channels and the air entering at steady state average summer meteorlogical conditions is $201^{\circ} \mathrm{F}$ and the peak temperature occurs at $3.75 \mathrm{ft}$ above the tank floor. As the cooling air flow rate is reduced, the peak sludge temperature will increase and the peak temperature location will cone closer to the tank bottom, and the tank bottom will ultimately reach an adiabatic condition. 
$W H C-S D-W M-E R-534$

Rev. 0

\section{ay263d3}

Wed Jan 3 12:32:26 1996

GOTH Version 3.4 - April 1991

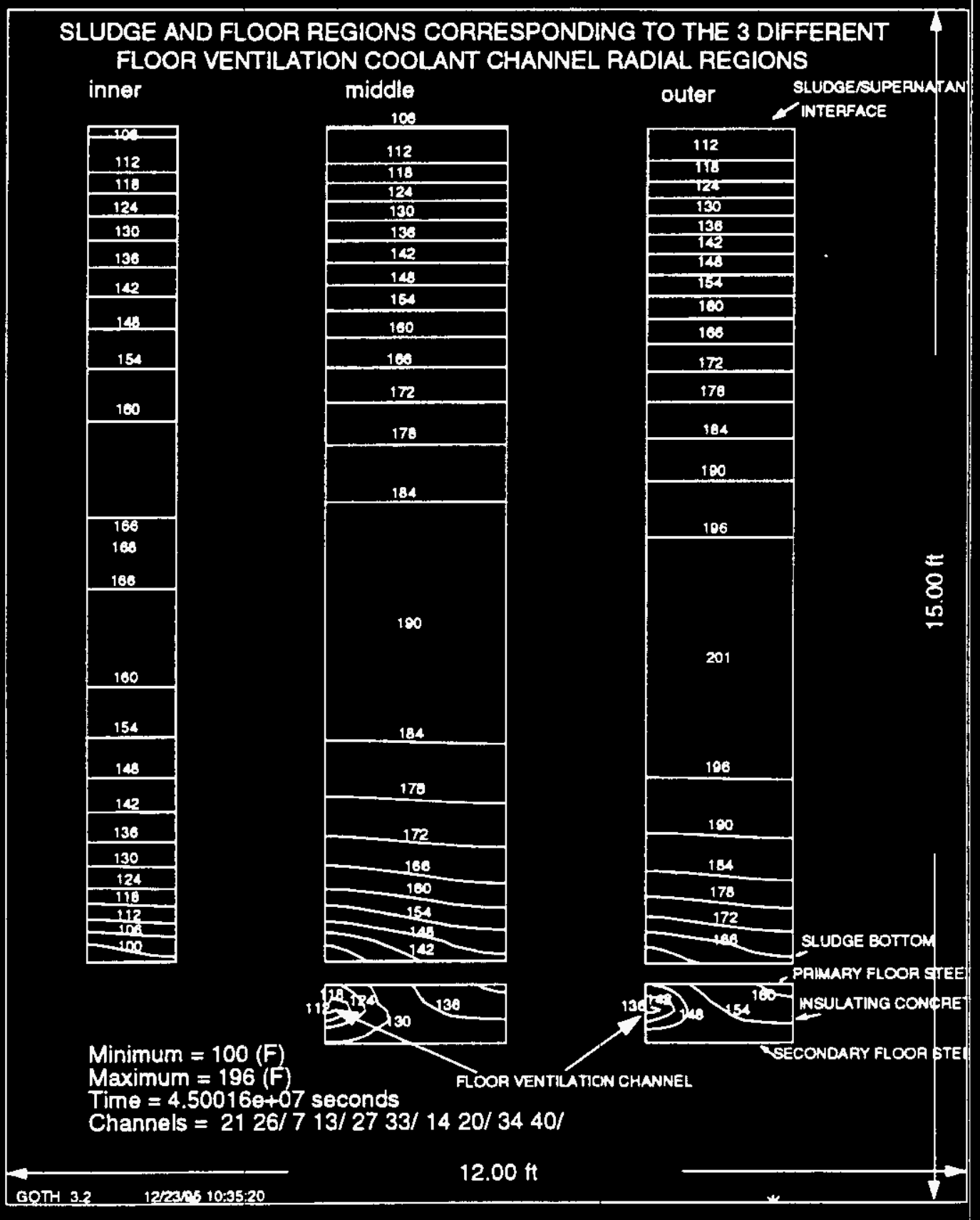

Figure 5.15 Three Region Sludge and Floor Temperature Contours--2000 CFM Floor Ventilation Flow, Fluff Factor 2.0 
WHC-SD-WM-ER- 534

Rev. 0

ay263d3

Sun Dec 24 10:25:07 1995

GOTH Version 3.4 - Apri 1991

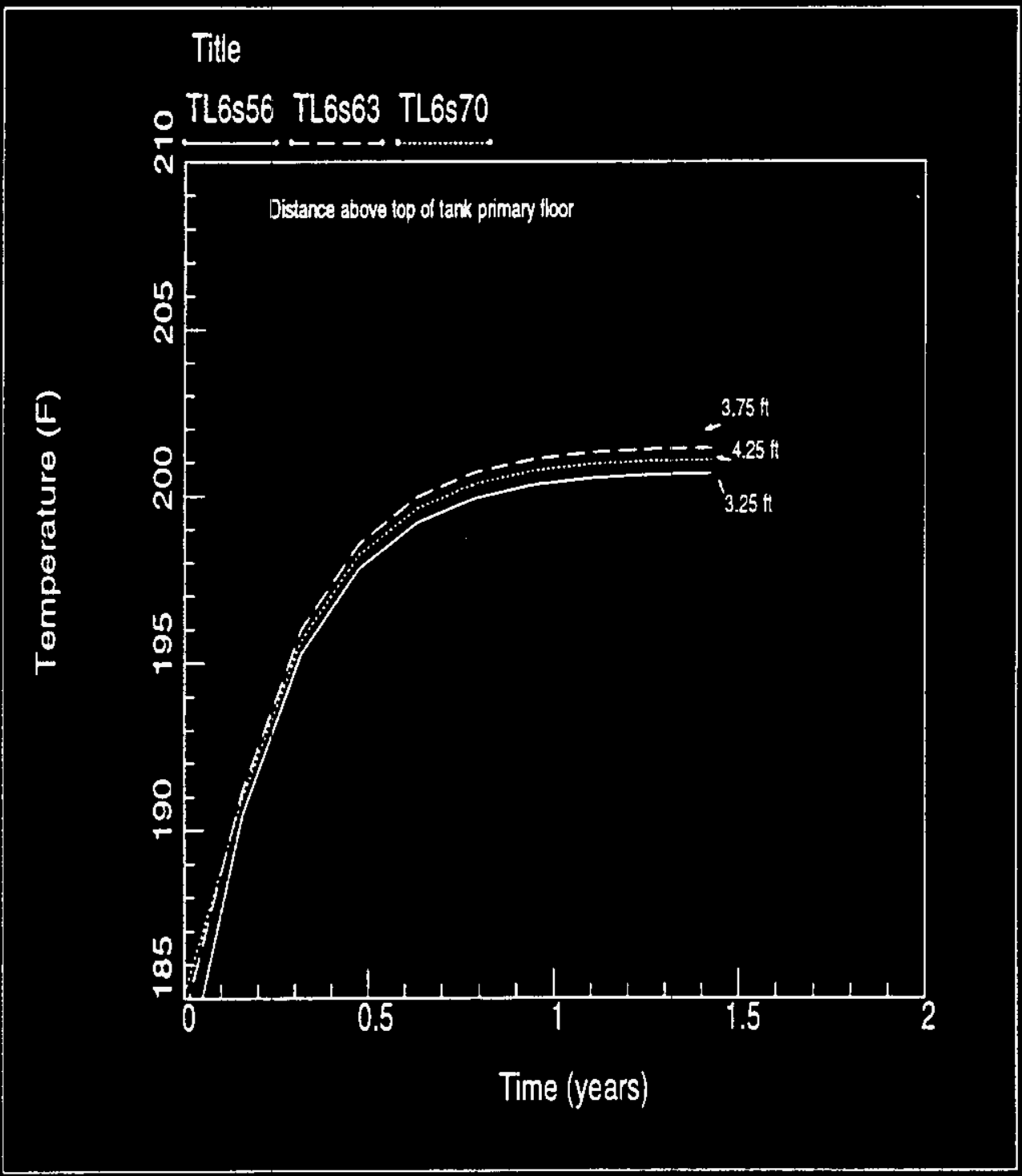

Figure 5.16 Temperatures at 3 Locations Near Hottest Sludge Region in Outer Region --2000 CFM Floor Ventilation Flow, Fluff Factor 2.0 
WHC-SD-WM-ER -534

Rev. 0

ay26303

Sun Dec 24 10:29:58 1995

GOTH Version 3.4 - April 1991



Figure 5.17 Air Outlet Temperatures at the 3 Different Floor Ventilation Regions - -2000 CFM Floor Ventilation Flow, Fluff Factor 2.0 


$$
\begin{gathered}
\text { WHC-SD-WM-ER- } 534 \\
\text { ReV. } 0
\end{gathered}
$$

5.3.2.3. 3000 CFM Flow with Annual Meteorological Conditions

Monthly averaged annual meteorological conditions will result in greater yearly average cooling of the tank waste than the constant temperature of $70^{\circ} \mathrm{F}$ and $50 \%$ relative humidity conditions considered for average summer conditions. However, it was not clear what the effect of annual cyclic meteorological conditions would have on the maximum sludge temperature during or following the summer season. A simulation using a monthly averaged annual meteorological cycle conditions for the inlet air to both the primary and secondary ventilation systems was developed. The predicted thermal response of the tank contents is shown in Figure 5.18 for an assumed flow rate of $3000 \mathrm{CFM}$. The maximum calculated temperature is $183{ }^{\circ} \mathrm{F}$ and this occurs in late sumer/early fall. Thermal inertia effects coupled with cold winter conditions therefore reduce the maximum temperature compared to the $190^{\circ} \mathrm{F}$ calculated with the steady state average summer conditions. 
WHC-SD-WM-ER- 534

Rev. 0

\section{ay268d7 \\ Tue Jan 2 14:30:49 1996 \\ GOTH Version 3.4 - April 1991}

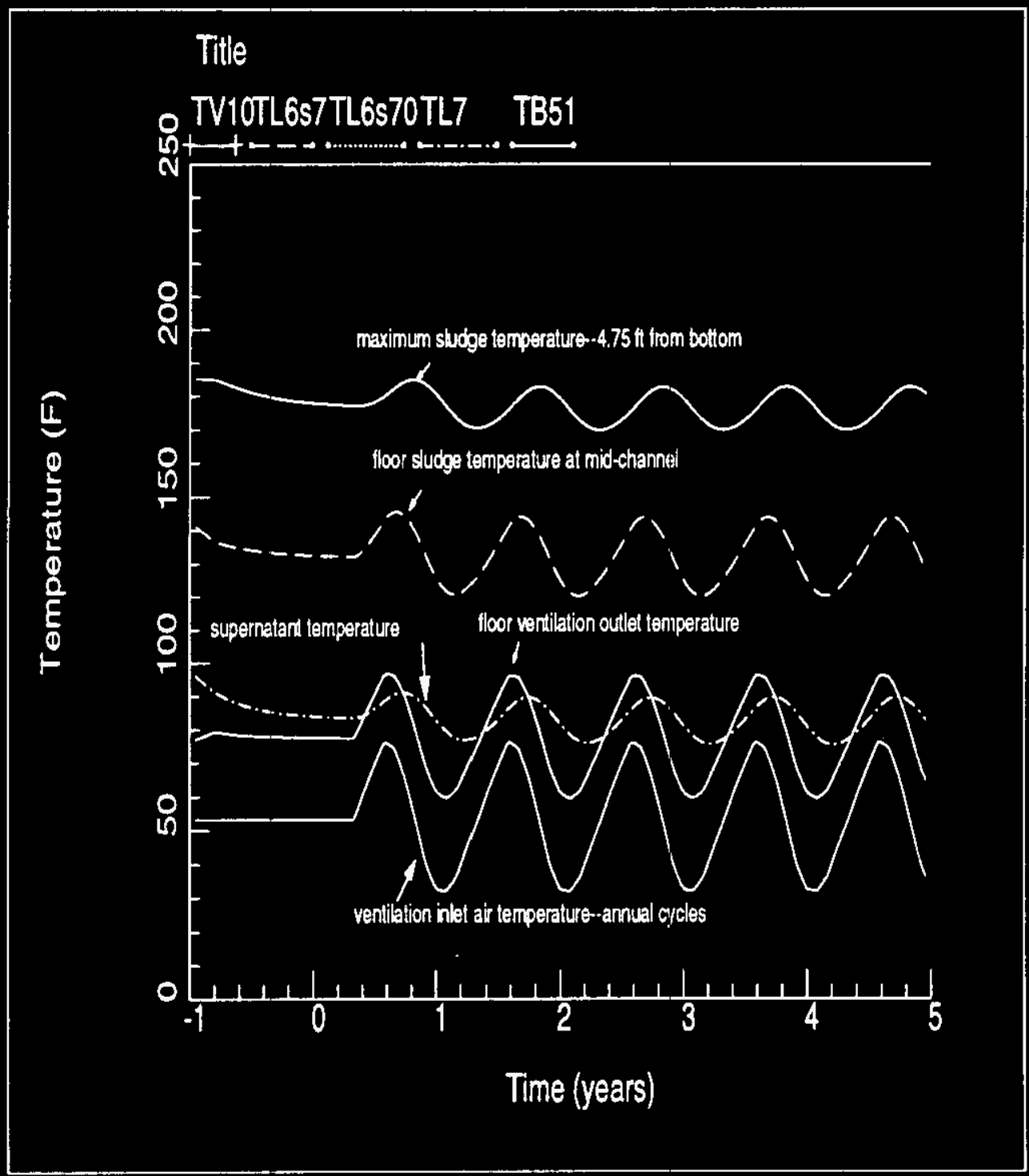

Figure 5.18 Annual Meteorological Cycle--Tank Contents Temperatures --3000 CFM Floor Ventilation Flow, Fluff Factor 2.0 


$$
\text { WHC-SD-WM-ER }-534
$$

Rev. 0

5.3.2.4. 3000 CFM Flow with 2 Weeks of Abnormally Hot Summer Conditions

The above simulation does not consider the impact of unusually hot summer periods upon the thermal hydraulic behavior of Tank AY-102 after the transfer of C-106. Figure 5.19 provides tank contents' temperatures resulting from two weeks of continuous $105^{\circ} \mathrm{F}$ weather superimposed upon the annual meteorological cycle based upon monthly average temperatures. Peak sludge temperature increases by about $2{ }^{\circ} \mathrm{F}$ to $185^{\circ} \mathrm{F}$. Although Hanford temperatures frequently exceed $105^{\circ} \mathrm{F}$, they do not typically remain continuously at or above $105^{\circ} \mathrm{F}$ both day and night for two weeks at a time. Feriods of unusually hot weather should therefore not result in significantly higher peak sludge temperatures than that calculated for the annual cycle based on monthly average temperatures.

Although the peak sludge temperature changes by only $2{ }^{\circ} \mathrm{F}$ due to the unusually hot 2 week weather period, larger changes were calculated for sludge near the tank floor which is more strongly affected by inlet air temperature changes than the maximum temperature region, $4.75 \mathrm{ft}$ above the tank bottom. Sludge temperature immediately above a floor cooling charnel near the center of the tank was calculated to increase an additional $20{ }^{\circ} \mathrm{F}$ above that calculated for the annual cycle based on monthly average temperatures. Temperatures near the top of the sludge layer increased by only about $1.5^{\circ} \mathrm{F}$ due to the large thermal inertia of the supernatant, and the increase in evaporation rate which somewhat compensates for the increased air inlet temperature. 
WHC-SD-WM-ER-534

Rev. 0

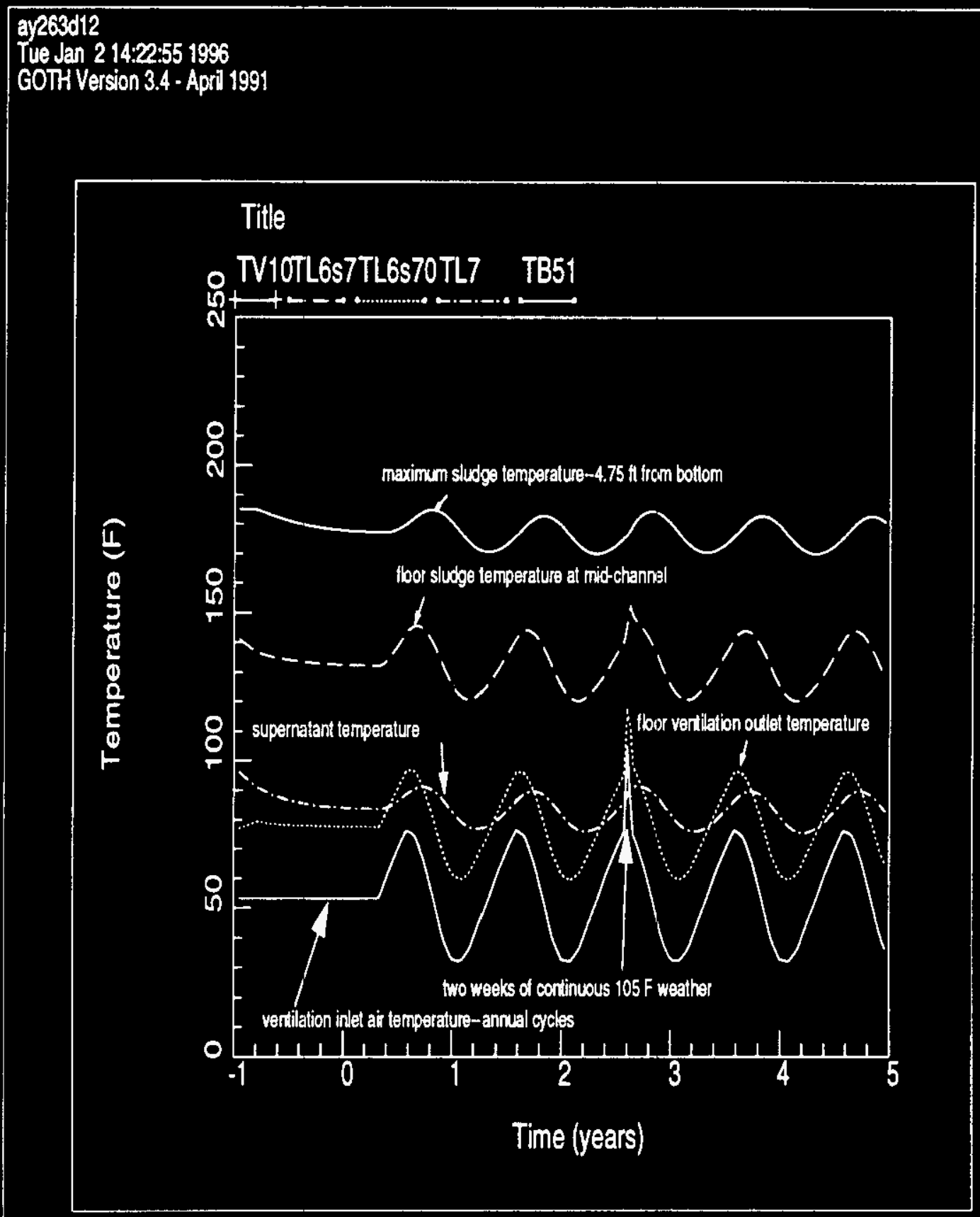

Figure 5.19 Annual Meteorological Cycle Plus 2 Weeks of Continuous $105^{\circ} \mathrm{F}$ Weather--Tank Contents Temperatures --3000 CFM Floor Ventilation Flow, Fluff Factor 2.0 
WHC-SD-WM-ER-534

Rev. 0

\subsubsection{Loss of Ventilation Systems}

Although safe operating conditions for the Tank AY-102 after sludge transfer have been identified with ventilation systems operating normally in this analysis, none of these operations are acceptable under continuous outage of either the primary, or secondary, or combined primary and secondary systems. The ventilation system outage simulations were conducted to define allowable outage time periods and the results are described in this section.

The 2-D GOTH model was utilized to evaluate the effect of loss of ventilation systems for the Tank AY-102 with consolidated sludge. Four different simulations were performed for loss of ventilation. The first and second simulations model combined primary and secondary ventilation outages for 58 days starting with 3000 and 2000 CFM secondary ventilation respectively. The third and fourth simulations assume a 58 day secondary ventilation outage and a 58 day primary ventilation outage respectively, both with a 2000 CFM initial secondary flow rate.

5.3.3.1. Combined Ventilation systerns Outage- 3000 CFM Flow Operation

This simulation assumes a secondary floor ventilation flow of 3000 CFM before and following the outage. The

temperature response of the hottest sludge location during a combined primary and secondary ventilation outage lasting 58 days and following restart is illustrated in Figure 5.20. The maximurn temperature reached is $227^{\circ} \mathrm{F}$ and occurs at or near tank bottom. This is below the water saturation temperature for a $30 \mathrm{ft}$ waste level, however, it does not provide $30^{\circ} \mathrm{F}$ margin required by the operational safety requirements(OSR) criteria. In order to maintain the peak sludge temperature with $30^{\circ} \mathrm{F}$ margin requirement, the outage must be limited to less than 48 days. 
WHC-SD-WM-ER- 534

Rev. 0

ar263011

Wed Jan 3 13:19:28 1996

GOTHVersion 3.4-Apri 1991

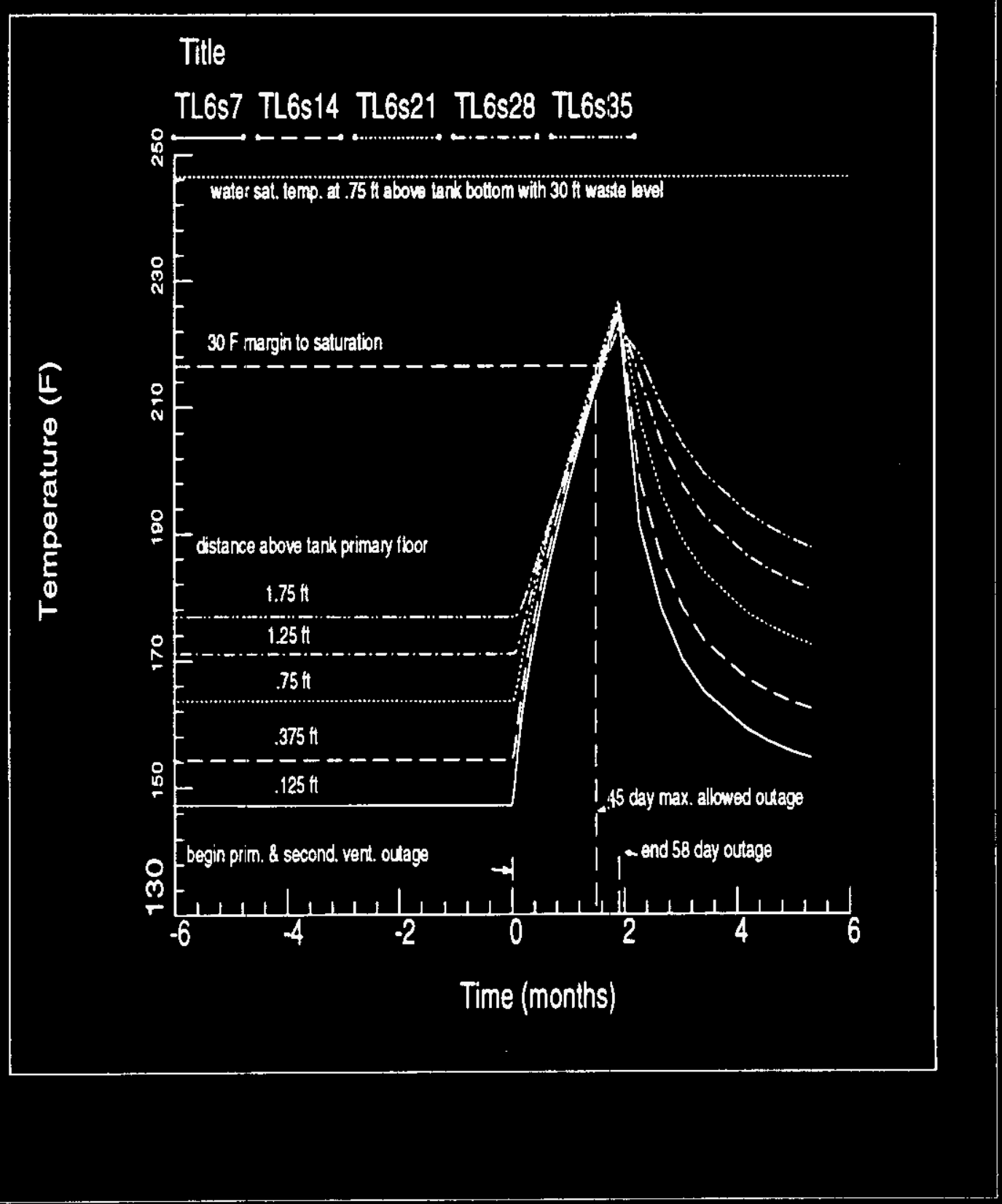

Figure 5.20 Temperatures Near Hottest Axial Location in Outer Region--3000 CFM Floor Ventilation Flow, Fluff Factor 2.0,--Combined Ventilation Outage 


$$
\begin{aligned}
& \text { WHC-SD-WM-ER-- } 534 \\
& \text { ReV. } 0
\end{aligned}
$$

For reduced waste levels, and therefore lower hydrostatic pressure and saturation temperature in the sludge, the allowable outage time must be reduced below 45 days. In the extreme conservative case if we assume the saturation temperature at tank bottom corresponds to water at atmospheric pressure, $212^{\circ} \mathrm{F}$, then no outage time is allowed if the $30^{\circ} \mathrm{F}$ margin must be maintained since the sludge would not be allowed to go above $182^{\circ} \mathrm{F}$. Neither would normal operation be acceptable since the waste is calculated to be above this limit under normal operation $\left(190^{\circ} \mathrm{F}\right)$. Under these circumstances current operation in tanks AZ-101, AZ-102, and C-106 would be unacceptable since they typically operate with sludge at or above $182^{\circ} \mathrm{F}$. Therefore, the high waste levels must be maintained to keep the peak sludge temperatures within operating limits.

5.3.3.2. 2000 CFM floor Ventilation and 58 Day Combined Ventilation Systems Outage

If the secondary Eloor ventilation flow rate is reduced to 2000 CFM, in comparison to 3000 CFM, the normal sludge operating temperatures increase, and as a result during a ventilation outage the sludge will rise to a higher temperature after a given outage time period. This can be observed by comparing Figure 5.20 for 3000 CFM to the following Figure 5.21 for 2000 CFM. For 2000 CFM, the maximum temperature reached after a 58 day outage is 240 ${ }^{\circ} \mathrm{F}$, or $13^{\circ} \mathrm{F}$ higher than the $3000 \mathrm{CFM}$ case. In this case the outage must be limited to 30 days assuming a waste level of $30 \mathrm{ft}$ to keep the peak sludge temperatures within operating requirements. For lower levels of waste, the outage time must be reduced further. 


\section{WHC-SD-WM-ER- 534 \\ Rev. 0}

\section{a)263dpso \\ Wed Jan 3 13:27:09 1996 \\ GOTH Version 3.4 - April 1991}

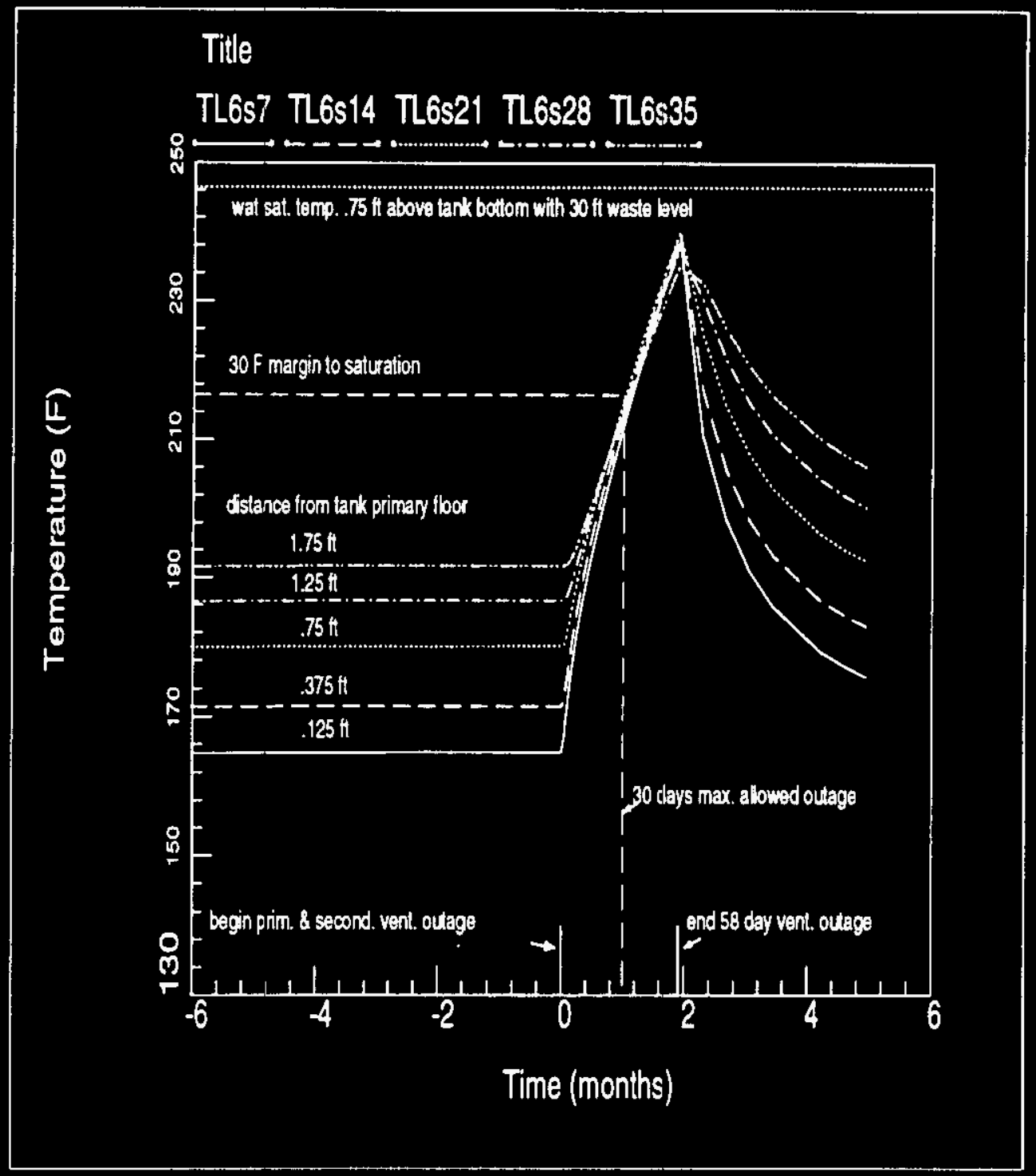

Figure 5.21 Temperatures Near Hottest Axial Location in Outer Region--2000 CFM Floor Ventilation Flow, Fluff Factor 2.0--Combined Ventilation Outage 
WHC-SD-WM-ER -534

Rev. 0

Thermal response of the tank dome gas and supernatant is illustrated in Figure 5.22. As the results show the temperature increase of supernatant is relatively small in comparison with the increase of sludge peak temperature. The temperature increase is supressed due the large thermal inertia of the supernatant and the relative rapid thermal transport due to convection within the supernatant. 
WHC-SD-WM-ER -534

Rev. 0

ay263dpso

Fri Dec 22 15:56:47 1995

GOTH Version 3.4-April 1991



Figure 5.22 Air Dome Gas and Supernatant Temperature

--2000 CFM Floor Ventilation Flow, Fluff Factor 2.0-Combined Ventilation Outage 
WHC-SD-WM-ER- 534

Rev. 0

5.3.3.3. 2000 CFM floor Ventilation and 58 Day Secondary Ventilation Outage

The thermal response of the sludge at the bottom of the tank during a secondary ventilation outage is essentially the same as that for a combined outage of both primary and secondary ventilation systems as can be observed by comparing Figure 5.21 with Figure 5.23. The thermal response of the dome gas temperature and supernatant is small since the primary coolant system is maintained operational in this case. This is illustrated in Figure 5.24 for comparison with Figure 5.22. The supernatant and dome gas decrease in temperature during the outage. Prior to the outage the hot air leaving the floor acts to heat the supernatant and dome gas as it rises in the annulus. When the outage occurs this heating process is discontinued, and the supernatant and dome gas decrease in temperature, in spite of the increasing temperatures near the tank bottom. When the secondary ventilation resumes operation, the air leaving the floor is now much hotter than the normal operation. This acts to heat the supernatant and dome gas above normal operating temperature, as do delayed thermal effects from the sludge caused by the outage. In summary the supernatant and dome gas decrease in temperature below normal operating temperature during the outage and increase in temperature above normal operating temperature following the outage with the resumption of secondary ventilation system operation. 
WHC-SD-WM-ER- 534

Rev. 0

\section{ay263dso}

Wed Jan 3 13:38:53 1996

GOTH Version 3.4 - Apri 1991

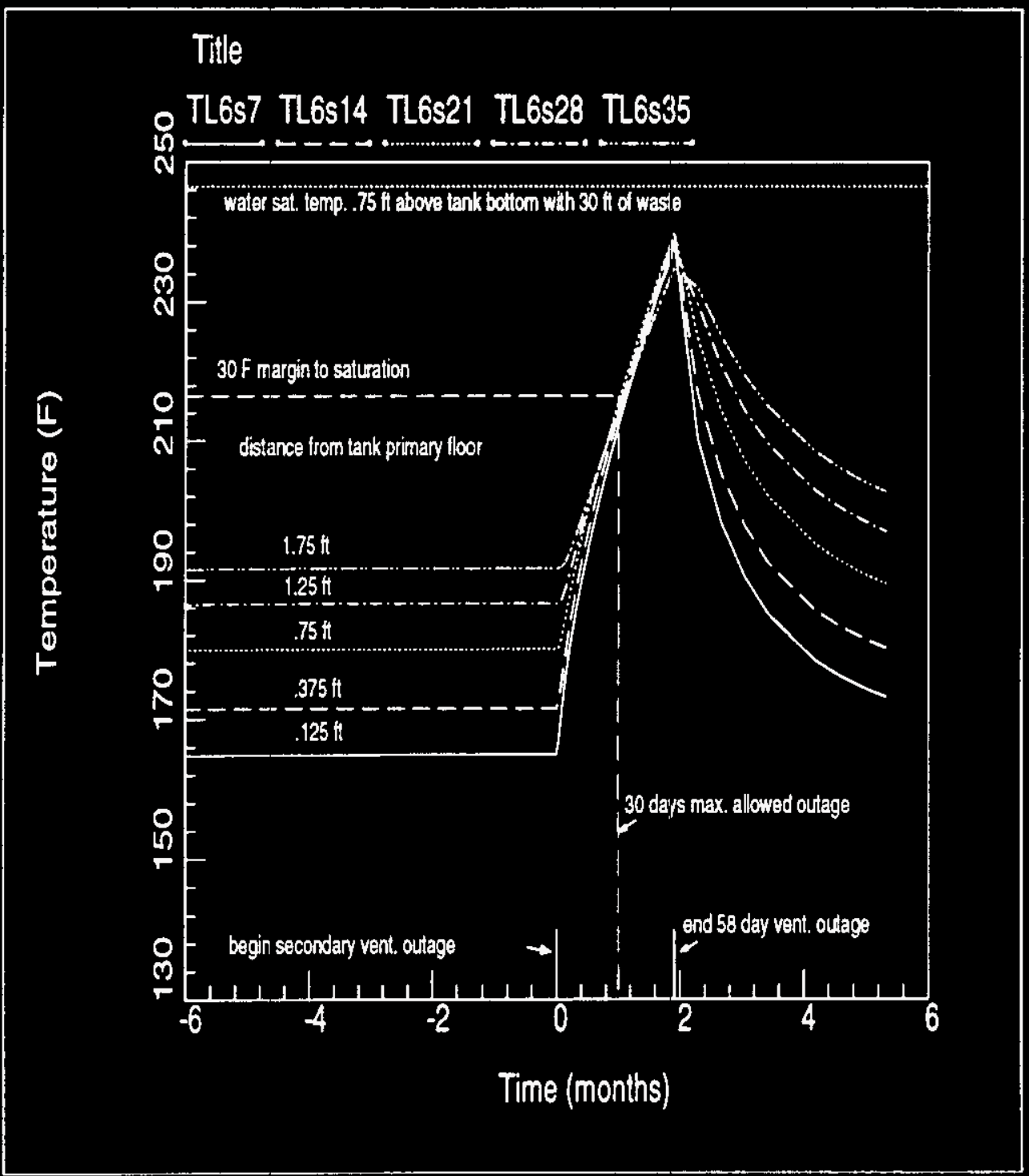

Figure 5.23 Temperatures Near Hottest Axial Location in Outer Region--2000 CFM Floor Ventilation Flow, Fluff Factor 2.0--Secondary Ventilation Outage 
WHC-SD-WM-ER-534

Rev. 0

\section{ayzo3dso}

Wed Dec 27 14:12:16 1995

GOTH Version 3.4 - Apri 1991

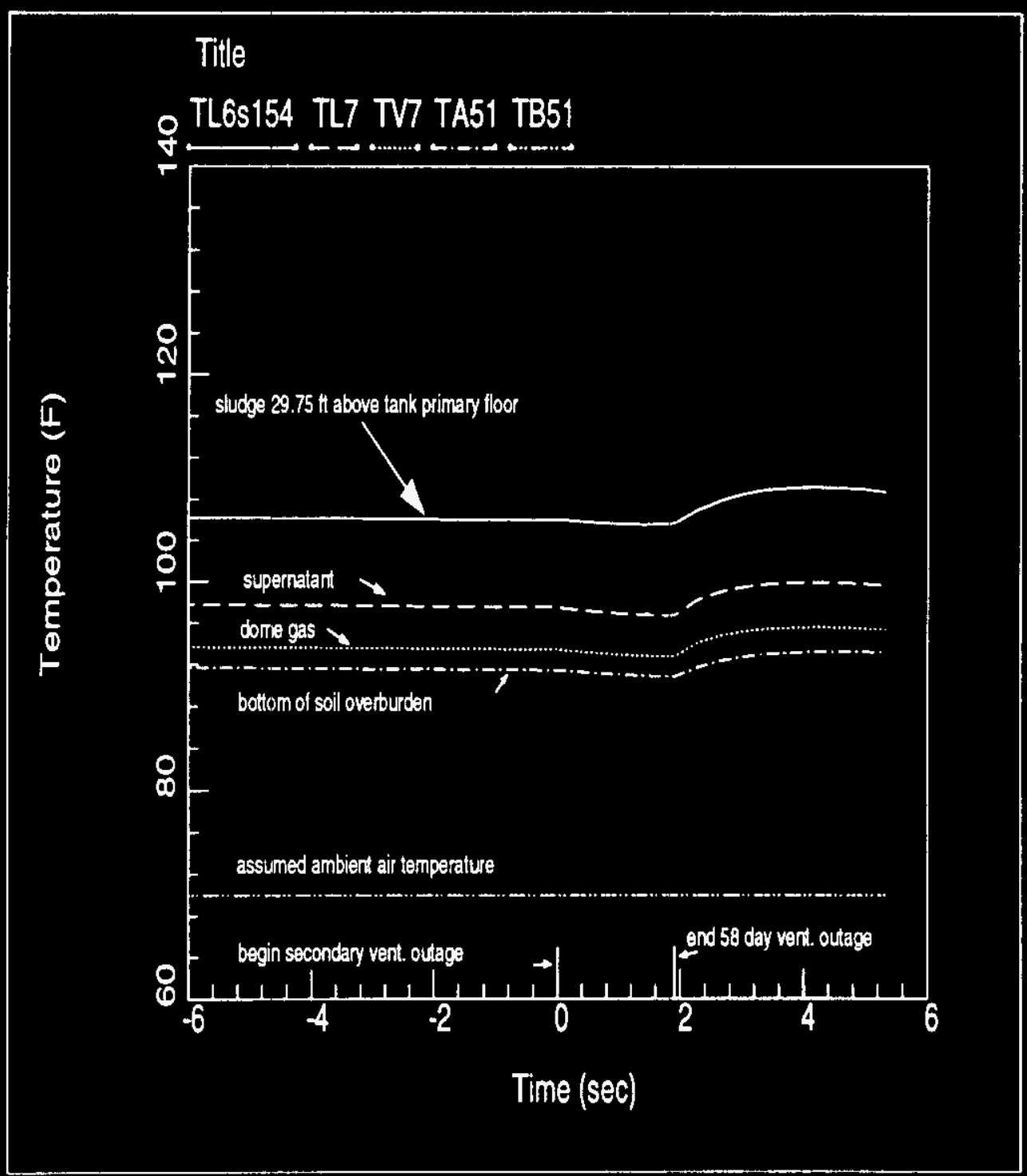

Figure 5.24 Air Dome Gas and Supernatant Temperature

--2000 CFM Floor Ventilation Flow, Fluff Factor

2.0--Secondary Ventilation Outage 


$$
\begin{gathered}
\text { WHC-SD-WM-ER- } 534 \\
\text { ReV. } 0
\end{gathered}
$$

\subsubsection{4. $2000 \mathrm{CFM}$ floor Ventilation and 58 Day Primary Ventilation Outage}

The thermal response of the consolidated sludge during a primary ventilation outage of 58 days is small. Increase in sludge temperature at the maximum temperature location is $2.5^{\circ} \mathrm{F}$ as shown in Figure 5.25. Increases in the dome gas and supernatant temperatures are shown in Figure 5.26 and can be compared to Figures 5.22 and 5.24 . Assuming the normal operating waste temperatures are well below operating temperature criteria based on saturation temperature, a primary ventilation system outage could be tolerated for an extended period of time beyond 58 days if the secondary ventilation system is operational. However, this should not be allowed as it exacerbates the sludge heatup problem if and when a secondary ventilation system outage occurs. 
WHC-SD-WM-ER- 534

Rev. O

ay263dpo
Wed Dec 27 14:14:38 1995
GOTH Version 3.4 - Apri 1991

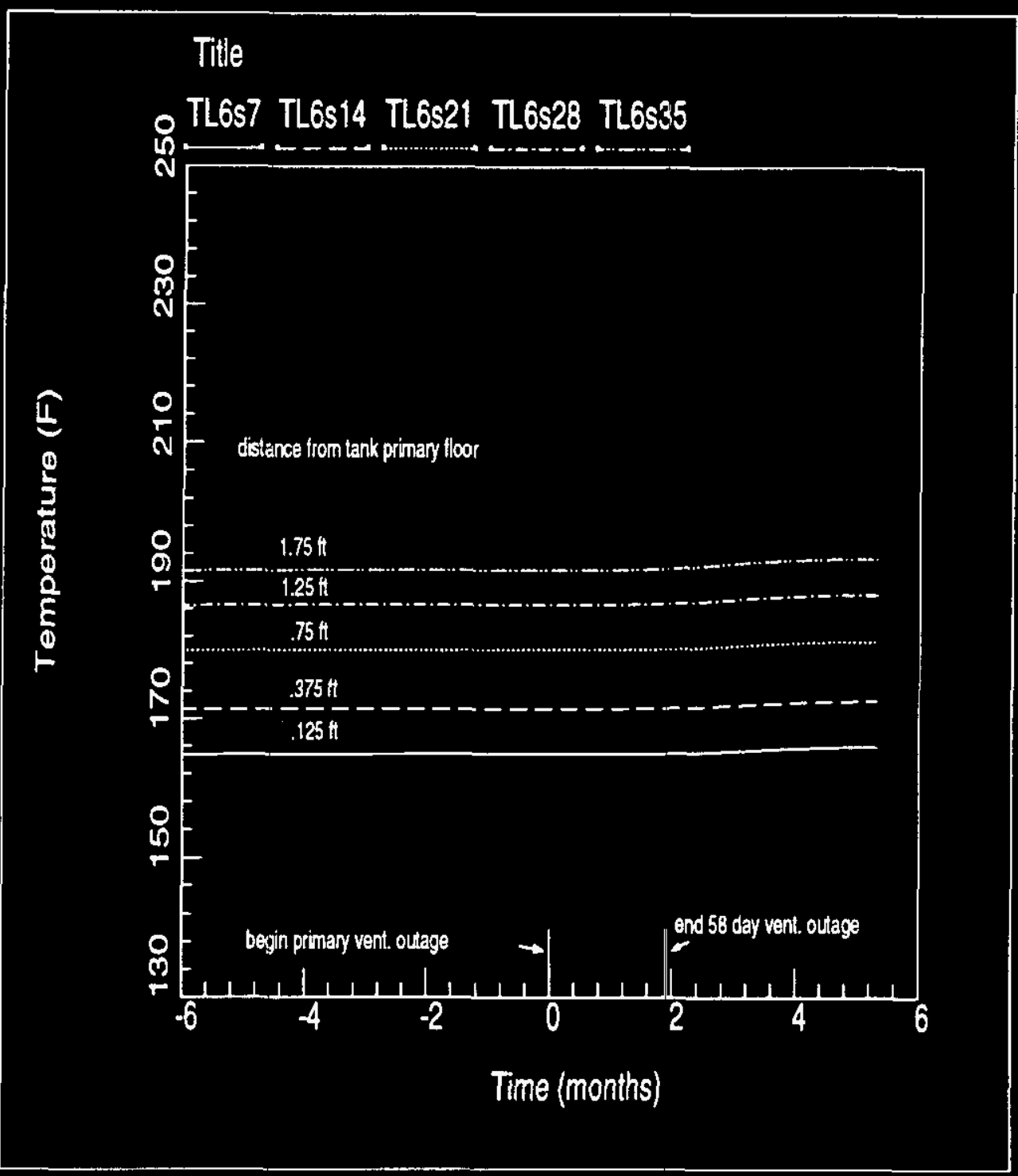

Figure 5.25 Temperatures Near Hottest Axial Location in Outer Region--2000 CFM Floor Ventilation Flow, Fluff Factor 2.0--Primary Ventilation Outage 
WHC-SD-WM-ER- 534

Rev. 0

\section{a)263dpo}

Wed Dec 27 14:16:28 1995

GOTH Version 3.4 - April 1991

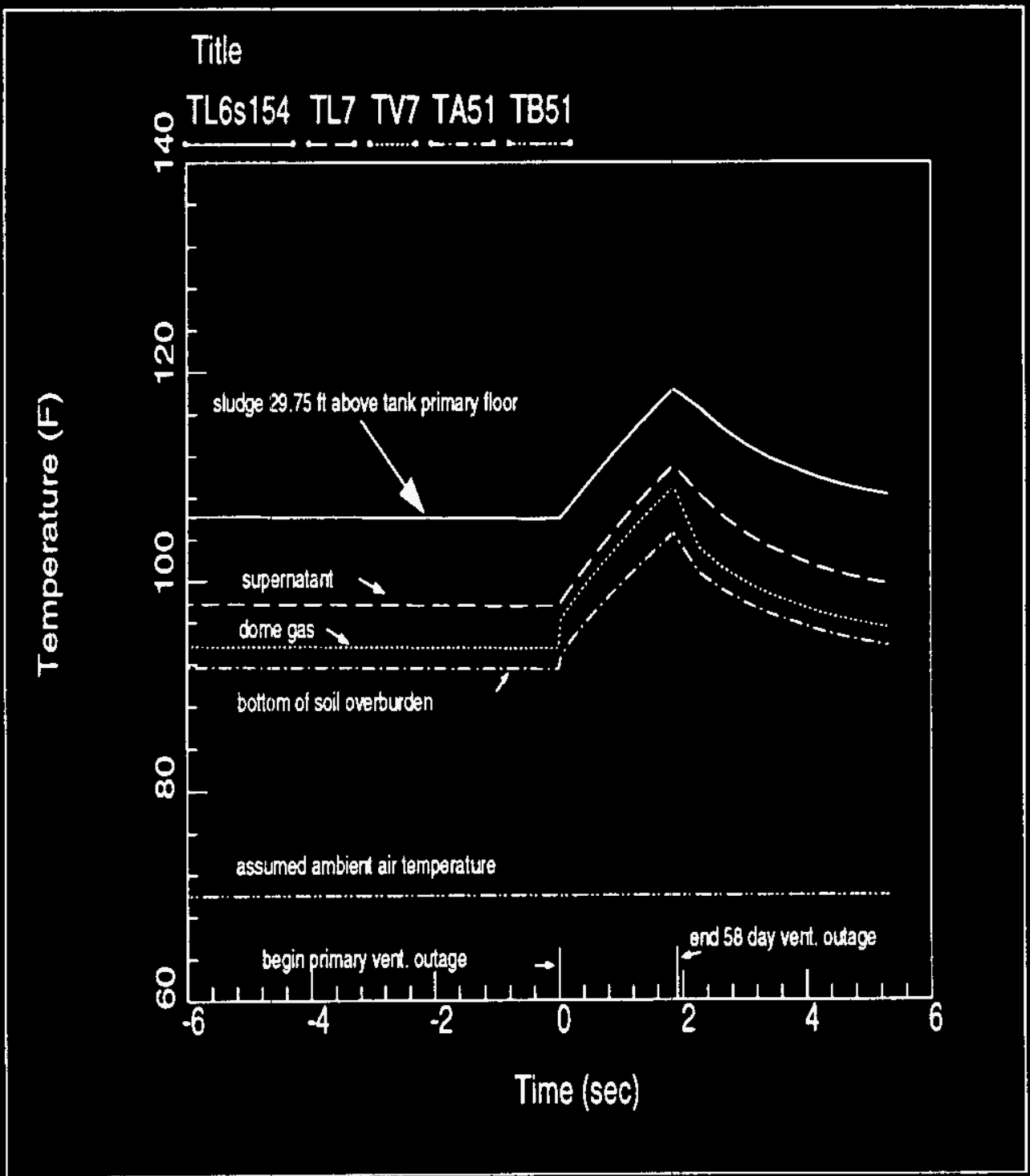

Figure 5.26 Air Dome Gas and Supernatant Temperature

--2000 CFM Floor Ventilation Flow, Fluff Factor

2.0--Primary Ventilation Outage 


$$
\begin{gathered}
\text { WHC-SD-WM-ER-534 } \\
\text { ReV . } 0
\end{gathered}
$$

\subsection{Summary of Results}

Table 5.1 below summarizes the GOTH 1-D and 3 Region 2-D simulations conducted for the Tank AY-102, and the parameters assumed. Listed in the table are the maximum sludge temperatures calculated for each simulation, the axial location of the maximum temperature, and the margin relative to saturation temperature.

\begin{tabular}{|c|c|c|c|c|c|c|}
\hline $\begin{array}{c}\text { Simulation } \\
\text { Purpose }\end{array}$ & $\begin{array}{l}\text { Simulation } \\
\text { Discriptor }\end{array}$ & $\begin{array}{c}\text { Reference } \\
\text { Tank } \\
\text { Number }\end{array}$ & $\begin{array}{c}\text { yodel } \\
\text { Type }\end{array}$ & $\begin{array}{c}\text { Refererice } \\
\text { Tank } \\
\text { Assumed } \\
\text { Heat } \\
\text { Load } \\
\\
5\end{array}$ & $\begin{array}{c}\text { Referenct } \\
\text { Tank. } \\
\text { Assumed } \\
\text { Sludge } \\
\text { Thickries: }\end{array}$ & $\begin{array}{c}\text { Assumed } \\
\text { C- } 106 \\
\text { Currerit } \\
\text { Heat } \\
\text { Luad } \\
\\
7\end{array}$ \\
\hline & & & & $\frac{\mathrm{btu}}{\mathrm{hr}}$ & ft & $\frac{\mathrm{btu}}{\mathrm{hr}}$ \\
\hline $\begin{array}{l}\text { Est imate heat load/comp. to data } \\
\text { Est imate sludge temp after transfer } \\
\text { Est imate sludge temp after transfer } \\
\text { Estimate sludge temp after transfer } \\
\text { Est imate sludge temp after transfer } \\
\text { Estimate sludge temp after transfer } \\
\text { Estimate sludge temp after transfer } \\
\text { Estimate sludge temp after transfer } \\
\text { Secondary \& Prim. vent. Outage } \\
\text { Secondary \& Prim. vent. outage } \\
\text { Secondary vent. outage } \\
\text { Primary vent. outage }\end{array}$ & $\begin{array}{l}\text { ay } 102 \mathrm{r} 4 \\
\text { ay } 1216 \mathrm{r} 3 \\
\text { ay } 1216 \mathrm{r} 2 \mathrm{x} \\
\text { ay } 1216 \mathrm{r} 3 \mathrm{x} \\
\text { ay } 263 \mathrm{~d} 4 \\
\text { ay } 263 \mathrm{~d} 3 \\
\text { ay263d7 } \\
\text { ay } 263 \mathrm{~d} 12 \\
\text { ay } 263 \mathrm{~d} 11 \\
\text { ay263dpso } \\
\text { ay263dso } \\
\text { ay263dpo }\end{array}$ & $\begin{array}{l}\text { AY }-102 \\
\text { AY }-102 \\
\text { AY }-102 \\
\text { AY }-102 \\
\text { AY }-102 \\
\text { AY }-102 \\
\text { AY }-102 \\
\text { AY }-102 \\
\text { AY }-102 \\
\text { AY }-102 \\
\text { AY }-102 \\
\text { AY }-102\end{array}$ & $\begin{array}{l}1-D \\
1-D \\
1-D \\
1-D \\
2-D \\
2-D \\
2-D \\
2-D \\
2-D \\
2-D \\
2-D \\
2-D\end{array}$ & $\begin{array}{l}33000 \cdot 0 \\
33000 \cdot 0 \\
33000 \cdot 0 \\
33000 \cdot 0 \\
33000 \cdot 0 \\
33000 \cdot 0 \\
33000 \cdot 0 \\
33000 \cdot 0 \\
33000 \cdot 0 \\
33000 \cdot 0 \\
33000 \cdot 0 \\
33000 \cdot 0\end{array}$ & $\begin{array}{l}1.0 \\
1.51 \\
1.01 \\
1.0 \\
1.0 \\
1.0 \\
1.4 \\
1.0 \\
1.6 \\
1.0 \\
1.0 \\
1.0\end{array}$ & 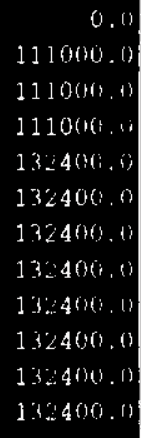 \\
\hline
\end{tabular}

Table 5.1 Summary of GOTH Model Simulation Cases 


\section{WHC-SD-WM-ER-534}

Rev. 0

\begin{tabular}{|c|c|c|c|c|c|c|c|c|c|}
\hline $\begin{array}{c}\text { C-106 } \\
\text { sludge } \\
\text { Transfer }\end{array}$ & $\begin{array}{l}\text { C-106 } \\
\text { sludge } \\
\text { Fluff } \\
\text { Factor } \\
\text { after } \\
\text { transfer } \\
\text { to } \\
\text { AY-102 } \\
9\end{array}$ & $\begin{array}{l}\text { Total } \\
\text { Sludge } \\
\text { Thickness } \\
\text { After } \\
\text { Transfer }\end{array}$ & $\begin{array}{l}\text { Supernatant } \\
\text { Thickness } \\
\text { After } \\
\text { Transfer }\end{array}$ & $\begin{array}{l}\text { Reference } \\
\text { Tank } \\
\text { sludge } \\
\text { Assumed } \\
\text { Thermal } \\
\text { Conductivity }\end{array}$ & $\begin{array}{l}\text { Transferred } \\
\text { Sludge } \\
\text { Assumed } \\
\text { Thermal } \\
\text { Conduztivity } \\
y \quad \text { after } \\
\text { transfer } \\
13\end{array}$ & $\begin{array}{l}\text { Reference } \\
\text { Tank } \\
\text { Total } \\
\text { Heat } \\
\text { Load } \\
\text { After } \\
\text { Transfer }\end{array}$ & $\begin{array}{r}\text { E } \\
\text { vor: } \\
\text { : }\end{array}$ & $\begin{array}{l}\text { Erim } \\
\text { rutil } \\
\text { Sys } \\
\text { Tyl }\end{array}$ & $\begin{array}{l}\text { gäry } \\
\text { lation } \\
\text { telr } \\
\text { nis }\end{array}$ \\
\hline \multirow{2}{*}{ ft } & & \multirow{2}{*}{ ft } & \multirow{2}{*}{ ft } & btu & bt: $u$ & btu & & & \\
\hline & & & & $h r-\mathrm{ft}-\mathrm{R}$ & $h r-t t-R$ & hr & & & \\
\hline 0.00 & 0.0 & 1.0 & 23.5 & 0.35 & 0.0009 & $33000 . d$ & Curie & ent & \\
\hline 4.50 & 1.0 & 5.5 & 24.5 & 0.35 & 0.5336 & $103000 . d$ & w-30 & & \\
\hline 4.50 & 1.0 & 5.5 & 24.5 & 0.35 & 0.5336 & 103000. & $W-30$ & & \\
\hline 6.00 & 1.0 & 7.0 & 23.0 & 0.35 & $0.533 \mathrm{e}$ & $143000 . \phi$ & $W-30$ & & \\
\hline 4.75 & 2.0 & 10.5 & 19.5 & 0.35 & $0.433 \%$ & $125400 . \phi$ & $W-30$ & or & aurrer \\
\hline 4.75 & 2.0 & 10.5 & 19.5 & 0.35 & 0.4338 & $125400 . \phi$ & $W-30$ & or & Currert \\
\hline 4.75 & 2.0 & 10.5 & 19.5 & 0.35 & $0.433 \%$ & 125400.0 & W. 30) & or & $\operatorname{cur} r$ telt \\
\hline 4.75 & 2.0 & 10.5 & 19.5 & 0.35 & $0.433 \%$ & $125400 . d$ & $w-30$ & $o r$ & surrert \\
\hline 4.75 & 2.0 & 10.5 & 19.5 & 0.35 & $0.433 \mathrm{~g}$ & 125400. & $W-30$ & or & currert \\
\hline 4.75 & 2.0 & 10.5 & 19.5 & 0.35 & $0.433 \%$ & 125400. & $W-30$ & $\partial r$ & currert \\
\hline 4.75 & 2.0 & 10.5 & 19.5 & 0.35 & 0.4338 & 125400. & $W-3(1$ & $o r$ & $\operatorname{curres}$ \\
\hline 4.75 & 2.0 & 10.5 & 19.5 & 0.35 & 0.4339 & 125400.9 & $W-30$ & $o r$ & $\sin r+\infty 1$ \\
\hline
\end{tabular}


WHC-SD-WM-ER-534

Rey. 0

\begin{tabular}{|c|c|c|c|c|c|c|c|}
\hline \multirow[t]{2}{*}{$\begin{array}{l}\text { Primary } \\
\text { System } \\
\text { operating } \\
\text { Mode }\end{array}$} & \multirow{2}{*}{$\begin{array}{l}\text { Primary } \\
\text { Normal } \\
\text { Inlet } \\
\text { Flow } \\
\\
17\end{array}$} & $\begin{array}{l}\text { Primary } \\
\text { Recirc } \\
\text { Flow }\end{array}$ & \multicolumn{2}{|c|}{$\begin{array}{c}\text { Secondarysecondary } \\
\text { System Vent } \\
\text { Type Flow to } \\
\\
\text { Tank } \\
\text { Bottom }\end{array}$} & $\begin{array}{c}\text { Meteorological } \\
\text { Conditions } \\
\text { Assumed }\end{array}$ & $\begin{array}{l}\text { Maximum } \\
\text { Sludge } \\
\text { Temperatur }\end{array}$ & $\begin{array}{l}\text { Location } \\
\text { of Max. } \\
\text { Sjurigh } \\
\text { Tempelatul } \\
\text { Abrive } \\
\text { Tank } \\
\text { Bott onll }\end{array}$ \\
\hline & & 18 & 19 & 20 & 21 & 22 & $\therefore$ \\
\hline & $\mathrm{ft}^{3}$ & $\mathrm{ft}^{3}$ & & $\mathrm{ft}^{3}$ & & $F$ & ft \\
\hline & $\min$ & $\min$ & & min & & & \\
\hline $\begin{array}{l}\text { once thru } \\
\text { recirc } \\
\text { recirc } \\
\text { recirc } \\
\text { once thru } \\
\text { once thru } \\
\text { once thru } \\
\text { once thru } \\
\text { once thru } \\
\text { once thru } \\
\text { once thru } \\
\text { once thru }\end{array}$ & $\begin{array}{l}600 \\
100 \\
100 \\
100 \\
600 \\
600 \\
600 \\
600 \\
600 \\
600 \\
600 \\
600\end{array}$ & $\begin{array}{r}0 \\
400 \\
400 \\
400 \\
0 \\
0 \\
0 \\
0 \\
0 \\
0 \\
0 \\
0\end{array}$ & $\begin{array}{l}\text { Current } \\
\text { Current } \\
\text { current } \\
\text { current } \\
\text { upgraded } \\
\text { upgraded } \\
\text { upgraded } \\
\text { upgraded } \\
\text { upgraded } \\
\text { upgraded } \\
\text { upgraded } \\
\text { upgraded }\end{array}$ & $\begin{array}{r}0 \\
0 \\
500 \\
500 \\
3000 \\
2000 \\
3000 \\
3000 \\
3000 \\
2000 \\
2000 \\
2000\end{array}$ & $\begin{array}{l}\text { MA--annual cycle } \\
\text { MA--annual cycle } \\
\text { MA--annual cycle } \\
\text { MA--annual cycle } \\
\text { average summer } \\
\text { average summer } \\
\text { MA--annual cycle } \\
\text { hot } 2 \text { wks--an. cyc } \\
\text { average sunmer } \\
\text { average sunmer } \\
\text { average summer } \\
\text { average sunmer }\end{array}$ & $\begin{array}{l}86.9 \\
248.9 \\
198.9 \\
240.9 \\
190.9 \\
211.9 \\
183.9 \\
185.9 \\
227.9 \\
240.9 \\
240.9 \\
204.9\end{array}$ & 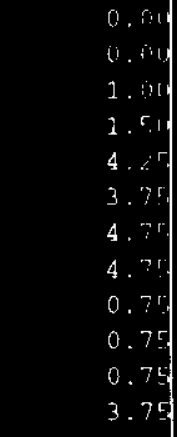 \\
\hline
\end{tabular}


WHC-SD-WM-ER-534

Rev. 0

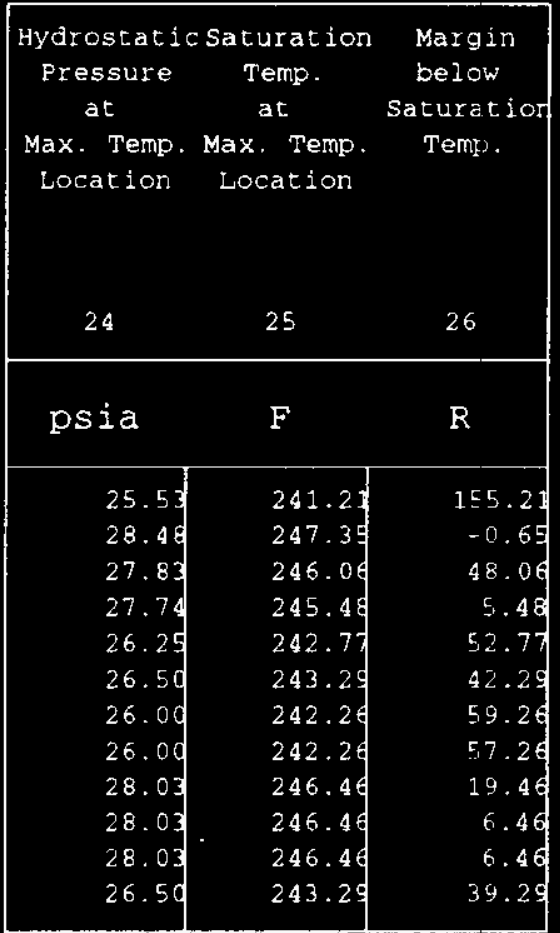

$107 c$. 
WHC-SD-WM-ER- 534
ReV. 0

Preliminary analysis results were documented in a memo dated september 20, 1995 [Sathyanarayana, 1995]. This report includes all the analysis performed. The composite results are summarized below.

1. Following transfer of 4.75 ft of Tank C-106 sludge the GOTH 2-D model predicts $190^{\circ} \mathrm{F}$ and $201^{\circ} \mathrm{F}$ peak sludge temperatures with 3000 and 2000 CFM secondary floor flow, respectively, and 600 CFM primary ventilation air inlet flow at average summer conditions of $70^{\circ} \mathrm{F}$ and $50 \%$ relative humidity. The peak temperatures occur at 4.25 and 3.75 feet respectively above the tank bottom. HUB analysis calculates peak sludge temperature of $191^{\circ} \mathrm{F}$ at an axial location of $4.25 \mathrm{ft}$ and $201^{\circ} \mathrm{F}$ at $3.75 \mathrm{ft}$ using 3000 and 2000 CFM secondary ventilation flow respectively corresponding to cooling effectiveness of the floor channels of about $32 \%$ and $37 \%$ respectively. The cooling effectiveness for the HUB analysis is determined from the GOTH simulation results for the same assumed conditions. The HUB methodology provides quick and reasonable results for parametric analysis.

The transfer of 4.75 feet of sludge from $\mathrm{C}-106$ will reduce the heat load for the remaining sludge in C-106 to 40000 btu/hr thereby qualifying it as a low heat load tank.

2. The assumed average summer meteorological conditions for the ventilation flow inlet conditions to the primary and secondary ventilation system is conservative. GOTH simulations based on a secondary ventilation floor flow of 3000 CFM result in a reduction in peak sludge temperature of $7^{\circ} \mathrm{F}$, relative to that for average summer meteorological conditions. Superimposing 2 weeks of unusually hot weather upon the annual meteorological cycle increases the maximum sludge temperature only an additional $2{ }^{\circ} \mathrm{F}$. Similar conclusions could be drawn for secondary ventilation flow rates of 2000 CFM. 
WHC-SD-WM-ER-534

Rev. 0

3. Maintaining the maximum sludge temperatures at or below $201{ }^{\circ} \mathrm{F}$ requires that the primary dome ventilation be maintained at its current level of about 600 CFM supplying air to the tank inlet at ambient inlet conditions. This means that if the transfer is made before the Project $W-030$ new ventilation system is operable, the old system must be capable of maintaining its current flow rates.

If the Project $\mathrm{W}-030$ new ventilation system becomes operational prior to the transfer, the primary or dome ventilation to Tank AY-102 should be operated in the once through mode with the tank inflow adjusted to a minimum of 600 CFM. Following the transfer, Tank AY-102 should not be operated in the recirculation mode following the transfer, until operating experience in the once through mode assures this operating mode is acceptable.

Maintaining these low sludge temperatures also requires that the secondary ventilation system be made operational and that a flow rate of $2000 \mathrm{CFM}$ be provided to the floor cooling channels. Although this analysis indicates ventilation flows as low as 2000 CFM may preclude exceeding sludge saturation limits, the 3000 CFM flow rate should be obtained if possible to allow larger safety and operations margin due to uncertainties in the tank heat loads, primary ventilation flow rates, heat load distributions, and transferred particle settling characteristics.

4. These calculations have assumed that the particles in the sludge retrieved from Tank C-106 will re-settle to a particle concentration at least half as large as that currently existing in Tank $\mathrm{C}-106$, (i.e. fluff factor of 2.0). Higher fluff factors will result in higher sludge temperatures, lower fluff factors will result in lower sludge temperatures.

5. Transferring all of the C-106 sludge to the top of the sludge current $I Y$ in $A Y-102$, without activating the 
WHC-SD-WM-ER -534

Rev. 0

AY-102 secondary ventilation, will result in reaching saturation temperature in the sludge at the tank bottom and the production of steam in the sludge--even if the combined sludges have thermal and physical properties, including particle concentration, similar to that which currently exist in these two tanks. Fluffing of the particle concentration of the transferred C-106 sludge would exacerbate steam production.

6. Activation of the secondary ventilation system can have significant cooling effects on the sludge both at the tank floor and throughout the tank. If flow rates of $3000 \mathrm{CFM}$ to the floor coolant channels can be obtained, over half the tank heat load will be removed with the secondary ventilation system and the balance with the primary or dome ventilation system, and heat loss via conduction through the soil. Operating a double shell tank in this high secondary floor ventilation heat removal mode is a significant departure from normal operating practice and was apparently not considered as part of the original design basis of the tanks. It should therefore be thoroughly investigated to insure no safety issues are overlooked before operating in this mode is undertaken.

7. The primary steel floor is a major factor in limiting the sludge temperature mid way between floor channels. It acts as an effective fin conducting heat azimuthaliy from the sludge far removed from a coolant channel to the air flowing in the channel.

8. The current AY/AZ tank farm primary ventilation system will provide less cooling to the combined AY-102/C-106 sludge than the current C-106 primary ventilation system, due to the 4 fold reduction in tank air flow. The Project W-030 new primary ventilation system for the AY/AZ tank farm will provide even less cooling than the current $\mathrm{AY} / \mathrm{AZ}$ primary ventilation system when operating in the recirculation mode due to further reduced air flow and worse ventilation air inlet conditions. In the 
WHC-SD-WM-ER-534

ReV. 0

once-through or non-recirculating mode the Project $\mathrm{w}-030$ new primary ventilation system will provide about the same tank inflow rate at ambient conditions that the current system does.

9. Due to the lack of operating experience and original tank design basis, demonstration of effective floor cooling at high ventilation flow rates should be considered using a high heat load tank such as Tank AZ-101 or AZ-102. Pre-demonstration simulations of the sludge temperature reductions expected at high secondary ventilation flow rates for these tanks should be made, and subsequently followed by the test for comparison to demonstrate the validity of the predictive thermal hydraulic tools and methods. 


$$
\begin{aligned}
& \text { WHC-SD-WM-ER }-534 \\
& \text { ReV. } 0
\end{aligned}
$$

\section{CONCLUSIONS}

1. Tank AY-102 car be operated below operating requirement temperature limits following the transfer of adequate sludge from Tank $\mathrm{C}-106$ to reduce the heat load in Tank C-106 below 40,000 btu/hr. This will require a floor ventilation air flow rate of 2000 CFM or greater to be provided to the central floor distribution plenum to cool the tank floor. It will also require that the transferred sludge achieve a particle volume fraction no less than $50 \%$ of that currently in Tank C-106 after settling to the non-convective condition (i.e. fluff factor must be 2 . or less). In addition tank waste level must be maintained nearly full, or liquid saturation pressure within the sludge must be demonstrated to be greater than that of water.

2. Ventilation outages of 1 month can be tolerated depending on the saturation temperature characteristics of the waste and the waste level maintained in Tank AY-102 after transfer. However, operating procedures should not allow outages longer than 2 weeks to allow some safety margin.

3. The analysis conducted includes potential conservatisms which limit the amount of sludge that can be transferred. If the fluff factor after transfer is found to be significantly lower than $2 .$, if the secondary floor ventilation flow rates can be raised significantly above 2000 CFM, and if the Tank C-106 heat load is determined to be lower than 132,400 btu/hr, then all of the Tank C-106 waste can possibly be transferred. 


$$
\begin{gathered}
\text { WHC-SD-WM-ER-534 } \\
\text { ReV. } 0
\end{gathered}
$$

\section{REFERENCES}

Aguirre, H., 1994, Interim Operational. Safety Requirements for the Aging Waste Facility, WHC-SD-WM-OSR-004, Westinghouse Hanford CO., Richland, WA.

Bander, T.J., 1993, Revised Thermal History of Tank 241-C-106, WHC-SD-ER-200, Westinghouse Hanford Company, Richland, WA.

Boelter, Gordon, and Griffith, 1946. Rates of Evaporation of Water by Natural Convection, Industrial Engineering Chemistry, 38, 596 .

Clifton, F.T., 1994. Project W-030 Tank Farm Ventilation Upgrade System Descriptions, TR-W-030-221, ICF-Kaiser Hanford Company, Fichland, WA.

Drawing Set. 1, H-2-64307, H-2-64372, H-2-64460, H-2-64449, U.S. Atomic Energy Commission, Richland Operations Office, Richland, WA.

Drawing Set 2., Drawings H-2-67244, H-2-67295, U.S. AtomiC Energy Commission, Richland Operations office, Richland, WA.

Fryer, B.C., and M.J. Thurgood, 1995, Revised Tank Heat Load Estimate For Tank C-106 Based on GOTH Analysis of the Process Test, JMI-9503-04, John Marvir Inc., Richland, WA.

Hanlon, B.M., 1995, Waste Tank Summary Report for Month Ending January 31, 1995, WHC-EP-0182-82, Westinghouse Hanford Co., Richland, WA.

MacLean, G.T., 1995. Personal Communication, Westinghouse Hanford Co., Richland, WA.

Norton, M.V. and F. Torres-Ayala, 1994a, Laboratory Testing In-Tank Sludge Washing--Summary Report, PNL-101153/UC-601, 


$$
\begin{aligned}
& \text { WHC-SD-WM-ER- } 534 \\
& \text { ReV. } 0
\end{aligned}
$$

Battelle Northwest Laboratory, Richland, WA.

Norton, M.V., 1994b, Personal Communication, Battelle Northwest National Laboratory, Richland, WA.

Powel, W.J., 1989, Double Shell Tank Air Flows, SA-WM-TA-017, Rev. 0 .

Sathyanarayana, K., M.J. Thurgood, and B.C. Fryer, 1993, Development of a Dynamic Computer Simulator for Aging Waste Tank Operations and Safety Assessment, WHC-SD-WM-ER-198, Rev. 0, Westinghouse Hanford Company, Richland, WA.

Sathyanarayana, K., B.C. Fryer, and M.J. Thurgood, 1994, Summary Report: Thermal Hydraulic Safety Analysis of Aging Waste Tank 101-AZ, WHC-SD-WM-ER-335, Westinghouse Hanford Company, Richland, WA.

Sathyanarayana, K., 1995. Current Status of Thermal Hydraulic Analysis and Results in Support of the Safety Documentation for Project $\mathrm{W}-320$, Internal Letter 74D1-95-PSSB-KS-036, to J.C. Conner, September 20, 1995, Westinghouse Hanford Co., Richland, WA.

Tardiff, G. 1995a. cc:Mail, Gary Tardiff to K. Sathyanarayana, AY-102 Annulus Exhauster, dated August 30 , 1995.

Tardiff, G. 1995b. cc:Mail, Gary Tardiff to John Conner, AY-102 Annulus Exhauster, dated September 21, 1995.

Thurgood, M.J., B.C. Fryer, D.M. Ogden, K. Sathyanarayana, 1995, GOTH Tank C-106 Thermal Hydraulics Analysis Related to the Process Test, Numerical Applications Inc., Richland, WA 


\section{DISTRIBUTION SHEET}

\begin{tabular}{|c|c|c|c|c|c|}
\hline \multirow{2}{*}{$\begin{array}{l}\text { To } \\
\text { Distribution }\end{array}$} & \multirow{2}{*}{\multicolumn{3}{|c|}{$\begin{array}{l}\text { From } \\
\text { Process Engineering Analysis }\end{array}$}} & \multicolumn{2}{|l|}{ Page 1 of 1} \\
\hline & & & & \multicolumn{2}{|c|}{ Date $01 / 15 / 96$} \\
\hline \multirow{2}{*}{\multicolumn{4}{|c|}{$\begin{array}{l}\text { Project Title } \text { Work Order } \\
\text { D2M75 }\end{array}$}} & \multicolumn{2}{|c|}{ EDT No. 613542} \\
\hline & & & & \multicolumn{2}{|l|}{ ECN No. NA } \\
\hline Name & MSIN & $\begin{array}{l}\text { Text } \\
\text { With All } \\
\text { Attach. }\end{array}$ & Text Only & $\begin{array}{l}\text { Attach./ } \\
\text { Appendix } \\
\text { Only }\end{array}$ & $\begin{array}{l}\text { EDT/ECN } \\
\text { Only }\end{array}$ \\
\hline $\begin{array}{l}\text { T. J. Bander } \\
\text { D. A. Carter } \\
\text { J. C. Conner } \\
\text { L. F. Dougherty } \\
\text { G. L. Dunford } \\
\text { G. R. Franz } \\
\text { B. A. Fryer } \\
\text { J. P. Harris, III } \\
\text { L. E. Johnson } \\
\text { K. W. Lel iefeld } \\
\text { G. T. MacLean } \\
\text { R. M. Marusich } \\
\text { G. A. Meyer } \\
\text { D. M. Ogden } \\
\text { R. Raco } \\
\text { K. Sathyanarayana (2) } \\
\text { J. P. Sloughter } \\
\text { M. J. Thurgood } \\
\text { G. R. Tardiff } \\
\text { A. H. Umek } \\
\text { Central Files (Original + 2) } \\
\text { OSfI (2) } \\
\text { PEA (Burstad 2) }\end{array}$ & $\begin{array}{l}\text { HO-34 } \\
\text { S2-48 } \\
\text { A2-25 } \\
\text { A2-25 } \\
\text { A2-34 } \\
\text { A2-34 } \\
\text { H0-34 } \\
\text { S2-48 } \\
\text { A2-25 } \\
\text { S2-48 } \\
\text { H5-49 } \\
\text { A3-34 } \\
\text { S2-48 } \\
\text { HO-34 } \\
\text { S7-73 } \\
\text { HO-34 } \\
\text { R2-54 } \\
\text { HO-34 } \\
\text { S5-05 } \\
\text { S7-81 } \\
\text { A3-88 } \\
\text { E6-44 } \\
\text { H0-34 }\end{array}$ & $\begin{array}{l}x \\
x \\
x \\
x \\
x \\
x \\
x \\
x \\
x \\
x \\
x \\
x \\
x \\
x \\
x \\
x \\
x \\
x \\
x \\
x \\
x \\
x \\
x\end{array}$ & & & $x$ \\
\hline
\end{tabular}

